\title{
ELECTRICITY CONSERVATION IN CONTEXT: A MIXED METHODS STUDY OF RESIDENTIAL CONSERVATION BEHAVIOUR DURING AN ELECTRICITY SHORTAGE IN NEW ZEALAND
}

\author{
by \\ Sally Blackwell \\ ENVIRONMENTAL STUDIES 593 \\ 2009
}

A 90 point thesis submitted to Victoria University of Wellington, as partial fulfilment of requirements for the degree of Master of Environmental Studies

School of Geography, Environment and Earth Sciences Victoria University of Wellington $3^{\text {rd }}$ July, 2009 
For Grant, Suzanne and Emma 


\title{
ELECTRICITY CONSERVATION IN CONTEXT: A MIXED METHODS STUDY OF RESIDENTIAL CONSERVATION BEHAVIOUR DURING AN ELECTRICITY SHORTAGE IN NEW ZEALAND
}

\author{
Sally Blackwell
}

\begin{abstract}
Household energy behaviour has been studied across a range of disciplines including economics, social psychology, diffusion of innovation and sociological models. Recognising that energy decisions are not economically 'rational' this study draws on approaches from social psychology and sociology. These recognise that whilst individual behaviour can be influenced to be proenvironmental it is often heavily constrained by contextual factors. This study explored whether a relationship existed between electricity conservation in households and the socio-political environment in New Zealand during a hydroelectricity shortage in 2008. This was done so that constraints on demandreduction initiatives might be better understood. A mixed methods approach was used. Study 1 used a thematic analysis of media reports to examine the sociopolitical context of the shortage period. It found that the issue was deeply political and debate was dominated by a focus on supply whilst conservation was predominantly portrayed as detrimental to households and the economy. Study 2 entailed a nationwide longitudinal survey that examined electricity conservation attitudes and behaviour. It found that householders increased conservation actions during the shortage by a small degree compared to everyday behaviour. Study 3 examined residential electricity consumption data from the period and estimated savings were lower than during previous similar shortages. The research suggests that a relationship did exist between the socio-political context and individual behaviour during the shortage. The research makes a case for a truly interdisciplinary approach to managing residential energy demand which takes into account the personal and social context within which energy consumption occurs and the multi-faceted social drivers of demand.
\end{abstract}

Key words: Energy behaviour, electricity shortage, thematic analysis, residential energy consumption 


\section{Acknowledgements}

Completing this thesis has been an incredible challenge. I would like to acknowledge the help, advice and support of a number of people whose generosity has enabled me to complete the research and allowed it to take the shape it did. Thanks for helping me along the way.

Firstly, I would like to thank my supervisors Ralph Chapman and Taciano Milfont for their advice and guidance, and for believing I could do this all the way along even when I didn't. Also thank you for gently suggesting when it was time to stop talking and start writing! Special thanks to Taciano for allowing me to use his survey data.

Secondly, huge thanks must go to Jonathan Lermit who analysed the Centralised Dataset so that I could see the demand response during 2008 and for so very kindly repeating the whole process again for 2003. Without his expertise and generosity, residential consumption data would not have been accessible for this project. I'd like to acknowledge the support of Air New Zealand for a travel grant to attend BECC 2008, Cory Franklin at Contact Energy for providing information on the 'Powersavers' campaign, Pip Lynch and Steve Batstone at NERI and many folk at EECA.

Finally, thank you to my wonderful family and friends. Thanks to Mum and Dad, for their love, support and encouragement. Also, special thanks to Grant and Suzanne for hours of proofreading, constructive feedback and help with statistical analysis, not to mention food and shelter. On that note, thanks are also due to Emma, Maggie, Cosby and Ella-Marmite for playing their part... And of course I'd like to thank all my generous, kind, patient and supportive friends who've encouraged (and humoured) me along the way. Life wouldn't be right without you guys. A special note of thanks goes to the Adam-Green's: to Terence for being an ever-faithful thesis buddy and to the lovely Catherine for designing my conference posters. And to Rebecca Lal for the final edit. Thank you! 


\section{Table of Contents}

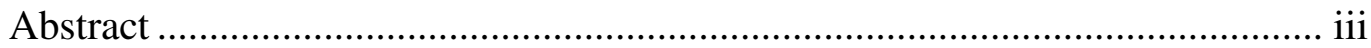

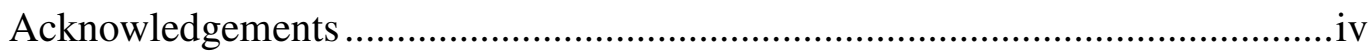

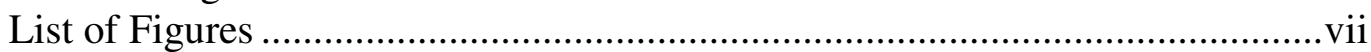

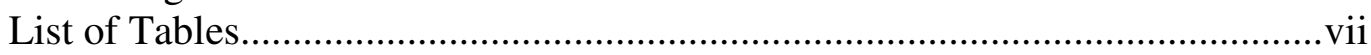

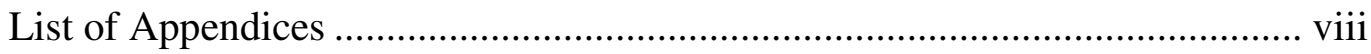

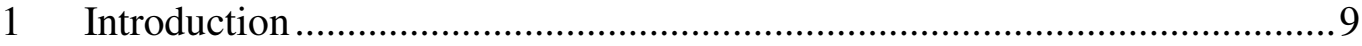

1.1 Global energy consumption and environmental impacts .....................9

1.2 Residential electricity demand in New Zealand.................................. 10

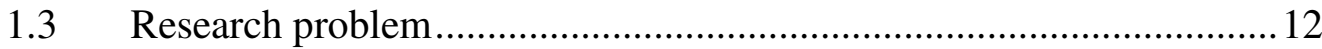

1.4 A hydro-electricity shortage and conservation campaign in 2008 ....... 12

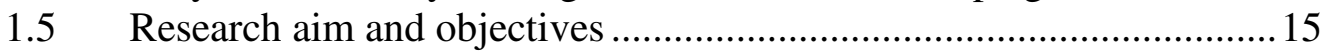

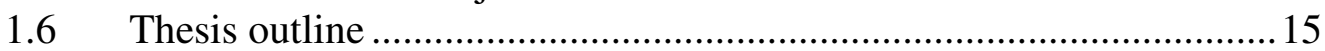

2 A behavioural and social perspective on household energy behaviour ....... 17

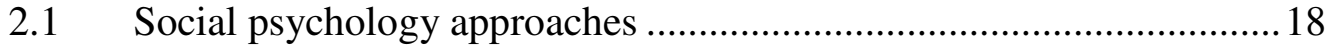

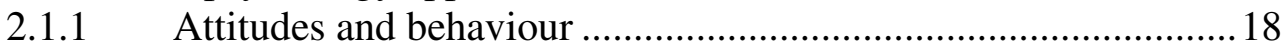

2.1.2 Information, feedback and goal-setting................................... 19

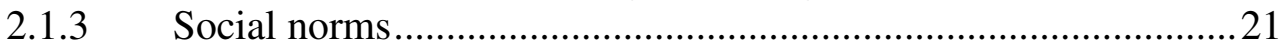

2.2 Sociological perspectives on energy behaviour ..............................24

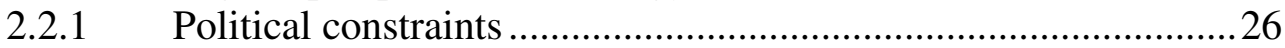

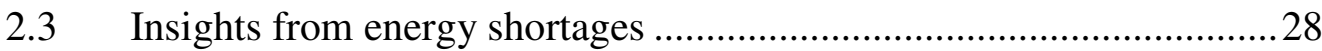

2.3.1 Awareness and public perceptions .............................................28

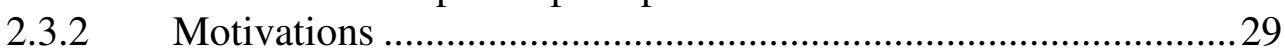

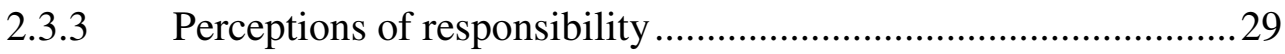

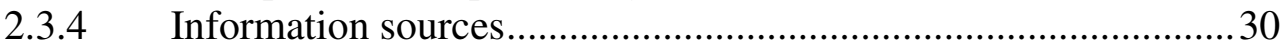

2.3.5 Most common conservation actions ............................................. 31

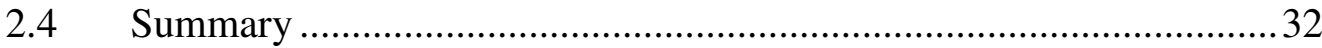

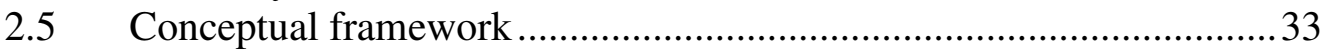

3 Study 1: Thematic analysis of media reports relating to the electricity shortage

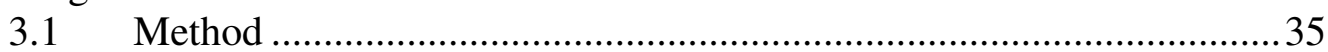

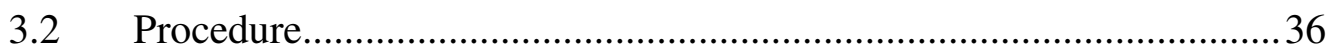

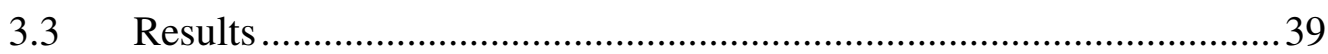

3.3.1 Electricity supply as a political issue …....................................39

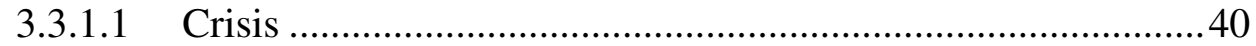

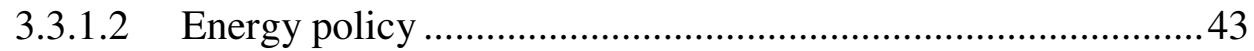

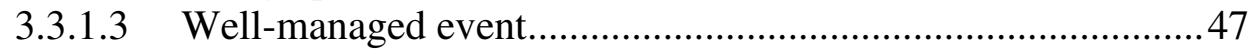

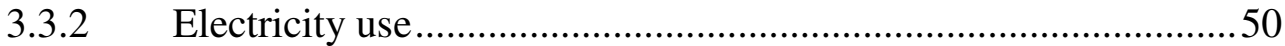

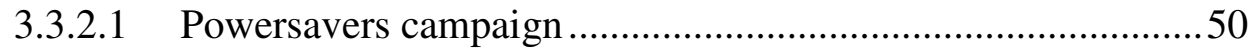

3.3.2.2 Concern with demand ...........................................................52

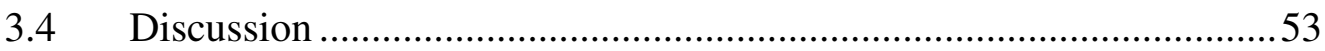

4 Study 2: Household surveys of conservation behaviour ...............................57

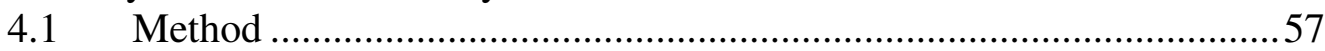

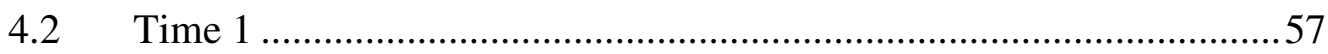

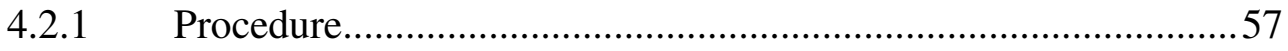

4.2.2 Survey design and instruments ..............................................58 


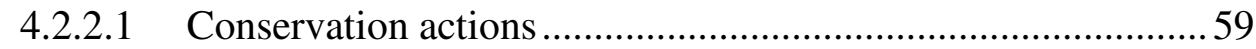

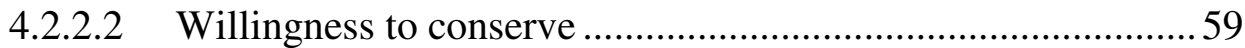

4.2.2.3 Motivations for conservation ..................................................6 60

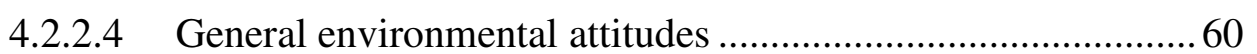

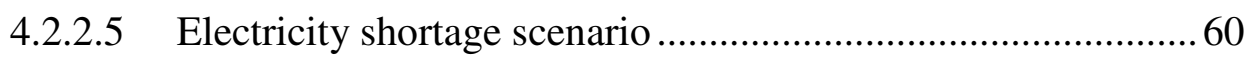

4.2.2.6 Socio-demographic measures .................................................62 62

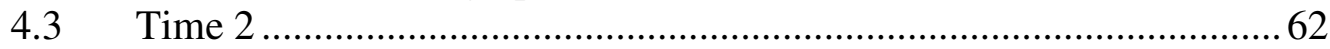

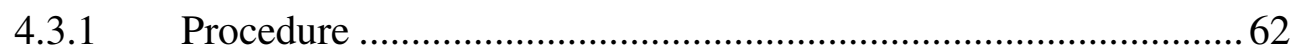

4.3.2 Survey design and instruments .............................................6 63

4.3.2.1 Conservation actions and motivations for conservation ..........63 63

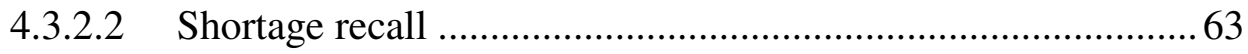

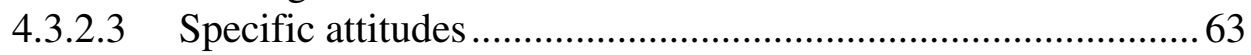

4.3.2.4 General environmental attitudes ............................................. 64

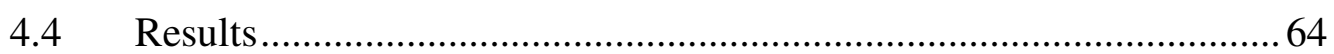

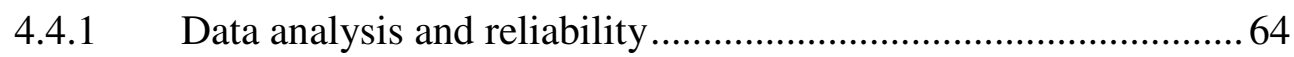

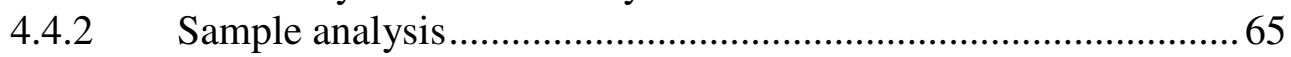

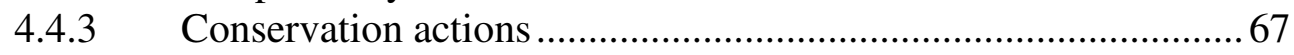

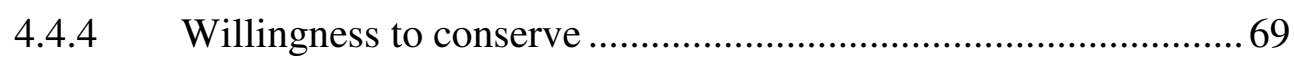

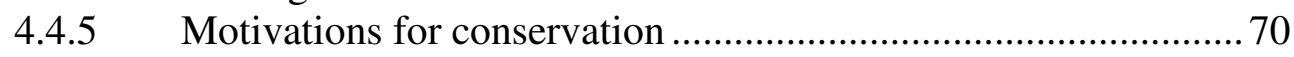

4.4.6 Perceptions of responsibility ................................................ 71

4.4.7 Relationship between environmental attitudes and behaviour.....71

4.4.8 Correlations between socio-demographic variables and behaviour.

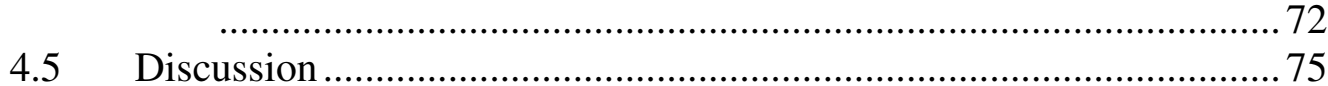

$5 \quad$ Study 3: Residential electricity demand response .................................... 79

5.1 Analysing residential electricity demand ....................................... 79

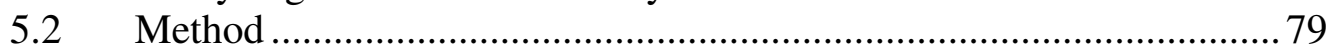

5.2.1 Method 1 (Lermit data) .......................................................... 79

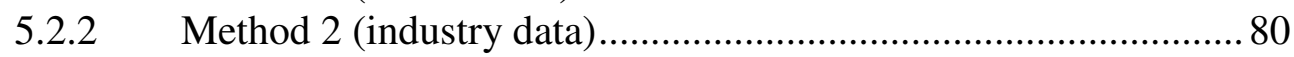

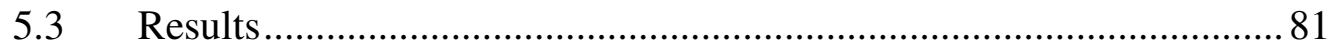

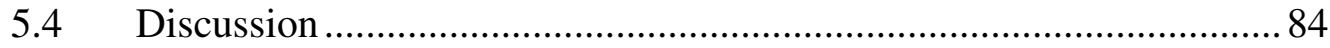

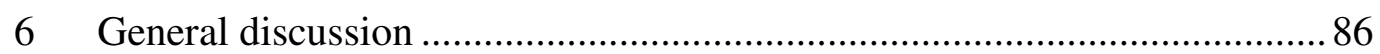

6.1 The socio-political environment and household behaviour ................8 87

6.2 Implications for behaviour change ............................................... 92

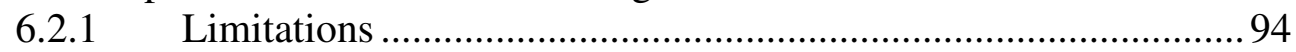

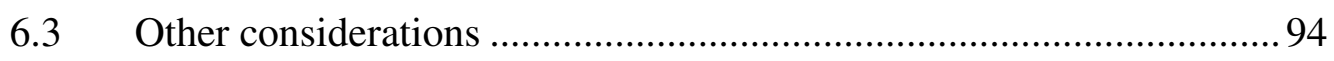

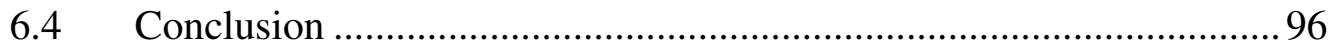

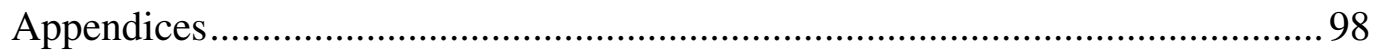

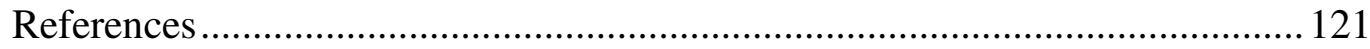




\section{List of Figures}

Figure 1: Powersavers campaign advertisement (example one) .......................... 14

Figure 2: Powersavers campaign advertisement (example two).......................... 14

Figure 3: A schematic model of Value Belief Norm Theory showing causal

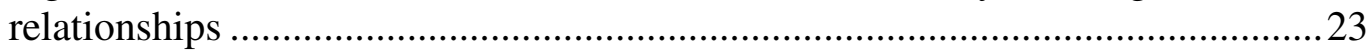

Figure 4: Map of themes identified in the media data set.................................38

Figure 5: Mean scores of conservation actions across time and during the

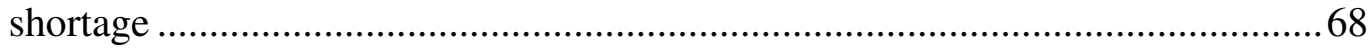

Figure 6: Lermit's (2009a) analysis of residential savings in 2008 .................... 81

Figure 7: Lermit's (2009b) analysis of residential savings in 2003 ................... 82

Figure 8: Industry data showing residential savings during the 'Target 10'

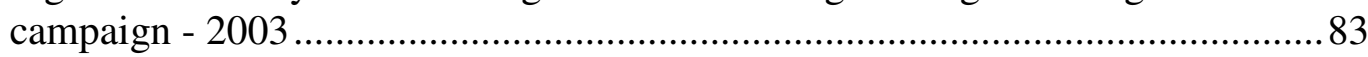

\section{List of Tables}

Table 1: A causal model of environmentally relevant behaviour: Adapted from

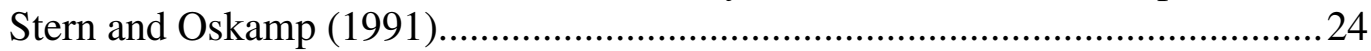

Table 2: Media sources and the number of items from each .............................37

Table 3: Braun and Clarke's (2006) summary of the phases involved in thematic

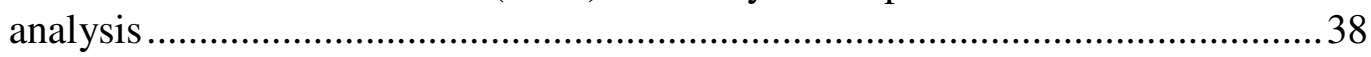

Table 4: Themes and sub-themes and number of sources and references ...........39

Table 5: Timeline of SAS Time 1 and Time 2 in relation to significant events ..58

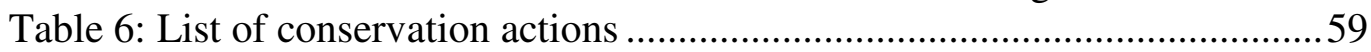

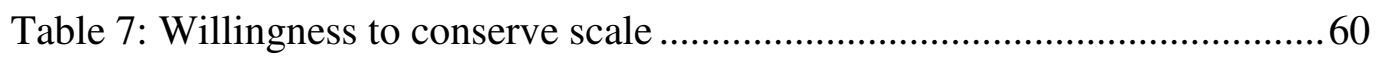

Table 8: List of motivations for conserving electricity ......................................6 60

Table 9: 'Severity of the shortage' and 'collective costs' scales .........................61

Table 10: Options provided for indicating perceptions of responsibility to act...62

Table 11: Shortage impact and attitude change scales........................................64

Table 12: Descriptive statistics for scales used in SAS Time 1 and Time 2........65

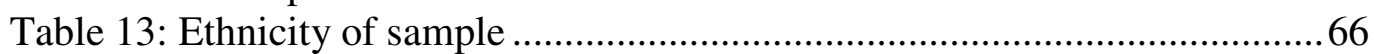

Table 14: Geographic distribution of sample by region ...................................67

Table 15: Most and least popular conservation actions ......................................69

Table 16: 'Other' conservation actions listed by respondents in Time 1............69

Table 17: Most popular reasons given for conserving electricity in Time 1 and

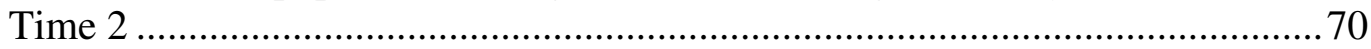

Table 18: Themes identified amongst other reasons given for conserving

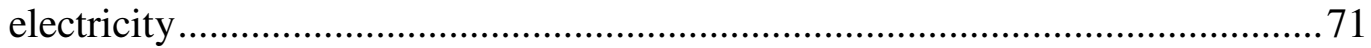

Table 19: Responsibility to take action under the shortage scenario ...................71

Table 20: Bivariate correlations between behaviour and attitude scores ..............73

Table 21: Bivariate correlations between socio-demographic variables and

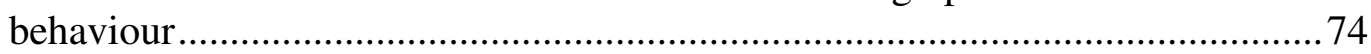

Table 22: Comparison of estimated residential electricity savings results for 2008

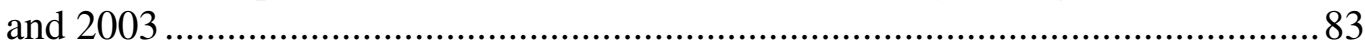




\section{List of Appendices}

Appendix 1: References to media extracts used as data in thematic analysis .....98 Appendix 2: Social Attitudes Surveys ......................................................... 104

Appendix 3: Dunlap et al's. (2000) new ecological paradigm scale .................. 116 Appendix 4: Milfont and Duckitt's (2007) preservation and utilization scales. 117 Appendix 5: 'Other' reasons given for conserving electricity in Time 1 and Time

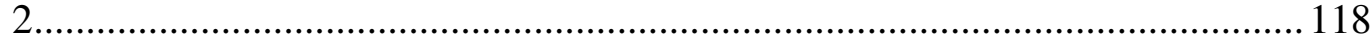

Appendix 6: 'Other' conservation actions provided by respondents - Time $1 . .120$ 


\section{Introduction}

\subsection{Global energy consumption and environmental impacts}

Total global energy consumption is growing, bringing with it significant environmental impacts (IEA, 2006), the most well recognised being those associated with global climate change. The Intergovernmental Panel on Climate Change (IPCC) (2007a) concluded in its Fourth Assessment Report that "warming of the climate is unequivocal" (p. 5). The report also concluded that it is "very likely" (p. 10) that the observed increase in global average temperatures is a result of anthropogenic greenhouse gases, which are primarily the result of increased fossil fuel use since the industrial revolution (2007b). Predicted effects of climate change include, sea level rise, increased regional climate variability, ecosystem and biodiversity loss and disruptions to social, economic and agricultural systems (IPCC, 2007c). From an energy consumption perspective, the risks of climate change are hugely significant as energy-related greenhouse gas emissions currently account for $70 \%$ of global emissions, including transport fuels (Sims et al., 2007).

If greenhouse gas concentrations stay at current levels, or increase, warming and sea level rise will continue for centuries due to the time lags in the climate system (IPCC, 2007a) creating inter-generational effects. This view is supported by Hansen et al. (2008) and others who claim that concentrations of $\mathrm{CO}_{2}$ in the atmosphere have already surpassed a level where we can "maintain the climate to which humanity, wildlife, and the rest of the biosphere are adapted" (p. 13). Others include Richardson et al. (2009) who note that recent emissions growth has been tracking above the scenario envelope indentified by the IPCC's Special report: Emissions scenario (2000) projections, raising future climate risks. Energy consumption is therefore a critical contributing factor to climate change and solutions must be sought at every level (Whitmarsh, 2009).

The consumption of electricity alone accounts for $16.7 \%$ of total global energy consumption (IEA, 2008, p. 28) and $41 \%$ of global energy-related $\mathrm{CO}_{2}$ emissions (IEA, 2006, p. 144). The IEA (2006) predicts world electricity demand will almost double over the period $2004-2030$, with an average annual growth rate of $2.6 \%$ 
(p. 138) and predicted increases in $\mathrm{CO}_{2}$ emissions of $2 \%$ per annum on average. The existing scale and projected growth of electricity consumption is an environmental challenge considering that the largest proportion of generation globally is from coal and peat (41\%) (IEA, 2008, p. 24) and coal is expected to increase to $44 \%$ of the total electricity fuel mix by 2030 (IEA, 2006). This situation is not environmentally sustainable (Sims et al., 2007); indeed Hansen et al. (2008) call for a phase-out of coal-fired generation over the next 20-25 years because "continued growth of greenhouse gas emissions, for just another decade, practically eliminates the possibility of near-term return of atmospheric composition beneath the tipping level for catastrophic effects" (p. 13).

These compelling statistics highlight the role of electricity consumption, and energy consumption generally, in global concerns about climate change. This thesis will focus on the consumption of electricity in New Zealand by residential consumers.

\subsection{Residential electricity demand in New Zealand}

A large proportion of electricity in New Zealand is generated from renewable sources which produce few greenhouse gas emissions. Statistics from 2007 show that $55 \%$ of electricity came from hydro-generation, with another $12 \%$ from other renewable sources, and the additional 33\% from fossil-fuel sources (oil, coal and gas) (Ministry of Economic Development, 2008a). This generating mix gives New Zealand a unique emissions profile. Almost half (46\%) of the country's greenhouse gas emissions are generated by the agricultural sector with only $20 \%$ from electricity (Ministry of Economic Development, 2008b, p. 8) which is around half the global average. However, the generating mix varies depending on hydro-lake levels and peak demand. When hydro-lake levels are low non-renewable generation (mainly from coal and gas (Ministry of Economic Development, 2006)) increases along with greenhouse gas emissions. Further, renewable generation is not without its environmental impacts or opponents. For example, hydro-generation raises concerns about social displacement, landscape destruction, mercury contamination and biodiversity loss (Rosenberg, Bodaly, \& Usher, 1995). Over the last 15 years similar concerns have meant some large scale hydro-generation projects have been delayed or cancelled, and 
it has dropped from the second largest source of electricity generation internationally to fourth (IEA, 2006).

These issues are currently being played out vividly in the planning stages of the Mokihinui hydro-generation proposal on New Zealand's West Coast, where economic, social and environmental interests are in conflict (for example Meridian Energy, 2008, 15 April; New Zealand Press Association, 2008, 26 September; Taylor Baines \& Associates, 2008, March). With electricity demand growth in New Zealand currently exceeding population growth (Ministry of Economic Development, 2009), and the National-led government's recent decision to overturn the 10 year moratorium on new thermal generation (New Zealand Government, 2008,16 December), the country faces difficult trade-offs, similar to many other countries, between meeting electricity demand and managing environmental effects.

Residential demand accounts for 33\% of New Zealand's electricity consumption (Ministry of Economic Development, n.d.). It also accounts for $52 \%$ of peak consumption (Parliamentary Commissioner for the Environment, 2009, p. 13), which for New Zealand occurs in winter largely due to the country's widespread use of electric space heating (Howden-Chapman et al., in press). Consumption from this sector has increased by 68\% since 1975 (Ministry of Economic Development, 2008a, p. 109) and is expected to continue growing at around 2\% per annum (Ministry of Economic Development, 2006, p. 108) depending on the price of carbon that the new Emissions Trading Scheme, passed into law in late 2008, introduces (Ministry for the Environment, 2007). Reliance on hydro-generation also leaves an electricity system vulnerable during periods of low rainfall. This has been observed in other hydrobased systems such as Brazil and Norway (Meier, 2005), and has been an issue for New Zealand in recent years when low rainfall and other stressors in the system have created supply problems during the winter high demand period. As a consequence, there have been calls for voluntary conservation behaviour to reduce demand from residential consumers in 2001, 2003 and 2008. 


\subsection{Research problem}

One outcome of these shortages and related conservation campaigns in New Zealand is that there has been a demonstrable, but temporary, reduction in demand for electricity. Savings were in the order of $10 \%$ as a result of the 2001 and 2003 campaigns in New Zealand (Meier, 2005). Because of the short duration and urgency of the conservation campaigns (leaving little time for energy reductions from structural improvements) the majority of the savings are assumed to have been generated by changes in behaviour by householders. Although there is some evidence that behavioural change can be maintained beyond the end of a shortage (Lutzenhiser, Kunkle, Woods, Lutzenhiser, \& Bender, 2004), consumption is generally expected to return to pre-shortage levels.

Electricity savings can bring benefits to households in the form of reduced power bills. Wider societal benefits include reduced dependency on imported fuel (Ministry of Economic Development, 2009) and avoided generation costs. However, in the New Zealand context, these savings may be associated with a rise in carbon emissions as more thermal generation has to be brought online when there is a hydro-electricity shortage. One important question raised by the behaviour change observed during a shortage is: If householders can reduce their electricity demand by $10 \%$ during a shortage, why aren't these demand reductions maintained? And following on from this: What are the factors that influence household electricity conservation behaviour?

\subsection{A hydro-electricity shortage and conservation campaign in 2008}

In 2008 New Zealanders were asked by the electricity industry to voluntarily reduce their electricity consumption for the third time in the decade as hydro-lake inflows reached their lowest level since 1931 (Hunt \& Isles, 2009). By February, falling hydro-lake levels and the possibility of a hydro-electricity shortage, and political debate around the issue, were becoming prominent in the media (Gorman, 2008). A number of other problems with the supply system also occurred in the first half of 2008: (a) the High Voltage Direct Current (HVDC) cable which carries electricity between the North and South Islands was partially disabled for repair, (b) Contact Energy's New Plymouth power plant was closed due to fears of asbestos 
contamination, and (c) the Otahuhu B power plant was taken offline temporarily for repairs (Weir, 2008, 10 June).

This combination of factors raised a great deal of media interest and debate between political actors, industry members and stakeholders about security of supply and who to blame for the situation. A general election was due to be held in November 2008 which may have led the opposition parties to highlight serious concerns about an emerging supply shortage in the lead-up to winter.

In June 2008 a voluntary conservation campaign named 'Powersavers' was launched by the electricity industry. The mass media campaign ran for six weeks but did not include a specific savings target. Campaign messages were seen in newspapers, on television and radio, on websites, buses and bus shelters and billboards (Mediaedge:cia, 2008). The 'Powersavers' campaign ran a website which included news, feedback on consumption data, regional comparisons of savings and information about hydro-lake levels and inflows. The website was also used as a means for communication by the campaign's lead agency Transpower Ltd, the stateowned operator of the national electricity grid.

Campaign advertisements all had a similar look and consisted of cartoon-like figures which appeared to be drawn in green felt-tip pen on an unbleached paper background. Messages encouraged easy, low-cost conservation actions such as switching off lights, unplugging appliances and drying clothes outside instead of in a clothes dryer. The messages were simple and quite light-hearted; one for example encouraged people to invite friends for dinner and eat by candle-light while another encouraged people to get together to watch a rugby match on television to save on power. The majority of messages focused on savings to be made at home, although a number focused on behavioural changes at work, such as switching off lights in unused meeting rooms. Figures 1 and 2 show examples of the visual concepts used in the campaign. 
Figure 1: 'Powersavers' campaign advertisement (example one)

\section{DRY CLOTHES ON THE LINE INSTEAD OF IN THE DRYER.}

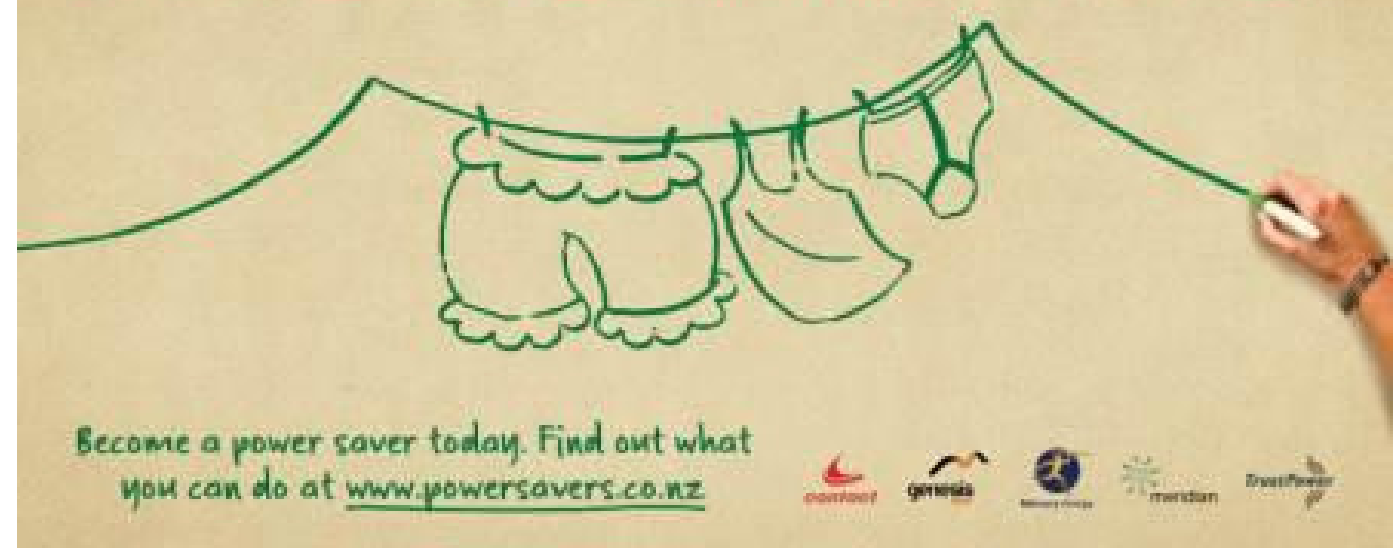

Source: Contact Energy Ltd. (Used with permission)

Figure 2: 'Powersavers' campaign advertisement (example two)

\section{INVITE FRIENDS OVER TO EAT - WITH CANDLES!}

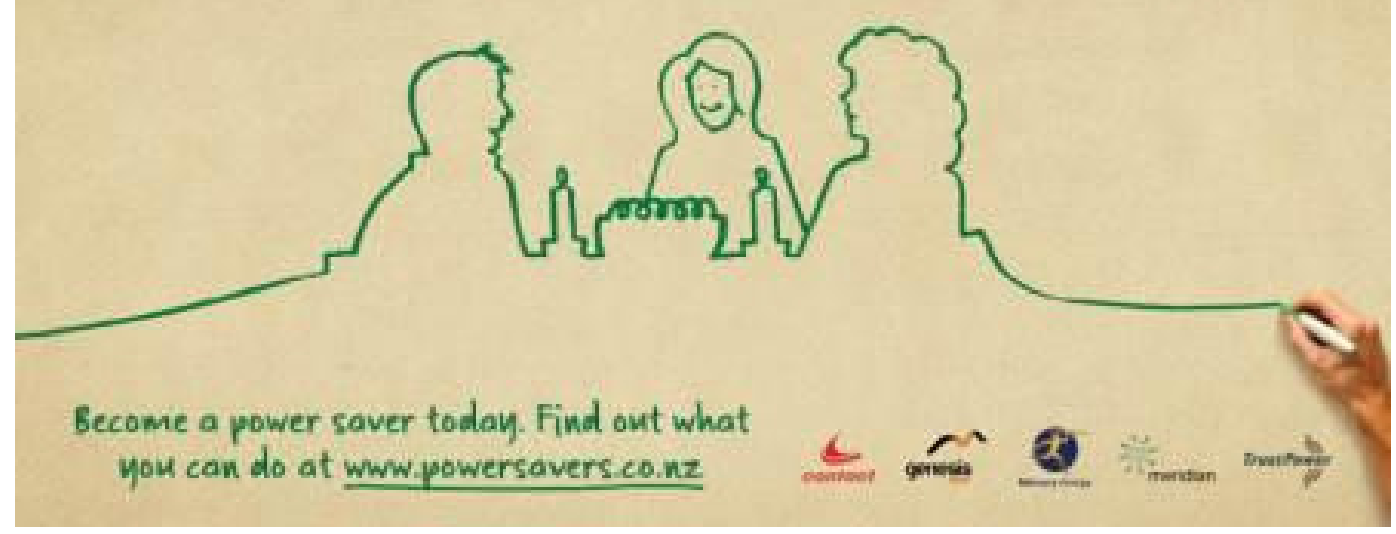

Source: Contact Energy Ltd. (Used with permission)

The campaign ended on $27^{\text {th }}$ July 2008 because lake levels had risen and the risk of outages was perceived to be lower. An average demand reduction of $3.6 \%$ was reported (Transpower New Zealand, 2008). The demand response to the supply shortage and campaign will be discussed in more detail in Chapters 5 and 6. 


\subsection{Research aim and objectives}

The current research investigates electricity conservation achieved through behavioural changes by New Zealand householders during the hydro-electricity shortage in 2008. Drawing on research largely from the fields of social psychology and sociology which have examined the motivators and barriers to energy conservation during times of shortage and of ample supply, this research investigates electricity conservation behaviour in a specific socio-political setting, the size of effects on electricity demand and the influence that the context of the time may have had on the behavioural response.

Specifically, the aim of the research is to explore whether a relationship existed between electricity conservation in households and the socio-political environment in New Zealand during the hydro-electricity shortage in 2008, so that influences on demand-reduction initiatives may be better understood. It is hypothesised that the socio-political environment was a significant contextual factor influencing household energy behaviour. Three objectives are identified to reach this research aim:

1. to analyse how electricity conservation was portrayed in the media and political discourse during the shortage period;

2. to understand whether and how householders changed their electricity attitudes and behaviour in the context of a supply shortage in New Zealand, and

3. to understand how behavioural changes affected electricity demand during this period.

\subsection{Thesis outline}

Following this introduction, Chapter 2 presents the literature review which outlines the findings from social psychology and sociological research into energy behaviour that have informed the research questions. The same chapter includes the conceptual framework and presents the theoretical lens through which the results will be discussed. Chapters 3, 4 and 5 detail the methods and results of three related empirical studies which examine the research problem. Study 1 (Chapter 3) is a qualitative study which uses thematic analysis to examine the socio-political context of the 
shortage. Study 2 (Chapter 4) is a quantitative study which uses two nationwide surveys to explore the attitudes and behaviour of householders in relation to electricity conservation during the shortage and under everyday conditions, and Study 3 (Chapter 5) presents the results of two quantitative analyses of electricity consumption data during shortages to measure savings. Finally, Chapter 6 discusses the results and draws some conclusions. 


\section{A behavioural and social perspective on household energy behaviour}

Household energy behaviour has been studied across a range of disciplines, including 'neo-classical' and behavioural economics, diffusion of innovation, social psychology and sociology, for a number of decades (Lutzenhiser, 1992, 1993; Wilhite, Shove, Lutzenhiser, \& Kempton, 2000; Wilson \& Dowlatabadi, 2007). Each disciplinary approach rests on a particular set of assumptions about what influences people's decision making in relation to energy use. The 'rational economic' model has been used as the basis for much energy conservation and energy efficiency policy (Dennis, Soderstron, Koncinski, \& Cavanaugh, 1990; Stern, 1986), although many programmes have been ineffective in implementation (Constanzo, Archer, Aronson, \& Pettigrew, 1986; Dennis et al., 1990; Stern, 1986, 1992). Given the limitations of the rational economic model in accurately predicting household energy behaviour, social psychologists have studied the field at length. Early interest was in response to the oil shocks of the 1970s and 1980s (Stern, 1992; Tashchian \& Slama, 1985) when energy consumption was high on the national agenda in the United States (Kempton, Darley, \& Stern, 1992). In subsequent years, interest in energy behaviour has been driven by other factors such as global climate change (Abrahamse, Steg, Vlek, \& Rothengatter, 2005; Kempton et al., 1992; Whitmarsh, 2009).

Over the years social psychologists have gained many insights into the role of personal variables such as attitudes, beliefs and personal and social norms in relation to energy behaviour. They have also recognised the important influence of context on individual behaviour. Sociologists and other social scientists have in turn called for a broader understanding of the contextual drivers of demand which does not focus solely on the individual. This review will examine insights from social psychology into the factors which promote and constrain energy conservation. Then it will examine the justification for a broader perspective on the issue, emphasising a social rather than an individual view of household energy consumption. 
It is important to make a distinction between different types of energy behaviour; i.e. conservation and energy efficiency. Energy conservation involves "curtailing the use of existing energy equipment" (Gardner \& Stern, 2002, p.260, emphasis in original) whilst energy efficiency is achieved when the same services are delivered using less energy (Kempton et al., 1992). It is important to make a distinction between the two as they are "politically, economically and psychologically" different (Kempton et al., 1992, p. 1216). Energy conservation often involves sustained changes in behaviour, may be harder to achieve and may have less effect on demand whereas energy efficiency often involves one-off investment decisions (Gardner \& Stern, 2002). Further, energy efficiency is more likely to be viewed as lifestyle improvement (Stern \& Oskamp, 1991) whereas conservation is often seen as a sacrifice and giving up comfort (McKenzie-Mohr, 1994), and some people associate conservation with poverty and an inability to pay the bills (Dennis et al., 1990). This thesis mainly focuses on energy conservation (i.e. curtailment) because the majority of electricity demandreduction during a shortage is an outcome of curtailment actions.

\subsection{Social psychology approaches}

\subsubsection{Attitudes and behaviour}

Initially social psychologists working in the field often focused on the role of attitudes and their relationship with behaviour (Stern \& Oskamp, 1991). The attitude-behaviour model rests on the assumption that attitudes directly influence behaviour (Archer et al., 1987; Constanzo et al., 1986) and therefore, by changing attitudes, changes to behaviour will follow. However, research into attitudes to energy use has had varying results. Heslop, Moran and Cousineau (1981) found that the only attitude related to consumption was price consciousness whilst Ritchie, Gordon and Claxton (1981) found that attitudes had less influence on energy consumption than non-psychological, structural variables (i.e. temperature, income and house size), which were all positively correlated with energy consumption. In other studies no link between attitude and behaviour was found, even among those with a strong belief that the US faced an energy crisis and that it was likely to get worse (Archer et al., 1987; Constanzo et 
al., 1986). Some researchers at this time put the lack of a link between attitudes and behaviour down to the existence of barriers at the household level (Crossley, 1983; Heberlein, 1975).

Later research highlighted that attitude and other behavioural variables such as beliefs and norms were often constrained by contextual factors. Black, Stern and Elworth (1985) found that personal variables have a stronger relationship with behaviour where actions are not constrained by external factors. For example, personal norms around comfort will affect behaviour if a person has control over temperature settings. However, where constraints exist (e.g. the temperature is set centrally) personal variables have much less influence on behaviour. Constraints are often larger for energy efficiency investment decisions which tend to be more expensive (e.g. converting to a more efficient space heating system). Research also suggested that general attitudes were not as predictive of behaviour as specific attitudes. Fishbein and Azjen (1975) found that there is a consistent correlation between attitude and behaviour only where the two are closely related (i.e., related to the same thing).

\subsubsection{Information, feedback and goal-setting}

Working from the basis that energy behaviour does not conform to a simple rational economic model, or a linear attitude-behaviour model, researchers investigated other factors influencing energy consumption. Information, feedback and goal-setting have been used with varying degrees of success to influence household energy behaviour. The rational economic model suggests that information affects behaviour by allowing people to make economically rational decisions (Stern, 1986). However it cannot be assumed households have accurate information about where (or when) energy is consumed (Kempton, Harris, Keith, \& Weihl, 1985; Yamamoto, Suzuki, Fuwa, \& Sato, 2008) and simply providing information will not necessarily lead to behaviour change (Abrahamse et al., 2005; Constanzo et al., 1986; Stern et al., 1986). The way information is transmitted, who it is transmitted by and other constraints on behaviour are all important factors in the effectiveness of information to change behaviour. For instance, when prices and awareness of energy are already high, information may lead to conservation behaviour but in their absence other 
motivations may also be required (Kempton et al., 1992). Mass media campaigns, for instance, have frequently been used to change behaviour but may increase knowledge without changing behaviour (Abrahamse et al., 2005).

Social psychologists have learned a great deal about how information can be most effectively used to change behaviour. It is most effective when it is vivid, personalised and comes from a credible source (Aronson, 1990; Constanzo et al., 1986; Stern, 1986). Aronson (1990) describes an experiment by his research group where they trained energy auditors to make information vivid and personal for householders. They described the cumulative effects of draughts around the door as being equivalent to a hole the size of a basketball and described potential energy savings by making reference to the householder's own power bill. These techniques were highly effective with $60.9 \%$ of the experimental group acting on audit advice compared to $39.1 \%$ of the control group where advice was delivered in a perfunctory manner. Further, the take-up by the experimental group was 3 to 4 times that of the national average (Aronson, 1990, p. 129). Credibility of the information source is also important and community groups and non-commercial interests have been found to be particularly successful in this regard (Stern, 1992). In one example a power company offering low-cost energy audits undertook some of the audits themselves, hired commercial sub-contractors to do some and sub-contracted some to community groups. The community groups had the greatest success in attracting customers and creating behaviour change (Polich, 1984 cited in Stern, 1992)

In a detailed review of the effectiveness of intervention studies aimed at reducing energy consumption, Abrahamse et al. (2005) found that goal-setting can be effective in changing behaviour and is most effective in combination with feedback. Feedback, a concept derived from learning theory (Stern \& Oskamp, 1991), provides consumers with the information to learn and increase the efficacy of their behaviour. Information tailored to a specific situation has been shown to be more effective than generalised information (Abrahamse, Steg, Vlek, \& Rothengatter, 2007; Brandon \& Lewis, 1999). Abrahamse et al. (2007) used a combination of tailored information, goal-setting and feedback to successfully reduce direct energy consumption. However, in another study 
around the same time, Kurz, Donaghue and Walker (2005) found there was no impact on energy conservation from the effect of providing information and feedback. Interventions are more likely to be effective if a combination of measures are used (Stern \& Oskamp, 1991) and the success of Abrahamse et al.'s (2007) intervention was partly attributed to this effect. Another feature of the latter research is that the tailored information was provided via interactive computer software, an approach which has been successful in other studies (Brandon \& Lewis, 1999; Ueno, Sano, Saeki, \& Tsuji, 2006).

The size and source of the goal can also be influential. Goals which people set for themselves are less likely to produce an effect than goals which are set for them (Harkins \& Lowe, 2000). It has also been found that a larger goal is more effective in eliciting savings than a small goal. Becker (1978) found that the joint effect of feedback and a difficult conservation target (i.e. a 20\% target) had a greater influence on household conservation behaviour than feedback and an easy target (i.e. a $2 \%$ target).

\subsubsection{Social norms}

Social norms can have a powerful influence on the way people act and have been used at length to try to understand and predict environmentally significant behaviour. Social norms define what is considered acceptable in group behaviour. Two types of norms may operate in any group: descriptive norms, referring to the way most people think and act; and prescriptive or injunctive norms, referring to the way people feel they should act or actions that are approved by the group (Prentice, 2007).

A behavioural theory which highlights the role of norms is the Focus Theory of Normative Conduct (Cialdini, Kallgren, \& Reno, 1991). It argues that behaviour is most likely to be influenced by the norm currently in focus even if it conflicts with other norms held by an individual. Cialdini et al. (1991) conclude that injunctive social norms (norms which dictate how one 'should' act) are likely to have the broadest influence on behaviour. Consistent with this theory, Schultz, Nolan, Cialdini, Goldstein, \& Griskevicius (2007) found that descriptive norms 
had a clear influence on energy conservation, but when participants consumed below the norm a boomerang effect was observed (i.e. consumption increased toward the norm). However, when an injunctive norm was included, those below the norm continued with their lower than 'normal' level of consumption. In a related study it was found that although people self-reported that how the neighbours acted had the least influence on their behaviour, an experiment showed that it had the greatest impact (Nolan, Schultz, Cialdini, Goldstein, \& Griskevicius, 2008).

Various models have been developed over time to attempt to explain the role of personal variables in environmentally significant behaviour. Stern (2000) outlines the work of his research group to develop a 'coherent theory' of such behaviour. He presents the Value Belief Norm (VBN) theory (Stern, Dietz, Abel, Guagnano, \& Kalof, 1999) which draws together a number of earlier theories of environmental decision making: theories about the role of values in environmental behaviour, moral norm-activation theory (Schwartz, 1977) and the New Ecological Paradigm (NEP) (Dunlap \& Van Liere, 1978; Dunlap, Van Liere, Mertig, \& Jones, 2000).

Values are held to be relatively stable aspects of personality (Stern, 2000). Environmental researchers hold that those with self-transcendent (otherregarding) or 'biospheric' value orientations are more likely to engage in proenvironmental behaviour (Jackson, 2005; Milfont \& Gouveia, 2006) and these values are precursors to the acceptance of the NEP. The NEP measures certain beliefs which it is argued are inherent in environmentalism and have been taken to broadly reflect pro-environmental orientation (Dunlap et al., 2000). VBN theory holds that once the NEP has been accepted by an individual, personal norms must be activated before pro-environmental behaviour occurs. Therefore the theory links NEP and norm activation theory. Jackson (2005) paraphrases Schwartz by describing personal norms as "feelings of strong obligation that people experienced for themselves to engage in pro-social behaviour" (p. 54). Before moral norms are activated a person must believe something they care about will be affected (awareness of adverse consequences - AC) and also believe they could avert the adverse consequences if they took action (ascription 
of responsibility - AR). In this way beliefs impact on moral personal norms which in turn motivate behaviour (Jackson, 2005; Milfont, Sibley, \& Duckitt, in press; Schwartz, 1977; Stern, 2000). The different parts of VBN are linked in a causal chain where one variable impacts on the next (Stern, 2000). Figure 3 demonstrates the causal chain of VBN theory.

Figure 3: A schematic model of Value Belief Norm theory showing causal relationships

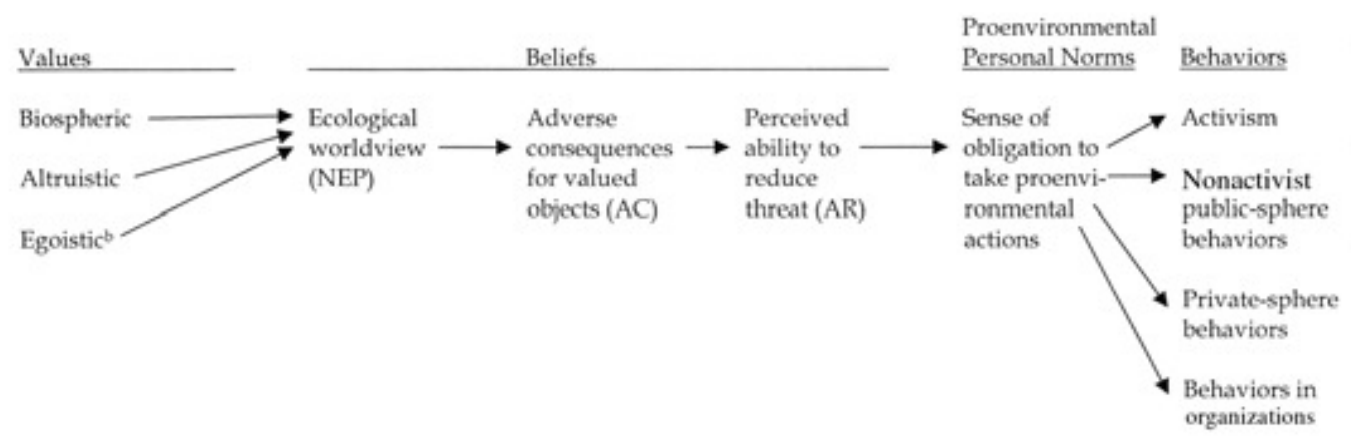

Source: Stern (2000 p. 376)

Stern (2008) re-presents a causal model of environmentally significant behaviour first published in the 1980s (Stern \& Oskamp, 1991). ${ }^{1}$ The 2008 model clearly demonstrates how VBN theory sits within the wider context of human behaviour which has important influences on individual behaviour. ${ }^{2}$ Stern (2008) states that "this model suggests that it is possible to influence individual behaviour within the limits set by context, habit, personal capability, and the like, by making people aware of the consequences, particularly adverse ones, for things they value, and by showing them that their personal behaviour is important enough to make a difference" (p. 376). He also reflects that contextual variables often have the strongest influence on behaviour. Table 1 shows the causal model of environmentally relevant behaviour. The level of causality column denotes how higher order variables may directly influence lower numbered variables (Stern, 2008). Stern highlights that "the most important effects" may skip levels (e.g. strong contextual effects at level 7 may have direct influence on knowledge at level 3) (p. 377).

\footnotetext{
${ }^{1}$ Reprinted in 1991.

${ }^{2}$ In Table 1 the factors which are incorporated in VBN theory have been italicised.
} 
Table 1: A causal model of environmentally relevant behaviour: Adapted from Stern and Oskamp (1991)

\begin{tabular}{|c|c|c|}
\hline $\begin{array}{l}\text { Level of } \\
\text { causality }\end{array}$ & Type of variable & Examples \\
\hline 7 & $\begin{array}{l}\text { Social background and general } \\
\text { personal capabilities }\end{array}$ & Race, socioeconomic status, financial resources \\
\hline 7 & $\begin{array}{l}\text { External conditions (incentives and } \\
\text { constraints) }\end{array}$ & Prices, regulation, technology, convenience \\
\hline 7 & Social influences & Social norms, advertising \\
\hline 6 & Basic values & $\begin{array}{l}\text { Egoism, altruism, openness to change, maintaining } \\
\text { tradition }\end{array}$ \\
\hline 5 & General beliefs and norms & $\begin{array}{l}\text { Belief that the environment is fragile or resilient; } \\
\text { attitude about environmental protection }\end{array}$ \\
\hline 4 & $\begin{array}{l}\text { Behaviour-specific attitudes, beliefs } \\
\text { and personal norms }\end{array}$ & $\begin{array}{l}\text { Belief that recycling is good for the environment, } \\
\text { sense of personal obligation to reduce fossil fuel } \\
\text { use; beliefs about the personal and environmental } \\
\text { costs and benefits of particular behaviours }\end{array}$ \\
\hline 3 & Behaviour-specific knowledge & $\begin{array}{l}\text { Knowing which packaging is biodegradable; which } \\
\text { household behaviours emit air pollutants; how to } \\
\text { petition legislators }\end{array}$ \\
\hline 2 & Behavioural commitment & Decision to travel by bus \\
\hline 1 & Environmentally relevant behaviour & Automobile purchase \\
\hline
\end{tabular}

Source: Stern (2008 p. 377)

\subsection{Sociological perspectives on energy behaviour}

A number of researchers have criticised the social psychology approach to understanding energy behaviour at the household level and have called for a broader perspective which takes into account other social factors and contextual influences to achieve greater understanding of the influences of consumption (Keirstead, 2006; Lutzenhiser, 1992; Wilhite et al., 2000). In a review of the social and behavioural aspects of energy use Lutzenhiser (1993) claims there is a consensus in the literature that models of energy behaviour need to be more concerned with social contexts than just individual behaviour. These approaches generally take a cultural, socio-technical or socio-political view of energy demand.

Lutzenhiser (1992) puts forward a 'cultural' model of energy demand and argues that the weakness of the social psychology approach is the focus on the individual consumer. He contends that to fully understand energy demand the 
relationship between human groups and available technology must be understood. In the cultural model Lutzenhiser sees consumer energy choices as “culturally sensitive and collectively-sanctioned" (p. 54). In other words, people do not make energy consumption choices in isolation. They are influenced by lifestyles and are "increasingly shaped by the standardizing, Western industrial influences" (Lutzenhiser, 1992, p. 54).

Cultural analyses of energy consumption have found that culturally or socially derived factors play an important part in shaping demand. A cross-cultural study of energy consumption in Japan and Norway found that cultural factors influenced the make-up of demand in each country in important ways (Wilhite, Nakagami, Masuda, Yamaga, \& Haneda, 1996). In Norway space heating and norms around lighting were significant, while in Japan a focus on bathing meant there were opportunities to reduce consumption by targeting hot water efficiency. The cultural importance of lighting in Nordic countries has been noted as a barrier to energy conservation by other researchers. Throne-Holst, Strandbakken and St $\varnothing$ (2008) found that interior lights, especially pools of light and shadow have a cultural association with a homely environment in Norway. As such Norway has the world's highest per capita lighting energy consumption (ThroneHolst et al., 2008).

From a socio-technical perspective, Haas, Auer and Biermayr (1998) found that energy savings due to efficient technology will be less than that calculated in engineering studies due to the role of human behaviour. Similarly, in a UK study Wall and Crosbie (2009) found that while energy savings of over 50\% for energy used for lighting could technically have been achieved if all participants had adopted compact fluorescent light bulbs (CFLs), the probable reduction was much less. Something often overlooked in energy policy analysis is the acceptability of the technology to consumers. Even among environmentally aware householders there has been dissatisfaction with the services delivered by CFL bulbs (e.g. quality of light, aesthetics, time taken to warm up), raising serious doubts about the expectations of rapid wide scale adoption of the technology and anticipated reductions in demand. 
Another Norwegian study (Aune, 2007), explored the socio-technical nature of energy consumption using Lutzenhiser's (1992) 'cultural model' as a starting point. Through a qualitative analysis of interviews and observations three concepts of 'home' were identified: 'home as a haven', 'home as project' and 'home as an arena for activities'. Each of these home concepts was an affective and symbolic construct as well as a physical environment. Aune (2007) concluded that the implications for policy are that "advice about behavioural change and technologies directed towards the 'home market' have to meet the requirements of different images and practical constructions of the home and [should] not expect a simple diffusion process of either information or energyefficient technologies" (p. 5464).

Other researchers have also attempted to create a broadly inclusive model of energy behaviour, beyond the constraints of psychology. Keirstead (2006) examined earlier research into household energy behaviour (referred to in his paper as 'domestic energy consumption' or DEC) that has attempted to present an integrated interdisciplinary model. He categorised these studies as presenting: 1) the behavioural model; 2) the political economy model; 3) the cultural model; 4) the systems approach and 5) the global consumption model. Keirstead (2006) in turn presented an agent-based integrated framework that considers household consumption in relation to government, physical environment, market, dwelling (house) and society in the hope that it could be used in practical and policy applications. Other researchers have recognised the need for integrated conceptual frameworks and explored the possibilities of a new model which integrates a range of consumer behaviour theories (see Faiers, Cook, \& Neame, 2007; Owens \& Driffill, 2008).

\subsubsection{Political constraints}

A common criticism from sociologists of much existing energy policy is the focus on the role of the consumer as the point of change (Joerges \& Müller, 1983; Lutzenhiser, 1992; Shove \& Wilhite, 1999). It is argued by some that this position is more politically acceptable than focusing on the real social and institutional drivers of demand (Lutzenhiser, 1992; Weiss \& Tschirhart, 1994). 
Conservation (i.e. curtailment) of energy has been politically contentious in the past. In the United States in the 1980s it was considered "un-American" to conserve as the nation had become great by "building, growing and consuming" (Hirst \& Brown, 1990, p. 274), and incentives or regulation to change behaviour have been labelled an infringement of consumer freedom (Kempton et al., 1992).

In a cross-national study of energy policies in eight western countries, Joerges and Müller (1983) conceptualised energy conservation as part of complex societal, organisational, political and behavioural processes at macro and micro levels. They found that at all levels (central and local government and utility companies), conservation policy placed a great deal of focus on consumer behaviour. Consumers were considered to be autonomous and the success of conservation efforts rested with them. However, significant structural constraints such as the influence and interests of utility companies in increasing demand were ignored.

Shove and Wilhite (1999) also criticised the common focus on the individual as the agent of change and the lack of analysis of the role of manufacturers, business interests, government and non-governmental organisations. They analysed examples of energy policy to demonstrate the limited understanding of the dynamics of consumption and social change which drives demand. They used the adoption of air-conditioning in the United States as an example of how product manufacturers created needs among consumers which have redetermined socially acceptable levels of comfort and cultural norms around indoor temperature. They argue that a radical shift in the conceptualisation of demand is required to effect change. Wilhite et al. (2000) similarly argued that the "nature and causes of 'energy demand' have been oversimplified, reduced or ignored in the community of energy research and policy" (p. 109), and that social science research has generally been limited to a focus on the behaviour of individuals. They call for 'demand' rather than 'behaviour' to be examined in light of the "interactions in the social, cultural and technological contexts in which individual lives are played out" (p. 123). Lutzenhiser (2002a) also encourages researchers to consider that energy is often 'embedded' in daily lives 
and routines and that constraints are placed on consumer choice by limitations in the marketplace and marketing efforts which promote energy use.

\subsection{Insights from energy shortages}

A significant amount of energy behaviour research has been driven by previous shortages such as the 'oil shocks' in the United States in the 1970s and the Californian 'energy crisis' of 2001. Much of this research has been reviewed above. A smaller number of studies have specifically addressed shortage situations, public perceptions, attitudes and resultant behaviour. Much research in this field appears to be in government reports or research undertaken by private research companies which has not been accessible for this study. Trends which have emerged in the available literature are summarised here.

\subsubsection{Awareness and public perceptions}

Awareness of energy supply and consumption increases in the lead-up to energy shortages as media interest in the issue increases. For example, awareness of electricity-related concerns rose significantly in California between 1989/99, when it was not raised at all, and 2001, when it was mentioned by $56 \%$ of respondents in one poll (Goldman, Barbose, \& Eto, 2002). Increased awareness of electricity-related concerns has also been seen in New Zealand. Before New Zealand's 2003 'Target 10' campaign started savings of 3\% (compared to the previous year) were made due to media coverage of the issue (Communications Agencies Association of New Zealand, 2003).

The importance and relevance of energy supply issues to individuals appears to vary depending upon the context. A review of survey data relating to energy conservation in the US during the energy shortages found that people were confused about the nature and causes of the energy shortages and in one study more than $50 \%$ of respondents expressed a cynical view about the shortages, commenting that they saw it as fabricated by energy providers (Tashchian \& Slama, 1985). At that time people were optimistic that future energy supplies would remove US reliance on oil and gas (Tashchian \& Slama, 1985). In California in 2001, a number of decades later, $85.7 \%$ of respondents had been 
thinking "a lot" or "some" about the effects of the shortage (Lutzenhiser, 2002b) and 12 months after that shortage $80-93 \%$ of respondents still thought energy was an important issue and conservation was important (Lutzenhiser et al., 2004). According to market research undertaken for the electricity industry in New Zealand in 2008 (Y\&R Marketing New Zealand, 2008) 83\% of respondents thought the power shortage was "very" or "quite" critical before the campaign started and this stayed at around $80 \%$ in the first four weeks of the five week campaign.

\subsubsection{Motivations}

Stated motivations for energy conservation vary but seem to generally include financial incentives as at least part of the motivation. Gmelch and Dillman (1988) found in a US study that economic benefit and a conservation ethic were the most significant motivations for conservation, and Tashchian and Slama (1985) identified financial reasons and 'the energy shortages' as consistent motivating factors in another US study. In 2001 the most important motivations were to reduce electricity bills, avoid blackouts, use energy wisely and stop utility companies overcharging. Environmental protection ranked much lower as a motivating factor (Bender, Kandel, \& Goldstone, 2004; Lutzenhiser, 2002b). Other reasons given included commonsense and past experiences and civic responsibility (Lutzenhiser et al., 2004). In New Zealand, the Y\&R (2008) research indicated that around $60 \%$ of respondents said they were motivated to save energy in order to save money over a five week sample period.

\subsubsection{Perceptions of responsibility}

During energy shortages people tend to blame the government and utility companies (Lutzenhiser, 2002a). In a US study Belk, Painter and Semenik (1981) found the four parties most often held responsible for the energy shortages were 1) governments for mismanaging energy policies; 2) oil companies for restricting supply; 3) the public for wasting resources and 4) OPEC for manufacturing the shortages. Taschian and Slama (1985) found similar results and that other sources of blame were the general public, 'big business' and environmentalists for lobbying for cleaner energy production. A similar pattern was evident in a 
2001 public opinion poll which found that more people (57\% compared to 36\%) thought the energy shortages in California were driven by utility companies wanting to increase prices rather than a shortage of supply (DiCamillo \& Field, 2001). The same 'Field Poll' found that $60 \%$ of respondents blamed environmental groups for opposing new generation.

\subsubsection{Information sources}

Since the 1970s news media have been a dominant source of information about energy issues, probably more than official information campaigns. According to US survey results the main sources of information following the 1973 oil embargo were news media and commercials (Morrison et al., 1978). Media were also a significant source of information during Californian's 2001 'crisis'. Media stories were found to be more influential than campaign advertisements (Lutzenhiser, 2002b) and the media provided advice and tips about how to save energy (Goldman et al., 2002) as well as raising awareness.

Mass media campaigns have been used in the past to encourage conservation behaviour with some success (Lutzenhiser, 2002b); however, Abrahamse et al. (2005) found that mass media and workshops can increase knowledge but do not necessarily effect consumption. Lutzenhiser (2002b) undertook an analysis of survey results of actual consumption data following the Californian shortage in 2001 and showed that a minority of respondents (about 30\%) accounted for 75\% of the demand reduction, indicating that although a high proportion of people were aware of the issue and took some actions, a relatively small proportion of the population contributed most of the demand reduction.

The Californian 'Flex Your Power' campaign in 2001 drew on insights from social psychology and social marketing in its design. Bender et al. (2002) presented an analysis of the campaign design. Campaign messages were kept simple and delivered clear messages of what to do. In a move atypical of other campaigns (Bender et al., 2004) there was little focus on the financial benefits of lowering consumption. The campaign appealed to social norms to give people 'permission' (Bender et al., p. 8.22) to act and to link actions to larger social 
consequences. Messages tried to heighten people's self-efficacy so they felt empowered and focused on actions within their individual control such as turning off lights and lowering thermostats. Campaign messages tried to make energy visible by using vivid images, for example by showing a curtain blowing in front of a fan or an image of a power plant.

\subsubsection{Most common conservation actions}

Studies have shown that environmentally important actions are more likely where when they are low-effort and low-cost (Black et al., 1985; Diekmann \& Preisendörfer, 2003). Further, people are more likely to take actions which are obvious or highly visible (Stern, 1986) and as a result common energy conservation actions tend to be things which come to mind easily such as turning off lights. Consistent with this, the most common conservation actions during shortages have been low-cost and low-effort, with switching off lights usually the most popular action. In California in 2001, almost all households surveyed reported turning off lights compared to a quarter who reported unplugging equipment even though the latter was promoted heavily in the advertising campaign. Smaller proportions of respondents reported changing clothes washing habits (21\%), installing CFLs (18\%) and adjusting thermostats (7\%) (Lutzenhiser, 2002b).

In a telephone survey of New Zealanders aged over 18, UMR Research (2001) found the most common actions taken in response to publicity about the likelihood of an electricity shortage later in the year was turning off lights (47.8\%) and fuel switching (i.e. from electricity to solid fuel) (35.5\%). The same research found that the top five electricity saving actions as a matter of course were: turn off lights (96\%); wash laundry in a cold wash (77\%); check monthly power bill (74\%); heat only the room one is in (73\%) and have shorter showers $(68 \%)$.

In California in 2001, analysts were surprised by the willingness of $40 \%$ of respondents to go without air-conditioning or use it less (Lutzenhiser, Hill Gossard, \& Bender, 2002) even though the 'Flex Your Power' campaign did not 
target this behaviour. Turning off the air-conditioner requires more effort as it affects comfort and is in contrast to the normal tendency toward low-cost, loweffort actions. It has been suggested this may have been partly due to the visibility and salience of air-conditioners, especially during summer (Bender et al., 2004). Although the adoption of efficient technologies was widely promoted during the campaign, demand reductions were largely due to behaviour changes (Lutzenhiser et al., 2004).

\subsection{Summary}

The social sciences have much to contribute to the understanding of energy behaviour at a household level. As this review has shown, the consumption of energy is not economically rational; personal variables such as attitudes, beliefs and norms matter, and behaviour is often constrained by strong contextual influences, including socio-economic, technological and informational variables. People consume energy for the services it provides, not for its own sake. End uses may be utilitarian (e.g. heating, lighting) but demand preferences also reflect lifestyles and marketing efforts and have cultural and social meaning. Social psychology has learned a great deal about effective ways of encouraging energy conservation and points of intervention but recognises that the individual is constrained by external and social factors beyond their immediate control. Sociologists have called for a broader conceptualisation of demand which turns the focus away from only examining individual variables and looks at the often subtle social, cultural and institutional factors which shape demand. During shortages, energy consumption becomes more salient and visible (Kempton et al., 1992) and different motivations and constraints come into play. Little systematic evidence is available about conservation behaviour during shortages and afterwards, but it is clear that US and New Zealand consumers are prepared to take low-cost, low-effort actions and are motivated by both financial and nonfinancial factors to conserve. 


\subsection{Conceptual framework}

Drawing on the literature review above, the following section explains the conceptual framework for this thesis which has informed the research design and will be applied to the general discussion of the results in Chapter 6 .

The research is founded on a pragmatic worldview which focuses on "the primary importance of the research question asked rather than the methods... it is pluralistic and oriented toward 'what works' and practice" (Creswell \& Plano Clark, 2007, p. 23). A mixed methods approach was selected as one research approach was inadequate to address the research problem (Creswell \& Plano Clark, 2007).

The research is theoretically grounded in social psychology and also draws on a sociological approach, although it belongs in the interdisciplinary field of environmental studies. The research uses quantitative and qualitative research techniques from the field of social psychology. The research accepts that energy behaviour is too complex to be categorised by a simple economic model (Aronson, 1990) and that a focus on price "leaves obscure the behavioral phenomena that underlie the response to price and the non-price factors that can influence energy use" (Stern, 1986, p. 202).

People do not consume energy as such, rather they consume the services energy delivers: heat, comfort, food provision, entertainment and status, much of which is embedded in daily life (Lutzenhiser, 2002a). The need for these services may be driven by physical, psychological, social, cultural and political phenomena. In turn these phenomena may restrict or enhance an individual's ability or willingness to conserve energy. Effectively they are two sides of the same coin with the psychological view seeing the individual as more autonomous than the sociological view which considers that individual consumption is driven by a broad set of social constructs, over which the individual may have little immediate control.

To acknowledge these two perspectives Stern's (2008) causal model of environmentally significant behaviour has been used as a theoretical framework 
to examine household level behaviour within a broader social system (see Table 1). The model demonstrates clearly where in the hierarchy of influences personal variables sit and how they might be influenced by variables further up the chain. Stern (2008) states that "most of the personal variables of interest to environmental psychologists are likely to have practical importance for environmental consumption behaviours only under very limited conditions" and "such models must be considered within the larger context of influences on individual behaviour" (p. 378). To that end this research will explore whether a relationship existed between household level behaviour during a supply shortage and the socio-political context of the time to examine how contextual variables may have influenced individual level behaviour.

The qualitative study (Study 1) examines influences on behaviour at a high level in Stern's causal model (i.e. level 7) and identifies themes which may reflect social and political norms, whilst the quantitative study (Study 2) examines the personal level variables in the model (level 4) with a particular focus on attitudes, behaviour and motivations as reported by participants. Study 3 examines electricity demand data which estimates the electricity savings during the shortage period. Each study (chapters 3, 4 and 5) includes a detailed explanation of the methods used. 


\section{Study 1: Thematic analysis of media reports relating to the electricity shortage}

Objective 1 of this study, as noted in Chapter 1, is to analyse how electricity conservation was portrayed in the media and political discourse during the shortage period. This chapter presents the results of a qualitative study (Study 1) that explored the socio-political context of the supply shortage. A thematic analysis of media coverage and political debate related to the shortage was undertaken. Some quantification of results has also been included.

\subsection{Method}

Newspaper articles, press releases and parliamentary debates related to the shortage were analysed. The aim of Study 1 was to analyse the socio-political context within which the supply shortage and conservation campaign took place to consider how it may have influenced the environment for householders' decision-making. Media coverage and the content of political debates were selected as data because it was hypothesised they would reflect social and political norms around electricity conservation, supply and demand.

Thematic analysis "is a way of identifying, analysing and reporting patterns (themes) within data" (Braun \& Clarke, 2006, p. 79). This method of analysis was chosen because it is an "accessible form of analysis" within the domain of qualitative research (Braun \& Clarke, 2006, p. 81). Therefore a thematic analysis of media extracts was undertaken using the method outlined by Braun and Clarke (2006). Following this method a number of methodological decisions were taken and are made explicit here. This analysis provided a rich description of the entire dataset, allowing for the examination of the context of the shortage by searching for themes in the data. The analysis did not attempt to describe every aspect in detail and some nuances were necessarily lost. In this sense the analysis was somewhat inductive (i.e., it attempted to reflect elements present in the data and build themes up from them rather than impose a pre-conceived framework on to the data). However, the analysis also reflected a theoretical assumption that the socio-political context influenced the way the issues were presented and debated 
in the media and has sought to answer the specific research question at hand (cf. Braun \& Clarke, 2006).

The analysis took a semantic approach in which themes were identified through the standard meaning of words, and meaning has not been sought beyond what has been said or written (Braun \& Clarke, 2006). Following Ellis and Kitzinger's (2002) approach, epistemological issues of whether people believe what they are saying have not been addressed. It is assumed that people mean what they say, and an essentialist/realist approach has been adopted. That is, a simple relationship between meaning and language is assumed (Braun \& Clarke, 2006).

\subsection{Procedure}

The texts for analysis were gathered by searching two databases: Newztext Plus and the Otago Daily Times (ODT) online edition. The Newztext Plus database was chosen because it allowed access to all New Zealand's major metropolitan daily newspapers (with the exception of the $O D T$ ) as well as a number of other media sources. Print media was selected because the scope of the study did not allow for an analysis of all available media sources (i.e. television, radio, online sources). The media selected were taken to be representative of the mainstream media's presentation of the issue. Because of the large volume of material available in the databases, the search was limited to three sources within the Newztext Plus database: Fairfax Media sources, the New Zealand Herald and Scoop. Scoop is an independent online news portal that publishes news content in a "disintermediated" format (i.e., before it is reinterpreted by a journalist or editor) (Scoop Independent News, n.d.). A separate search of the ODT was undertaken because it is not covered by the Newztext Plus database and (like the New Zealand Herald) it is not owned by Fairfax media, raising the possibility that it might have introduced a different perspective to the issue.

Both databases were searched using the terms "electricity AND (shortage OR crisis) AND hydro" for articles between $1^{\text {st }}$ May 2008 and $31^{\text {st }}$ August 2008. The conservation campaign ran for a six-week period from Sunday $15^{\text {th }}$ June to Sunday $27^{\text {th }}$ July. Therefore, these dates allowed for at least one month of 
coverage either side of the conservation campaign. The search of Newztext Plus yielded 159 items and the ODT yielded a further 13 relevant articles. A number of items were removed due to lack of relevance to the issue or duplication. As a result the final sample size was 144 items. All items were copied into NVivo 8 for coding and analysis. As a first step they were categorised by media source. ${ }^{3}$ Table 2 shows the number of items by media source ranked by the quantity of items. A complete list of articles is included in Appendix 1 for reference.

Table 2: Media sources and the number of items from each

\begin{tabular}{ll}
\hline Source & Number of items \\
The Dominion Post & 26 \\
Scoop & 24 \\
The Press & 21 \\
The New Zealand Herald & 13 \\
The Otago Daily Times & 6 \\
Bay of Plenty Times & 5 \\
The Nelson Mail & 5 \\
The Sunday Star Times & 4 \\
Hawkes Bay Today & 4 \\
The Southland Times & 4 \\
The Waikato Times & 3 \\
The Daily Post & 3 \\
The Manawatu Standard & 2 \\
Independent Financial Review & 1 \\
The Northern Advocate & \\
\hline
\end{tabular}

Next, Braun and Clarke's (2006) six-phase process, shown in Table 3, was worked through. Themes were identified by repeated reading of the data set and collating extracts into coded categories which displayed common concepts and captured something "important about the data in relation to the research question" (Braun \& Clarke, 2006, p. 82). Coded extracts were read and re-read to find "recurring regularities" (Patton, 1990, p. 403) which became the basis for identifying themes. Themes were also judged by Patton's "internal homogeneity"

${ }^{3}$ NVivo 8 is specialised qualitative analysis software. 
and "external heterogeneity" criteria to strengthen their validity. These criteria refer to the way data in a category "hold together in a meaningful way" and the extent to which differences between categories are "bold and clear" (p. 403).

Table 3: Braun and Clarke's (2006) summary of the phases involved in thematic analysis

Phase Description of the process

1. Familiarizing yourself with

Transcribing data (if necessary), reading and re-reading the data, noting down the data: initial ideas.

2. Generating initial codes: Coding interesting features of the data in a systematic fashion across the entire data set, collating data relevant to each code.

3. Searching for themes: Collating codes into potential themes, gathering all data relevant to each potential theme.

4. Reviewing themes: Checking if the themes work in relation to the coded extracts (Level 1) and the entire data set (Level 2), generating a thematic 'map' of the analysis.

5. Defining and naming themes: Ongoing analysis to refine the specifics of each theme, and the overall story the analysis tells, generating clear definitions and names for each theme.

6. Producing the report:

Following the process outlined above a thematic map was drawn to illustrate the themes and sub-themes identified in the data. This map is depicted in Figure 4 and gives a structural overview of the results discussed below.

Figure 4: Map of themes identified in the media data set

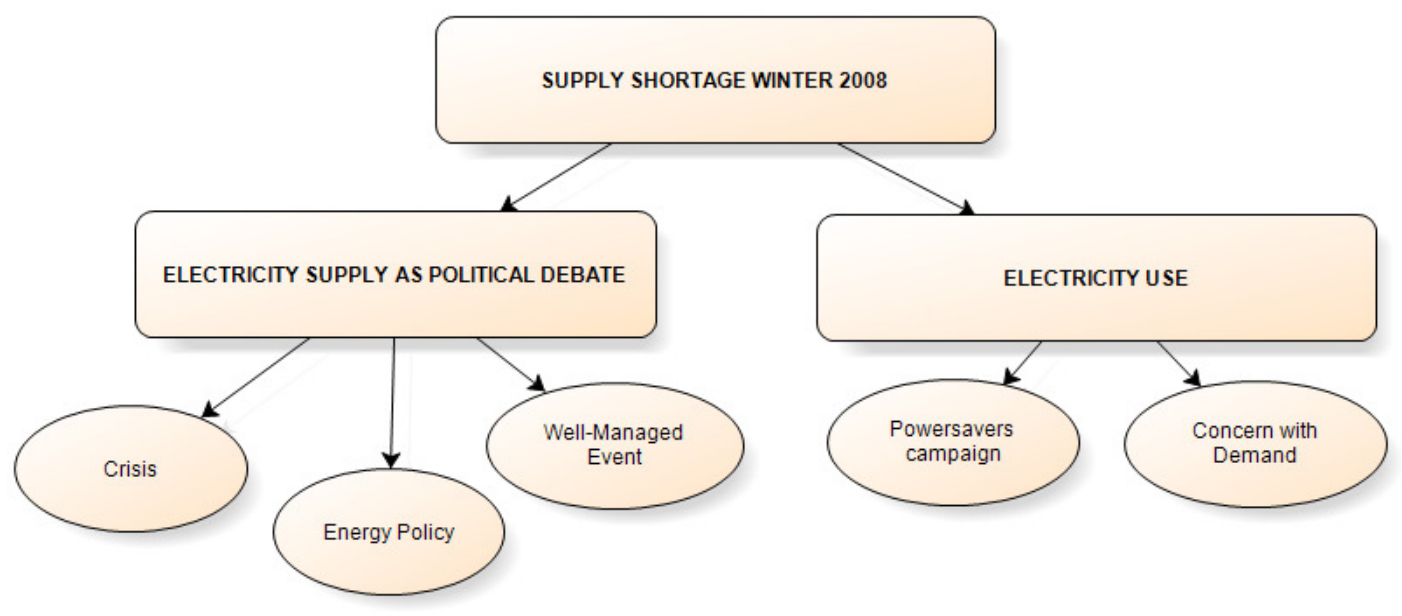




\subsection{Results}

Two themes were identified in the dataset: Electricity Supply as a Political Issue and Electricity Use. The themes are complex and incorporate a number of related and inter-related issues which reflect the inter-connected nature of the electricity system. Each theme contains a number of sub-themes which are shown in Table 4 with the number of coded extracts indicated. The number of sources refers to the number of articles which have been coded to the theme, whilst the number of references refers to the number of pieces of text coded. This means that for each theme and sub-theme multiple pieces of text (often in a single article) have been identified and coded to that theme or sub-theme. The themes and their specific sub-themes are discussed below.

Table 4: Themes and sub-themes and number of sources and references

\begin{tabular}{llrr}
\hline Theme & Sub-theme & Sources & References \\
Electricity Supply as a political issue & Crisis & 112 & 233 \\
& Energy policy & 103 & 219 \\
& Well-managed event & 51 & 92 \\
Electricity use & Powersavers campaign & 65 & 107 \\
& Concern with demand & 36 & 46 \\
\hline
\end{tabular}

\subsubsection{Electricity supply as a political issue}

This theme captures the politics of the shortage. It encompasses debate around energy policies in New Zealand, whether the situation was the result of successive failures by the government of the day or was an inevitable but wellmanaged outcome of drought in a hydro-dominant electricity system. The system effects and implications of an uncertain electricity supply were debated and questions were raised about the design of the electricity market, associated policies and where responsibility lay. Three sub-themes were identified: Crisis, Energy policy and Well-managed event. The first two sub-themes are dominated by consistent criticism of the government whilst the third sub-theme (Wellmanaged event) is typified by positive framing of the issue and/or the use of more neutral language. The political significance of the electricity supply issue was accentuated by the proximity of the shortage to the 2008 New Zealand General Election which took place on $8^{\text {th }}$ November, five months after the conservation campaign. Within media extracts it was referred to as a motivating factor for the actions of those on both sides of the political debate. 


\subsubsection{Crisis}

The Crisis sub-theme is a central one within the analysis as it reflects the dominant way the hydro shortage was framed by the media across the data set. It is also the most predominant theme with 233 coded references. With few exceptions, the low hydro-lake levels and the down-stream effects of this were referred to, or portrayed as, a crisis. Extracts reflect the sense of risk, danger and lack of control inherent in a crisis:

Power lines companies are warning customers that electricity could be cut off 'without warning', for at least 30 minutes, as the industry gears up for the growing risk of blackouts. [Dominion Post, $3^{\text {rd }}$ May, 2008]

Civil Defence chiefs from all Auckland's councils met yesterday to discuss the crisis. Civil Defence emergency management group chairman Derek Battersby described Auckland as 'the boiler room' of New Zealand. 'Our country is in a fragile situation and if it hits us in the next few months, it won't bode well for New Zealand,' he said. [Bay of Plenty Times, $7^{\text {th }}$ June, $2008]$

Extracts coded to the Crisis sub-theme deal with the negative effects of the shortage situation, responsibility for the situation (which is usually levelled at the government) and a sense that an electricity shortage is an unacceptable occurrence.

References to the negative effects of the shortage have been grouped together under economic effects, effects on households and environmental effects. Economic effects and effects on households received the greatest amount of coverage (63 references each) with the focus being on loss of production (and therefore loss of earnings), the potential loss of businesses off-shore, and damage to New Zealand's international business reputation: 
It's not a 'crisis' yet but international headlines saying that Kiwis are being told to 'turn the lights off' and wash dishes by hand are harming New Zealand's image as an investment destination. The problem is that even though New Zealand may well manage its way through the winter, the repetitive nature of these so-called one-in-60-year mini-crises is stoking perceptions the Government is not sufficiently focused on ensuring security of the national power supply. [New Zealand Herald, $16^{\text {th }}$ May, 2008]

I don't think you should ever have a case where companies have to turn things off. It's got really negative impacts. Overseas companies will be looking at things like that and thinking New Zealand doesn't even pass first base if we can't guarantee we can turn the lights on. [New Zealand Herald, $10^{\text {th }}$ May, 2008]

In terms of negative effects on households, key issues were the health and safety of at-risk householders such as the sick and the elderly, the negative portrayal of going without electronic appliances (e.g. dishwashers, electric blankets and clothes driers), and residential price rises associated with an insecure power supply.

In contrast, eight extracts were coded to environmental effects. These extracts mainly deal with localised effects of extremely low lake levels:

Hawea is going to suffer the consequences for months or years to come from having a lower lake, but the country as a whole isn't making any sacrifice, he said. The Government refuses to acknowledge there is a crisis, so why sacrifice our environment if there is no crisis? [Otago Daily Times, $27^{\text {th }}$ June 2008]

Responsibility for the shortage and its consequences was repeatedly directed towards the government and a sense of anger and frustration was often present:

As sure as summer follows spring, every autumn we are delivered the scare of potential power shortages in the coming winter. What have all our governments, past and present done about it, apart from talk and levy us for an 'electricity commission'? Nothing! [Bay of Plenty Times, $26^{\text {th }}$ June, 2008]

The government was accused of avoiding responsibility by turning a blind eye to the situation for political reasons: 
'...they're in total denial,' Mr Brownlee said. 'It's the crisis you have when you're not admitting there's a crisis.' [New Zealand Herald, $10^{\text {th }}$ June, 2008]

The Government has ignored the warning signs of another power shortage and the risk of blackouts is now 'one in five', independent energy consultant Bryan Leyland says. 'We are in a power shortage now, with industry backing off use,' Mr Leyland said yesterday. A public power savings campaign had not been started yet because the Government considered that 'political suicide'. [Dominion Post, $28^{\text {th }}$ May, 2008]

Further, the government was portrayed as naïve and patronising compared with the businesses community that was portrayed as serious and responding appropriately in the circumstances.

For weeks, our big industrial electricity users have been quietly pointing out they are worried. These are serious people whose company livelihoods depend on real figures, not chummy little tips and a television campaign that Mr Parker says will be pitched at a level that won't risk causing any real concern. [Manawatu Standard, $11^{\text {th }}$ June, 2008]

Inherent in the criticism of the government and concern about the effects of the shortage was a sense of the 'unacceptability' of the situation. Not only was the shortage portrayed as unacceptable from an economic perspective but it was portrayed as somewhat shameful that householders should be encouraged to consume less electricity. These comments suggested a sense of 'going without' which has been identified in the literature (Gardner \& Stern, 2002), and appeared to reflect frustration and embarrassment about living in a country which could not support security in a desired lifestyle:

It's a joke asking consumers to save more power when the higher cost of power would have already achieved that. Perhaps tourism could be promoted with the slogan 'Come to New Zealand and experience the dark age. [Hawkes Bay Today, $7^{\text {th }}$ May, 2008]

It's a travesty that in a country as energy-rich as New Zealand that every couple of years there have to be television advertisements and begging from the Government for the public to turn off their electric blankets and heated towel-rails, and for business to cut back on production. [Scoop, $14^{\text {th }}$ August, 2008] 


\subsubsection{Energy policy}

The second sub-theme, Energy policy (219 references) consists of a far-reaching debate around the appropriateness of government policies for electricity supply, where the responsibility for the shortage lay, and what changes should be made. This debate centred on electricity generation, market design and security of supply issues. Both sides of the debate were heard although criticism of the government and its policies predominated.

The shortage gave rise to debate around what type of new generation is most appropriate for New Zealand, for example, whether thermal or renewable new generation would be preferable:

We need a mix of new generation sources to balance out the risks associated with renewable generation such as hydro and wind, Mr Matthes said. [Dominion Post, $5^{\text {th }}$ June, 2008]

Wind and hydro generation are perfect partners - when the wind is blowing hydro-dam water can be stored for use when it is not. [Scoop, $6^{\text {th }}$ June, 2008]

The Labour government's $90 \%$ renewable target and its 10 -year moratorium on new thermal generation were questioned with commentary mostly critical of the government:

The shortage raised questions about the Government's renewable electricity target banning fossil fuelled power stations, when those in the North Island were now filling the supply gap created by a fall in hydro electricity. [The Press, $6^{\text {th }}$ May, 2008]

The Government must take the blame for this predicament. It needs to let the power industry respond appropriately by building new generators. It needs to remove the ban on new baseload thermal generation so that Genesis Energy can build another plant. [New Zealand Herald, $15^{\text {th }}$ June, 2008] 
Precisely how Labour is going to move the electricity system towards a greater reliance on renewable energy when scientists predict an even drier climate is anyone's guess. While it cannot be held responsible for the climate, it is responsible for general policy settings, and the Government has, for some time, been discouraging new thermal investment and encouraging wind farms instead. [The Press, $16^{\text {th }}$ June, 2008]

The design of the electricity market was also debated at length. The electricity market is complex, and supply, demand, lake levels and spot prices are closely inter-related. Concerns were raised about whether the market provides incentives for new generation, whether spot prices delivered through the market were appropriate, the role of the electricity commission and the reserve generator at Whirinaki, and whether the system is open to 'gaming' (i.e. a market structure which allows generators and retailers to raise prices artificially). A small number of parties called for a review and restructure of the market although most did not explicitly do so. For example:

The design of the market system did not reward those who built a reserve power station to be used when lakes were low, he said. [Dominion Post, $28^{\text {th }}$ May, 2008]

The prices are absolutely unjustifiable and the present Government doesn't appear to have any sympathy. [Hawkes Bay Today, $11^{\text {th }}$ June, 2008]

Funded by an industry levy passed on to our monthly electricity bills, the [Electricity] commission was tasked to make sure the 2003 shortage didn't happen again. It appears to have failed, and it needs to step up and be accountable. [Sunday Star Times, $22^{\text {nd }}$ June, 2008]

So is it a rip-off or a fair price in a drought? Nobody knows for sure. If there were signs of market 'Californication' here, the Commerce Commission should act. [Dominion Post, $3^{\text {rd }}$ May, 2008]

Commercial power users have called on the Government to conduct a 'proper review' that examines the whole sector, including the Electricity Commission's role and the behaviour of the major suppliers. [Dominion Post, $21^{\text {st }}$ July, 2008]

Security of supply (or the lack of it) was identified as an important issue within the dataset although it was mainly emphasised among parties opposed to existing 
government policy. Concern about infrastructure and generation capacity was identified as a key part of this issue. Two aspects appear most prevalent: lack of faith in the existing system and a shortage of capacity due to lack of investment.

The risk of supply failure was heightened in 2008 because a number of system weaknesses became evident in close succession. Firstly, the Otahuhu B plant closed temporarily for maintenance just as a household conservation campaign was being considered:

One of the country's biggest gas-fired power stations has failed just days before electricity companies are expected to call a nationwide energy savings campaign because of the drought in the South Island. [Dominion Post, $6^{\text {th }}$ June, 2008]

This was set against a background of the recent closure of Contact Energy's New Plymouth plant due to fears about asbestos exposure (although the plant was later re-opened):

To help avert a crisis, Contact Energy has reopened part of a Taranaki power station, closed last September because of its age and asbestos danger. [Daily Post, $30^{\text {th }}$ May, 2008]

At the same time there were concerns about the impact should the Huntly power station fail because of the increased portion of the load being provided by thermal generators:

He [Meridian spokesman Alan Seay] said Meridian was still optimistic that winter power shortages could be avoided, with one warning: 'if Huntly falls over, we've got an instant code red.' [New Zealand Herald, $7^{\text {th }}$ June, $2008]$

And concerns were expressed about the vulnerability of the partly disabled Cook Strait high-voltage direct-current (HVDC) cable which carries electricity between the two main islands.

The lack of [South Island hydro lake] water means the South Island's power supply is at risk if the single Cook Strait cable transferring electricity south fails. [The Press, $6^{\text {th }}$ August, 2008] 
These unusual circumstances appear to have made security of supply an even more salient issue. The government came under harsh criticism for this concurrent turn of events and the issues were made much of by the Opposition with National's spokesperson repeatedly quoted on the issue of infrastructure:

The situation is remarkably bad. Just to keep the lights on, New Zealanders are relying on a broken Cook Strait cable, an asbestos-riddled mothballed plant in New Plymouth, and a diesel-guzzling emergency generator at Whirinaki, [The Press, $6^{\text {th }}$ June, 2008]

The issue of available capacity was also important. Two perspectives on the topic are reflected in extracts from parties with different political priorities. By some it was portrayed as government failure and by others it was portrayed as a reality of having a sustainable hydro-dominant supply system. The Opposition energy spokesman Gerry Brownlee repeatedly laid the blame for lack of capacity with the government:

We suffered power crises in 2001, 2003, 2006 and now 2008. National's Gerry Brownlee wryly observed that while the Government put the blame on dry weather 'these so-called one-in-60-year events are proving to be far too common'. Indeed, they appear now to be one-in-two-year events. Brownlee contends the Government urgently needs to 'future proof' our energy infrastructure and build more generating capacity. [New Zealand Herald, 4th May, 2008]

In contrast, the chairman of the Electricity Commission, which has responsibility for "ensuring that electricity is produced and delivered to all classes of consumers in an efficient, fair, reliable and environmentally sustainable manner and promoting and facilitating the efficient use of electricity" (Ministry of Economic Development, 2008c, p. 2), had a different perspective on the issue and alluded that attitudes to demand were part of the capacity issue:

Caygill said many people believed they should expect to be able to use power when and how they wanted. But a country which relied $60 \%$ on hydro- generated electricity had to be careful using electricity in those years when it didn't rain as much. The commission believed $\$ 24.4 m$ a year was a high price to pay for security. More Whirinakis, which would sit idle for most of the year, would be too high a price to pay for increased security. [Sunday Star Times, 22 ${ }^{\text {nd }}$ June, 2008] 
The juxtaposition of these two perspectives on generating capacity suggests the significant role framing can play in handling an issue so that it meets the priorities of the party or individual in question. The Opposition's 'poor energy policy' framing was consistent with the Crisis sub-theme noted earlier, while the Electricity Commission's framing was more considered. It raised issues about moderation in consumption, and was an implicit rejection of the Opposition's framing.

\subsubsection{Well-managed event}

In contrast to the first two sub-themes, extracts under the final sub-theme framed the shortage in a more positive light and messages were predominantly delivered by voices from the government and electricity industry.

Media extracts coded to sub-theme three reflected a co-ordinated response by the government and electricity industry (including the system operator, Transpower, and industry regulator, the Electricity Commission) to present the situation as under control, even though it was not ideal. This sub-theme is typified by the use of relatively neutral language and positive framing of the situation, and contains three distinct clusters of extracts. Firstly, the repeated use of the word 'prudent' to describe the desired approach to electricity use by householders; secondly, repeated messages by the Minister of Energy that there was no crisis, but simply a well-managed situation; and thirdly, responses which appear to have been purposefully intended to be objective, transparent and pragmatic, from all industry players. Concurrent with these messages is the ongoing debate about the appropriateness or otherwise of the government and industry responses.

The consistent use of the terms 'prudent' and 'prudence' ( 24 references) by different sources suggests a co-ordinated effort was made to deliver the same message across the industry and by the government to mitigate political risk. The message was that only 'prudence' was required, rather than hard conservation measures or sacrifice, and therefore no one would have to suffer unduly: 
People should just be 'more prudent', it [the government] said. [Dominion Post, 10 ${ }^{\text {th }}$ June, 2008]

And given that the situation was not a 'crisis', people should not expect blackouts:

It's not a crisis, it's just another step along the way when you have a dry winter, he said [Energy Minister, David Parker]. [Otago Daily Times, $10^{\text {th }}$ June, 2008]

Further, the message was that people (especially the vulnerable) should not go without heating or other essential electrical services:

The power bills are higher in the winter and people shouldn't turn off heaters and get cold. But they can switch off lights when they leave a room. [Bay of Plenty Times, $11^{\text {th }}$ June, 2008]

Another key message was that the issue was being effectively managed. This was delivered by government spokespeople (usually the Minister of Energy) through the careful use of language. The same messages were repeatedly delivered: that there is no crisis, that the situation is different to other years because it is being better managed, that 'doomsayers' are wrong and that the system is operating as intended. For example:

We haven't got a crisis. What we've got is a shortage of water. [Dominion Post, 16 ${ }^{\text {th }}$ June, 2008]

Miss Clark said the situation was different from 2003. Genesis didn't have sufficient coal supplies on hand [then] to fire up Huntly to full capacity. So we are in a better position now with other means of generating power than we were in 2003. [Dominion Post, $4^{\text {th }}$ June, 2008].

Predictions by doomsayers that the lights are expected to go out as a result of low lake levels are wrong, Mr Parker said. [Dominion Post, 9th June, 2008]

Thanks to better information made available since the Electricity Commission was set up, and good industry coordination, the tight energy situation has been well managed. The outcome should be seen as proof that the system is robust, rather than the reverse. [Scoop, 15 th July, $2008-$ Government press release] 
Messages were deliberately framed this way to stress good management. The Minister went so far as to explicitly state he is careful with his language around the issue.

Energy Minister David Parker says he always watches his words when he's talking about power supplies. That's because he's anxious people don't get the idea there's a crisis, although an energy saving campaign will start on $T V$ this Sunday - unless it rains a lot between now and then. 'We're not saying the lights are going out,' Mr Parker told a press conference yesterday. 'That's why we're very careful with our language around here because no matter what we say some people seem to come out with a doomsday prediction that the lights are going out.' [Otago Daily Times, $10^{\text {th }}$ June, 2008]

A sense of 'calm pragmatism' was identified among responses from both government and industry that also suggests a co-ordinated response. Their messages sought to remain objective and non-emotive, describing the situation but not laying blame. They also display a sense of transparency, often expressing concern or that the situation was serious but also that it was being managed and did not warrant anxiety or panic. The industry appears to have worked cooperatively with this stance as this sense of pragmatism was expressed widely by its spokespeople.

Western Bay households will get through winter without having power cuts forced on them. That's the word today from TrustPower chief executive Keith Tempest who said 'There is still a large amount of energy available. I'm pretty sure it will last and we are a long way from a (supply) crisis. The lights won't go off.' [Bay of Plenty Times, $11^{\text {th }}$ June, 2008]

Transpower chief executive Patrick Strange said the national grid operator remained concerned about storage levels after low inflows in the past fortnight. 'We are the lowest since 1992, but we are still well above 1992 levels'. In three weeks, if there was no rain or a big power station failed, Transpower would move beyond asking people to be prudent with power, Mr Strange said. [Otago Daily Times, 27 ${ }^{\text {th }}$ May, 2008]

All the elements in this sub-theme reflected a co-ordinated response from government and industry to frame the situation as anything but a crisis. It is expected that each party is likely to have had its own motivations to present this image. The government would have wanted to avoid criticism about the fact the 
situation had arisen at all; it would have wanted to appear in control and to avoid criticism that people may be suffering in any way (e.g. going without heating) as a result of the situation. The industry, largely state-owned (although including two private companies), ${ }^{4}$ would not have been entirely insulated from these government objectives but it is expected it may have had its own commercial reasons to appear in control, and as competent and responsible businesses, who were concerned yet realistic.

\subsubsection{Electricity use}

In comparison to the theme of Electricity Supply as a Political Issue which reflected the politics of the issue, the second theme Electricity Use is about the consumption of (demand for) electricity rather than its supply or distribution. There are two sub-themes: Powersavers campaign, and Concern with demand. The Powersavers campaign sub-theme is concerned specifically with the conservation campaign which was instigated during the shortage and deals with the design, timing and response to the campaign as well as debate around its appropriateness and acceptability. Concern with demand focuses on electricity use but is concerned less with the 'Powersavers' campaign per se and more with a wider debate around winter electricity supplies and overall security of supply in New Zealand from a demand-side perspective.

\subsubsection{Powersavers campaign}

The Powersavers campaign sub-theme (131 references) encompasses the necessity of and encouragement for conservation in the context of a dry winter. Media extracts show the promotion of and support for conservation even by parties who do not generally promote energy conservation as a solution to supply constraints; it was seen as necessary and comment includes conservation tips and praise for savings that had been made:

\footnotetext{
${ }^{4}$ Contact Energy Ltd and Trustpower Ltd.
} 
Mr Jackson said users needed to conserve energy wherever possible to prolong what little reserves were left in the South Island's lakes.

Limiting use of clothes driers, dishwashers and washing machines would be a good step, he said. People should also look to reduce their lighting usage by half. [Bay of Plenty Times, $7^{\text {th }}$ June, 2008]

The National Party is calling on consumers to ignore the Government and save as much power as they can as the row continues over whether the country faces electricity shortages this winter. [The Press, $11^{\text {th }}$ June, 2008$]$

At the same time, there was admonishment for public or private organisations that were seen not to be making a suitable level of effort:

Some Auckland businesses seem to be ignoring the electricity industry's request for people to save power, contributing to a potential blackout...The Herald took a night-time drive through Auckland City to see what major companies were responding to the call. [New Zealand Herald, $23^{\text {rd }}$ June, 2008]

The other aspect present in this sub-theme was criticism of the government and industry for the design and timing of the campaign. Specifically that no saving target was set and that in comparison to other shortage years the campaign was late in starting:

But it [the government] stopped short of introducing a campaign of its own and refused to set a savings target. People should just be 'more prudent', it said. The response contrasts with 2001, when the Government led a \$2.25 million campaign for savings of 10 per cent over 10 weeks. The country achieved 8 per cent. [Dominion Post, $10^{\text {th }}$ June, 2008]

According to critics of the government this was due to political sensitivity around the issue in an election year. It is in this second element that one can see the sharpest political debate occurring between the government and industry on the one hand and the opposition and government critics on the other: 
It [the government] also does not want to be responsible for telling voters in an election year that they must cut their consumption. Parker yesterday denied downplaying the situation, saying the Government had been 'absolutely transparent' about the hydro-lake levels. He admitted politics did play a part. 'I suppose politics is involved in everything in an election year.' He again refused to state any target, although it is understood the Government has been told about 5 per cent savings are likely. [The Press, $11^{\text {th }}$ June, 2008]

\subsubsection{Concern with demand}

The second sub-theme, Concern with demand, consists of extracts that focused on electricity use rather than supply, but they were less concerned with the 'Powersavers' campaign per se and more with a wider debate around security of winter electricity supplies and overall demand in relation to supply in New Zealand. Extracts acknowledged the role of demand in relation to system capacity:

As people stay at home to look after their children, demand for power can spike up more than 100 megawatts, power industry sources say. [Dominion Post, 13 ${ }^{\text {th }}$ June, 2008].

They also mentioned the roles various demand-side measures could take in controlling demand:

Initiatives, such as reducing power to hot water cylinders, would be the first step towards reducing demand on the national grid. 'It's one of the measures we're investigating because obviously we want to avoid blackouts'. [The Daily Post, $30^{\text {th }}$ May, 2008];

and the benefits of maintaining efficient electricity use patterns beyond the timeframe of the shortage:

On another front, the Government must review how New Zealand uses its energy, and devise more effective approaches to encourage energy conservation, not just piecemeal campaigns when a power crisis is looming. [The Press, $3^{\text {rd }}$ May, 2008]

Two characteristics are notable about the extracts in this sub-theme. Firstly, the entire sub-theme is limited to 46 references making it the smallest sub-theme in 
the data set. By comparison, 233 references are coded to Crisis and 219 to Energy policy which is suggestive of the perceived relative importance of these issues to the media. Secondly, there was no discussion of how reducing or constraining demand in the long term could bring system-wide benefits to the country. Despite some reference to longer term measures being desirable there was no explicit link made to a systematic alternative approach.

Therefore, two key messages are identified in the extracts coded to the Concern with demand sub-theme. Firstly, electricity conservation is acceptable in certain contexts only (i.e. when it is the lesser of two evils and the country will be better of by reducing demand than facing the risk of total loss of supply), although it is politically detrimental to the government of the day that this situation should arise at all, and more so in an election year. Secondly, while a limited number of voices recognised that controlling demand is a part of the solution to managing the energy system, there was no explicit recognition that reducing demand longterm through more careful and efficient use, as well as technology and management could have economy-wide benefits in the form of reduced infrastructure expenditure or the avoidance of costs associated with new generation. This omission is surprising and is discussed further below.

\subsection{Discussion}

The analysis of media extracts identified two clear compound themes. The first, Electricity as a Political Issue, captures the political contentiousness of the shortage (although politics are not entirely absent from the second theme). Both political perspectives on the issue are seen in this theme. On the one hand, in the Crisis and Energy policy sub-themes, the shortage was portrayed as a 'crisis' with serious negative effects on the economy and households (with a minimal focus on negative environmental effects).

The government of the day was portrayed as responsible for the situation which had arisen out of poor decision making and policy, resulting in suffering for businesses and households. On the other hand, in the Well-managed event subtheme, extracts demonstrate a different perspective. Industry and government 
spokespeople portrayed the situation as a carefully managed outcome of drought in a hydro-dominated electricity system. Extracts emphasise that the situation was under control, that only 'prudence' in consumption was required, and that no one, especially 'at risk' consumers, should suffer or make sacrifices as a result.

In contrast, the second theme, Electricity Use deals with comment on the demand for electricity. This theme predominantly captured reference to the industry-led 'Powersavers' conservation campaign although some reference to demand per se were also included. The minimal focus on the latter is notable. Media extracts under the Powersavers campaign sub-theme encompass the politics around the conservation campaign. The second sub-theme Concern with demand was interesting because it went beyond a supply-side focus and referred to the role demand plays in system management. Extracts acknowledged the role of demand in adjusting to limited system capacity (i.e., there are means to control the demand) but there was no discussion of how demand could play a longer term strategically implemented role in the management of the electricity market in New Zealand.

These themes suggest a number of things. Firstly, that electricity supply was a deeply political issue in the context of the supply shortage in winter 2008. It seems reasonable to assume that it was more political than it may otherwise have been because it was an election year. Minister Parker's comments cited above support this (cross ref. 3.3.2.1). Secondly, the dominant message in the media about ways to solve supply concerns was that it was necessary to increase supply rather than reduce demand. Thirdly, electricity conservation was actively encouraged by parties on both sides of the debate for a time, and by implication it was more 'acceptable' in the context of the supply shortage. It is argued that this promotion of conservation behaviour at a time of shortage supported and promoted social norms around electricity conservation thereby encouraging conservation behaviour.

The political nature of the shortage provided opportunities and challenges for all interested parties, although they can be broadly separated down political lines as National and Labour, and respective supporters. The National Party, in 
opposition, and business interests with aligned views, were presented with an opportunity to criticise the government for its management of the electricity market and policies which focused on investment in renewable energy and a moratorium on the construction of new thermal generation, thereby in their view threatening security of supply and production. They focused on security of supply as a key issue and promised alternative policies to protect New Zealand's economy, international business reputation and the interests of householders. Demand-side solutions were ignored except for a brief period in the context of encouraging conservation through the 'Powersavers' campaign to avoid a 'crisis'.

In response, Labour and the electricity industry made a concerted effort to emphasise that the situation was under control and being well managed, and that the lights would not go out. They focused in a non-alarmist way on the need to conserve electricity by calling for 'prudence', highlighting that the market was operating as intended and emphasising that no one would need to suffer as a result of a conservation campaign. Their approach was one of calm pragmatism, which acknowledged that there was a shortage of supply because of unusual circumstances but not a 'crisis'.

It appears that in the context of the supply shortage in the winter of 2008 , electricity conservation became, for a time, an acceptable notion. Although there was an ongoing debate being undertaken in the media about the acceptability of the situation and who was to blame, conservation was encouraged by all industry and political participants because of the net benefits (i.e., reduce demand and avoid blackouts which may have more significant impacts). There was the industry-led conservation campaign, and tips and encouragement for making savings from across the political spectrum.

There was also admonishment in the media for companies who did not appear to be pulling their weight in the conservation effort and criticism of the government for not encouraging more conservation, specifically, by delaying the start of the campaign (according to some) and by excluding a savings target from the campaign design. 
In short, demand reduction was seen generally as a reasonable short-term option. However, this demand-side focus was very superficial. There was a limited discussion in the media at the same time about the role of demand, demand-side measures and ongoing conservation efforts. For example, the Minister of Energy did not venture past the notion of being 'careful' with electricity in the longer term.

And, in the context of a speech in which the leader of the Opposition stated that National would revise upwards forecasts for future demand growth, he did briefly refer to improving energy efficiency:

Furthermore, National will support energy efficiency by making sure the Energy Efficiency and Conservation Authority and its programmes are well funded. Increased energy efficiency saves households and the country money in the long run. [Scoop, $14^{\text {th }}$ August, 2008]

However, there was no discussion of the potential benefits of giving demand-side management (either through conservation or improved energy efficiency) a key role in energy policy. It appears that in the context of the shortage and the sociopolitical environment of the time there was no space for this debate. Overwhelmingly, increased supply was seen as the primary means to achieve economic and social development. 


\section{Study 2: Household surveys of conservation behaviour}

The second objective of this study, set out in Chapter 1, was to understand whether and how householders changed their electricity attitudes and behaviour in the context of a supply shortage in New Zealand. This chapter accordingly discusses the method, procedure and results of a longitudinal study into householder attitudes and behaviour in relation to the supply shortage. The aim of Study 2 was to measure the electricity conservation attitudes and behaviour of residential consumers under everyday circumstances, and measure them again in the context of the supply shortage and conservation campaign, to allow a comparison to be made.

\subsection{Method}

Study 2 was undertaken using two self-completed surveys conducted in June and November 2008 (Time 1 and Time 2), which formed part of the 2008 Social Attitudes Survey (SAS). The SAS is a longitudinal research project investigating environmental and social issues in New Zealand conducted by Dr Taciano L. Milfont of Victoria University of Wellington. Human ethics approval was granted for this project on $22^{\text {nd }}$ May 2008 (SOPHEC \# 0835 May). A number of questions relating specifically to electricity conservation and the electricity shortage were included in the SAS questionnaires for the purpose of this study. The questions were designed so that everyday electricity conservation behaviour could be examined across time and compared with conservation behaviour during a shortage. Therefore a number of questions were repeated under different conditions in Time 1 and Time 2. The design of each survey is detailed below and copies of the surveys have been included in Appendix 2 for reference.

\subsection{Time 1}

\subsubsection{Procedure}

A nationwide sample was sought for the SAS, therefore 3,000 names were collected at random from the 2007 New Zealand Electoral Roll held in hard copy at the Wellington Public Library. The sample was split across 69 electorates and 
each sub-sample was proportional to the size of the electorate. A Microsoft Excel random number generator was used to select page numbers in each electoral roll. ${ }^{5}$ The list of numbers was sorted in ascending order and the second name on the page matched by each number was recorded. Three-thousand names were selected but five addresses were invalid resulting in an initial sample of 2,995 households.

The survey was posted with a consent form and covering letter which described the SAS and invited the named person or another member of the household to participate. A freepost return envelope and an entry form for a draw to win $\$ 500$ worth of grocery vouchers were included to encourage participation. The survey was posted on $9^{\text {th }}$ June and the sample period ran until $15^{\text {th }}$ July 2008 . On the $10^{\text {th }}$ June 2008 Transpower announced an industry-led media campaign would be launched (i.e. $15^{\text {th }}$ June, 2008) to encourage households to save electricity (Transpower New Zealand, 2008, June 10). Table 5 shows a timeline of the two surveys in relation to the 'Powersavers' campaign and the New Zealand general election.

Table 5: Timeline of SAS Time 1 and Time 2 in relation to significant events

\begin{tabular}{|c|c|c|c|c|c|c|c|}
\hline \multicolumn{4}{|c|}{$\begin{array}{l}\text { 'Powersavers' } \\
\left(15^{\text {th }} \text { June }-27^{\text {th }} \text { Jul }\right)\end{array}$} & & \multicolumn{3}{|c|}{$\begin{array}{l}\text { NZ general election } \\
\left(8^{\text {th }} \text { Nov }\right)\end{array}$} \\
\hline \multicolumn{5}{|c|}{ 'SAS (Time 1)' $\left(9^{\text {th }} \mathrm{Jun}-15^{\text {th }} \mathrm{Jul}\right)$} & \multicolumn{3}{|c|}{ 'SAS (Time 2)' $\left(10^{\text {th }}\right.$ Nov $-10^{\text {th }}$ Jan $)$} \\
\hline Jun '08 & Jul ‘08 & Aug'08 & Sep '08 & Oct '08 & Nov '08 & Dec '08 & Jan '09 \\
\hline
\end{tabular}

\subsubsection{Survey design and instruments}

The relevant sections of the 'SAS (Time 1)' focused on three aspects of energy behaviour. Firstly, questions were asked about householders' electricity conservation behaviour, their willingness to conserve and their motivations for conservation under everyday conditions. Secondly, a scenario question was used to test participants' willingness to conserve and attitudes toward and perceptions of conservation during an electricity shortage. Finally, environmental attitudes were tested and socio-demographic data were collected.

\footnotetext{
${ }^{5}$ Each electorate has its own roll printed and each roll book has a different number of pages.
} 


\subsubsection{Conservation actions}

Participants were asked to indicate how often they performed 13 actions "regularly, out of habit, to save electricity" using a 5-point Likert scale anchored by never (1) and very often (5) (see Table 6 below). The list was developed from conservation actions used, or brought to light, in other questionnaires (e.g., Lutzenhiser, 2002b; Ministry for the Environment/Research New Zealand, 2008) and the author's professional experience in the field of residential energy efficiency and conservation. Participants were given the option of providing alternative actions. The list of actions and abbreviations used throughout the discussion are also included in the table below.

Table 6: List of conservation actions

\begin{tabular}{cll}
\hline$\#$ & Action as listed in survey & Abbreviation \\
\hline 1 & Turned the lights off in rooms that were not being used & Lights off \\
2 & $\begin{array}{l}\text { Unplugged appliances or switched them off at the wall when they } \\
\text { were not in use (i.e., avoided leaving appliances on stand-by) }\end{array}$ & Unplug appliances \\
3 & Used energy-efficient appliances or electrical equipment & EE appliances \\
4 & Pulled the curtains before dark to keep the heat in & Curtains \\
5 & Only heated rooms which were in use & Heat rooms in use \\
6 & Air-dried clothes instead of putting them in a clothes drier & Air-dry clothes \\
7 & Pro-actively chose 'green' electricity products and services & Green supply \\
8 & Restricted the length of showers to save electricity & Shorter showers \\
9 & Turned off equipment (television, computers, etc) when not in use & Appliances off \\
10 & Air-dried towels instead of putting them on heated towel rails & Towel rail off \\
11 & Used cold water instead of hot or warm water when washing clothes & Cold water wash \\
12 & Used electrical devices less often & Use appliances less \\
13 & Used blankets or warm clothes instead of turning the heating on & Less heating \\
\hline
\end{tabular}

Source: Author, drawing on Lutzenhiser (2002b) and MfE Research NZ (2008).

\subsubsection{Willingness to conserve}

The willingness of participants to conserve electricity in general was measured under everyday circumstances and then using a shortage scenario (cross ref. 4.2.2.5) bearing in mind that when the 'SAS (Time 1)' was posted, the shortage campaign had not begun and its exact timing was uncertain. Participants were asked to indicate on a 7-point scale how willing they were to conserve electricity at home. The scale was anchored by not at all willing (0) and very willing (6) as shown in Table 7. 
Table 7: Willingness to conserve scale

In general, how willing are you to conserve electricity at home?

\begin{tabular}{ccccccc}
$\begin{array}{c}\text { Not at all } \\
\text { willing }\end{array}$ & \multicolumn{1}{c}{$\begin{array}{c}\text { Somewhat } \\
\text { willing }\end{array}$} & & $\begin{array}{c}\text { Very } \\
\text { willing }\end{array}$ \\
0 & 1 & 2 & 3 & 4 & 5 & 6
\end{tabular}

\subsubsection{Motivations for conservation}

Participants were asked about their motivations for saving electricity in everyday circumstances. They were given a list of five reasons and asked to indicate which were applicable to them or to provide their own reasons. The list (shown in Table 8) is derived from a similar question in the Ministry for the Environment's Household Sustainability Benchmark Survey undertaken by Research New Zealand (2008).

Table 8: List of motivations for conserving electricity

1. To save money

2. Because its good for you and your family's health

3. It's what your friends are doing

4. It's good for the environment

5. Don't know/no particular reason

6. Another reason (please specify)

Source: adapted from MfE/Research New Zealand (2008).

\subsubsection{General environmental attitudes}

General environmental attitudes were measured using the revised New Ecological Paradigm (NEP) Scale (Dunlap et al, 2000). The NEP was designed to measure adherence to an ecological worldview and is a widely accepted measure of pro-environmental attitudes and beliefs (Lundmark, 2007). The complete NEP scale is included in Appendix 3 for reference.

\subsubsection{Electricity shortage scenario}

Participants were then presented with an electricity shortage scenario (i.e., "Suppose New Zealand faces an electricity shortage this winter") and asked to answer a number of questions on that basis. The scenario was used to test 
willingness to conserve during a shortage, perceptions of the shortage and perceptions of responsibility. This model was chosen because it was uncertain at the time the questionnaire was designed and delivered to participants whether there would be a shortage and public conservation campaign, and exactly when this might eventuate if it did.

The same one-item willingness to conserve measure (Table 7 above) was used to assess participants' willingness to conserve electricity at home in the shortage scenario.

Specific attitudes about saving electricity in a shortage were examined under the scenario condition using questions drawn from van Vugt and Samuelson's (1999) questionnaire, which examined perceptions and decision making related to a water shortage in England. Participants in the present study were asked to answer the questions in Table 9 using a 5-point Likert scale anchored by strongly disagree (1) and strongly agree (5). These questions make up two 'scales' - the severity of the shortage and collective costs scales - which are based on similar constructs used by van Vugt and Samuelson (1999).

Table 9: 'Severity of the shortage' and 'collective costs' scales

\begin{tabular}{|c|c|}
\hline Severity of the shortage & Collective costs \\
\hline $\begin{array}{l}\text { 1. The electricity shortage would have an } \\
\text { important impact on me and other } \\
\text { members of my household }\end{array}$ & $\begin{array}{l}\text { 1. I would be willing to exercise restraint } \\
\text { because I would feel personally } \\
\text { concerned about the electricity shortage }\end{array}$ \\
\hline $\begin{array}{l}\text { 2. The electricity shortage would have an } \\
\text { important impact on the people living in } \\
\text { my community }\end{array}$ & $\begin{array}{l}\text { 2. I would be willing to exercise restraint } \\
\text { because there might be consequences } \\
\text { for others }\end{array}$ \\
\hline $\begin{array}{l}\text { 3. The electricity shortage would have an } \\
\text { important impact on people all over } \\
\text { New Zealand }\end{array}$ & $\begin{array}{l}\text { 3. I would not need to be asked by the } \\
\text { government to save electricity because } \\
\text { of the shortage, I would have done so } \\
\text { anyway }\end{array}$ \\
\hline \multirow[t]{2}{*}{$\begin{array}{l}\text { 4. The electricity shortage would have an } \\
\text { important impact on our economy }\end{array}$} & $\begin{array}{l}\text { 4. I would not need to be asked by the } \\
\text { electricity company to save electricity } \\
\text { because of the shortage, I would have } \\
\text { done so anyway }\end{array}$ \\
\hline & $\begin{array}{l}\text { 5. During the shortage, I would seek } \\
\text { information on how to use electricity } \\
\text { wisely and how to conserve }\end{array}$ \\
\hline
\end{tabular}

Source: Based on van Vugt and Samuelson (1999).

Finally, perceptions about responsibility for acting under the scenario were tested. Participants were asked: "Given this electricity shortage scenario, who 
do you believe would be responsible for doing something about it?" [Bold in original]. Then using a 7-point Likert scale anchored by not at all responsible (0) and very responsible (6) they were asked to indicate how responsible they felt each of eight parties were. There was also room to indicate other parties people felt were responsible for taking action.

Table 10: Options provided for indicating perceptions of responsibility to act
1. The Government
2. Regional/local councils
3. Farmers
4. All industry and business in general
5. All New Zealanders/Everyone
6. Myself
7. Small to medium enterprises
8. Large scale industrial and commercial users
9. Other (specify)

Source: Adapted from MfE/Research New Zealand (2008).

\subsubsection{Socio-demographic measures}

Socio-demographic data for age, gender, and income and education level were collected.

\subsection{Time 2}

\subsubsection{Procedure}

The second survey ('SAS Time 2') was posted to participants in November 2008 immediately after the New Zealand General Election, which was a factor of interest to the SAS. Another six-page questionnaire was used and this time mailed to 570 respondents from the first sample who had agreed to participate again. The questionnaire was posted with a freepost return envelope, a covering letter and an entry form for a draw to win $\$ 50$ worth of grocery vouchers. It was posted on the first business day following the General Election $\left(10^{\text {th }}\right.$ November 2008) and the sample period ran until $10^{\text {th }}$ January 2009. Refer to Table 5 above (cross ref. 4.2.1) for a timeline of events. 


\subsubsection{Survey design and instruments}

In Time 2 the relevant sections of the SAS focused on three aspects of energy behaviour. Firstly, participants were again asked about their electricity conservation behaviour and motivations for conserving under everyday conditions to test for consistency of behaviour with Time 1. Secondly, they were asked to recall their conservation actions during the recent shortage and finally, environmental attitudes were tested again.

\subsubsection{Conservation actions and motivations for conservation}

The same list of actions and motivations (Table 6 and Table 8 respectively) were used to assess participants' everyday electricity conservation actions and their motivations for carrying them out.

\subsubsection{Shortage recall}

Participants were asked to recall the recent electricity shortage and indicate their conservation actions at that time. The same scale which was used to measure everyday conservation behaviour across time was used again (see Table 6 above).

\subsubsection{Specific attitudes}

Specific attitudes related to electricity use in light of the recent shortage were then tested. Questions were asked on a 5-point Likert scale anchored by strongly disagree (1) and strongly agree (5). The shortage impact scale was drawn from van Vugt and Samuelson's (1999) questionnaire and examines impacts of the shortage on the household and the economy. The other scale (attitude change) was devised for this study and examines whether the shortage had influenced electricity behaviour. Both scales are shown in Table 11. 
Table 11: Shortage impact and attitude change scales
Shortage impact scale
Attitude change scale
1. The electricity shortage had an important impact on me and other members of my household
1. I now use less electricity than before the shortage
2. The electricity shortage had an important impact on our economy
2. I was willing to conserve electricity at home during the electricity shortage
3. The shortage did not change my use of electricity
4. My attitude to using electricity at home changed since the electricity shortage

Source: Milfont (2008) and drawn from van Vugt and Samuelson (1999).

\subsubsection{General environmental attitudes}

Finally, general environmental attitudes were measured again, this time using the Preservation and Utilization scales. Preservation and Utilization are high order dimensions of Milfont and Duckitt's (2008) Environmental Attitudes Inventory (EAI). The Preservation and Utilization scales measure general beliefs about whether the environment should be preserved from the effects of human use or whether it should be used and altered to meet human needs (Milfont \& Duckitt, 2008). The EAI has been included in Appendix 4 for reference.

\subsection{Results}

\subsubsection{Data analysis and reliability}

Responses to the completed questionnaires were coded and entered into SPSS 16.0 for analysis. Descriptive statistics were used to assess the distribution and representativeness of the sample, and check for normality. No data transformations were required.

All scores from all multiple item measures were averaged to get a mean score allowing for comparison between scales. A number of items in the NEP and Preservation and Utilization scales are negatively worded to prevent response bias (Pallant, 2007), therefore these items were reversed before creating the scores so that analyses could be undertaken. All but two of the scales had high internal consistency with Cronbach's alpha $>.70$ (see Table 12) indicating their 
reliability (Nunally, 1978). The attitude change and shortage impact scales have slightly lower alpha scores ( 0.69 and 0.50 respectively) although they are acceptable for the research purpose.

Table 12: Descriptive statistics for scales used in SAS Time 1 and Time 2

\begin{tabular}{lrrrr}
\hline Scale & $\begin{array}{r}\text { No. of } \\
\text { items }\end{array}$ & $\boldsymbol{\alpha}$ & $\mathbf{M}$ & SD \\
Electricity Conservation Actions - Survey one & 13 & 0.80 & 3.94 & 0.58 \\
Electricity Conservation Actions - Survey two & 13 & 0.80 & 3.95 & 0.56 \\
Electricity Conservation Actions - Shortage Recall & 13 & 0.84 & 4.01 & 0.61 \\
New Ecological Paradigm & 15 & 0.82 & 3.55 & 0.56 \\
Preservation & 14 & 0.72 & 5.09 & 0.69 \\
Utilization & 10 & 0.76 & 3.52 & 0.89 \\
Severity of the Shortage & 4 & 0.81 & 4.13 & 0.63 \\
Collective Costs & 5 & 0.79 & 3.94 & 0.69 \\
Attitude Change & 4 & 0.69 & 3.35 & 0.77 \\
Shortage Impact & 2 & 0.50 & 3.19 & 0.82 \\
\hline
\end{tabular}

Differences in behaviour across time were compared using one-way analysis of variance (ANOVA) in SPSS. Homogeneity of variance was tested using Levene's test, and an alpha of 0.05 was used in all cases. Bivariate correlations were also undertaken to examine the relationship between conservation actions (Time 1, Time 2 and the shortage) ${ }^{6}$ and attitudes and socio-demographic data. The results of all these tests are presented and discussed below.

\subsubsection{Sample analysis}

For Time 1, 551 valid responses were returned (an 18\% response rate) compared to 358 in Time 2 . The response rate in Time 2 was $65 \%$, although it was expected to be higher as participants had agreed to take part when they responded in Time 1. The distribution of females to males was comparable in both samples although there were was a slightly larger proportion of females to males in Time 2: 61.6\% female to $38.4 \%$ male in Time 1 compared to $65.2 \%$ female to $34.8 \%$ male in Time 2. Respondents ranged in age from 18 to 91 in both samples, although the median age was higher in Time 2: median age of $49(\mathrm{SD}=16.65)$ in Time 1 and $52(\mathrm{SD}=16.51)$ in Time 2 .

\footnotetext{
${ }^{6}$ To remind the reader, results for behaviour during the shortage are taken from Time 2 where respondents were asked to recall actions they undertook during the shortage.
} 
In Time 1 ethnicity data were also collected. There are difficulties in comparing ethnicity in the sample population with the general New Zealand population due to different classifications used in the 2006 Census. ${ }^{7}$ However, it can be said that generally the current sample is more heavily weighted towards New Zealand European/Pakeha than the general population (82.2\% compared with $67.6 \%)$. It also has a lower proportion of Maori (7.4\% including Maori and New Zealand European/Maori compared to 14.6\%), Asian (2.4\% compared to 9.2\%) and Pacific Nations people (1.1\% compared to 6.9\%) than the general population (Statistics New Zealand, 2009a). The ethnic profile of the sample is summarised in Table 13.

Table 13: Ethnicity of sample

\begin{tabular}{lrr}
\hline Ethnicity & $\mathbf{N}$ & \% of total \\
New Zealand European/Pakeha & 452 & 82.2 \\
Maori & 21 & 3.8 \\
NZ European/Maori & 20 & 3.6 \\
Asian & 13 & 2.4 \\
British & 10 & 1.8 \\
Pacific Nations & 6 & 1.1 \\
Indian & 4 & 0.7 \\
Other & 24 & 4.6 \\
\hline
\end{tabular}

Data were also collected about the geographic spread of the sample. Generally the geographic distribution of the sample was similar to the general population, although it was under-representative of the general population in the Auckland region (22.7\% of respondents compared to $32.4 \%$ in the general population) and over-representative in the Wellington region (13.8\% compared to $11.1 \%$ ) (Statistics New Zealand, 2006). A comparison between the geographic distribution of the Time 1 sample and the general population is shown in Table 14 below.

\footnotetext{
${ }^{7}$ The New Zealand 2006 Census allowed respondents to identify with more than one ethnicity which results in double counting. The differences between definitions in the two data sets also make some comparisons ambiguous.
} 
Table 14: Geographic distribution of sample by region

\begin{tabular}{lrrr}
\hline Region & N & percentage of sample total & $\begin{array}{r}\text { percentage of general } \\
\text { population }\end{array}$ \\
Northland & 23 & 4.2 & 3.7 \\
Auckland & 125 & 22.7 & 32.4 \\
Waikato & 44 & 8.0 & 9.5 \\
Bay of Plenty & 40 & 7.3 & 6.4 \\
Gisborne & 4 & 0.7 & 1.1 \\
Hawke's Bay & 24 & 4.4 & 3.7 \\
Taranaki & 21 & 3.8 & 2.6 \\
Manawatu-Wanganui & 34 & 6.2 & 5.5 \\
Wellington-Wairarapa & 76 & 13.8 & 11.1 \\
Tasman & 4 & 0.7 & 1.1 \\
Nelson & 12 & 2.2 & 1.1 \\
Marlborough & 8 & 1.5 & 1.1 \\
West Coast & 11 & 2.0 & 0.8 \\
Canterbury & 76 & 13.8 & 13 \\
Otago & 33 & 6.0 & 4.8 \\
Southland & 15 & 2.7 & 2.3 \\
\hline
\end{tabular}

Overall the samples from both Time 1 and 2 are representative of the New Zealand population. However, there are few a points that deserve consideration. Female participants were over-represented in both samples, as the gender split for the general population of New Zealand is $51.2 \%$ female and $48.79 \%$ male (Statistics New Zealand, 2009b). Moreover, although the age of respondents had a wide range (from 18 to 91 across both samples), respondents were notably older than the national median age of 35.9 (Statistics New Zealand, 2009b).

\subsubsection{Conservation actions}

The mean scores for everyday conservation actions in Time 1 and Time 2 were above the midpoint of 3 ("unsure") and almost identical ( $\mathrm{M}=3.94$ and 3.95 respectively: $\mathrm{F}_{1,865}=0.133, p=0.72$ ), indicating consistency across time of a relatively high degree of habitual conservation behaviour. Therefore, data from Time 1 and 2 were combined and compared to behaviour during the shortage. The results show an increase in reported conservation actions during the shortage period $\left(\mathrm{M}=4.01: \mathrm{F}_{1,1202}=2.985, p=0.08\right)$, which approached the 0.05 level of statistical significance and indicates a high probability that householders increased their conservation behaviour during the shortage. These results are shown in Figure 5. 
Figure 5: Mean scores of conservation actions across time and during the shortage

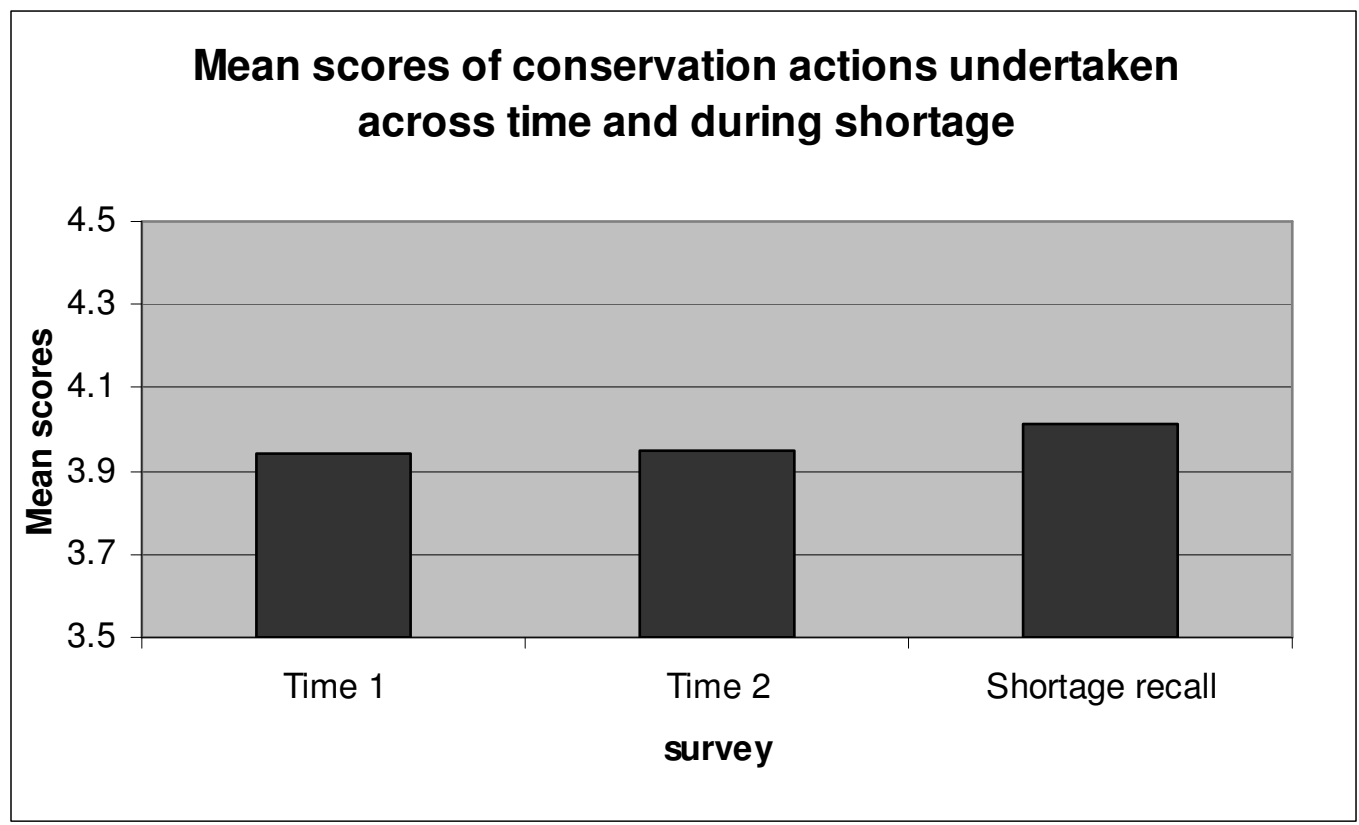

A reported change in behaviour during the shortage is to be expected in light of the conservation campaign and the extent of media interest in the issue.

However, the amount of change is relatively small.

The results also show consistency across time for the most and least popular conservation actions. In all cases the five most popular behaviours were a combination of the same actions although they were ordered slightly differently (see Table 15 below). The same can be said for the three least popular actions. 
Table 15: Most and least popular conservation actions

\begin{tabular}{lll}
\hline Time 1 & Time 2 & Shortage recall \\
Most popular actions & & \\
Lights off & Lights off & Lights off \\
Heat rooms in use & Heat rooms in use & Heat rooms in use \\
Curtains & Air-dry clothes & Air-dry clothes \\
Air-dry clothes & Cold water wash & Curtains \\
Cold water wash & Curtains & Cold water wash \\
& & \\
Least popular actions & & Shorter showers \\
Shorter showers & Shorter showers & Use appliances less \\
Use appliances less & Green supply & Green supply \\
Green supply & Use appliances less &
\end{tabular}

In Time 1 respondents were also given the opportunity to include other actions they took to conserve electricity. Some 48 actions were submitted which can be divided into three categories: behavioural change (i.e. using existing technology differently), the use of alternative fuels (a marked form of behavioural change), and investment decisions. The results are summarised in Table $16 .^{8}$

Table 16: 'Other' conservation actions listed by respondents in Time 1

\begin{tabular}{lrl}
\hline $\begin{array}{l}\text { Type of conservation } \\
\text { action }\end{array}$ & $\%$ & Examples of actions \\
Behavioural & 54.2 & $\begin{array}{l}\text { Turn hot water cylinder off between } 0600 \text { and } 1200 \\
\text { Cook using few appliances and have less washing up }\end{array}$ \\
Use alternative fuels & 25.0 & $\begin{array}{l}\text { Use wood stove for cooking and heating } \\
\text { Use wetback for heating/hot water }\end{array}$ \\
Investment & 18.8 & $\begin{array}{l}\text { Install solar panels } \\
\text { Buy energy efficient light bulbs } \\
\text { Other }\end{array}$ \\
\hline
\end{tabular}

\subsubsection{Willingness to conserve}

The mean score for willingness to conserve under normal circumstances ( $\mathrm{M}=$ 4.86) was compared with willingness to conserve under the shortage scenario ( $\mathrm{M}$ $=4.87)$. These scores indicated no significant difference between respondents'

\footnotetext{
${ }^{8}$ The full list of other actions is included in Appendix 5.
} 
willingness to conserve electricity in everyday circumstances and during an electricity shortage $(p>0.05)$. Given that these questions were presented very close to each other in the questionnaire and at the same point in time, the participants may have been tempted to provide similar responses for both; this may have contributed to the lack of significant difference.

\subsubsection{Motivations for conservation}

Respondents were asked about their motivations for everyday conservation in Time 1 and Time 2. The majority of respondents provided more than one reason (see Table 17 below) although some clear trends emerged. Some $94.2 \%$ and 93.6\% of respondents (Time 1 and Time 2 respectively) said that to save money was one of their motivating factors, although this was most often in combination with other reasons. A higher percentage of respondents (16.5\%) said to save money was their only motivation in Time 1 compared to $11.7 \%$ in Time 2 . Two combinations of responses stood out as the most significant across time.

Table 17: Most popular reasons given for conserving electricity in Time 1 and Time 2

\begin{tabular}{lll}
\hline & Time 1 & Time 2 \\
To save money as ONE OF the motivations & 94.2 & 93.6 \\
To save money as the ONLY motivation & 16.5 & 11.7 \\
To save money AND It's good for the environment & 33.4 & 32.4 \\
To save money AND It's good for the environment AND because & 25.8 & 30.4 \\
its good for you and your family's health and well-being & \\
\hline
\end{tabular}

Respondents also gave their own 'other' reasons for conserving electricity: 71 in Time 1 and 27 in Time 2. A number of themes were identified in both samples. The general themes have been ranked in descending order with the frequency of occurrences beside them (see Table 18). Although there are similarities there are also some notable differences across time such as the absence of Because of supply shortages and the inclusion of To make appliances last longer in Time 2. For a complete list of 'other' reasons see Appendix 5. Social or family norms appear to be present in other responses: habit, up-bringing, commonsense, the right thing to do, demonstrate to children - all have an element of the way things 'are' done or 'ought' to be done. 
Table 18: Themes identified amongst other reasons given for conserving electricity

\begin{tabular}{ll}
\hline Time 1 $(\mathbf{N}=\mathbf{7 1})$ & Time $\mathbf{1}(\mathbf{N}=\mathbf{2 7})$ \\
Because of supply shortages (17) & Habit/I was brought up that way (4) \\
Habit/I was brought up that way (10) & It's the right thing to do (4) \\
To avoid waste (9) & To make appliances last longer (4) \\
Commonsense (6) & Commonsense (4) \\
Demonstrate to children/lead by example (3) & To avoid waste (3) \\
\end{tabular}

\subsubsection{Perceptions of responsibility}

The questions about responsibility for taking action under the shortage scenario yielded a range of responses (see Table 19). The government and big business were seen as most responsible although not by a large margin and there was a strong sense that everyone had a part to play. For example, All NewZealanders/Everyone, and Myself, fall only some distance behind Government and Large scale industrial and commercial users. Participants were given the option of including other parties they deemed had a responsibility to act. The one other party deemed responsible by a significant proportion of the sample was Power Companies $(\mathrm{N}=37)$.

Table 19: Responsibility to take action under the shortage scenario

\begin{tabular}{lcc}
\hline & N & M \\
The Government & 540 & 4.47 \\
Large scale industrial and commercial users & 534 & 4.22 \\
All New Zealanders/Everyone & 540 & 4.19 \\
Myself & 538 & 4.00 \\
Regional/local councils & 534 & 3.93 \\
All industry and business in general & 537 & 3.85 \\
Small to medium enterprises & 536 & 3.57 \\
Farmers & 530 & 2.81 \\
\hline
\end{tabular}

\subsubsection{Relationship between environmental attitudes and behaviour}

Scores for conservation actions were correlated with the scales used to measure general and specific environmental attitudes as described in the preceding sections. As can be seen in Table 20, all the correlations between attitudes and 
behaviour are statistically significant and moderate in terms of effect size (Hemphill, 2003). Some general trends can also be identified. Firstly, the relationships between the measures used in both Time 1 and 2 were consistent across time, indicating test-retest reliability. Secondly, environmental attitudes and conservation behaviours were positively related and this relationship was stable across time, which is in line with previous findings (e.g. Kaiser, Wölfing, \& Fuhrer, 1999; Milfont \& Duckitt, 2004).

Furthermore the relationship between pro-environmental attitudes (as measured by the NEP) and conservation behaviour was weaker during the shortage (0.187) than under everyday circumstances, i.e. Time 2 (0.221). This suggests that situational constraints (i.e., a change in context) during the shortage may have altered the strength of the relationship between attitude and behaviour: people appear to have increased their conservation behaviour regardless of their proenvironmental attitudes. This seems to suggest that psychological constructs (i.e., environmental attitudes) may have less influence on people's behaviours than situational variables.

\subsubsection{Correlations between socio-demographic variables and behaviour}

Bivariate correlations were undertaken to explore the relationships between socio-demographic variables and conservation behaviour. The results are shown in Table 21. Again the correlations are statistically significant and moderate in terms of the size of effect. In general, the relationships were stable across time and consistent with findings in the literature (e.g. Fransson \& Gärling, 1999): male participants and those on a higher income tend to perform less conservation behaviours than their counterparts. 
Table 20: Bivariate correlations between behaviour and attitude scores

\begin{tabular}{|c|c|c|c|c|c|c|c|c|c|c|}
\hline & 1. & 2. & 3. & 4. & 5. & 6. & 7. & 8. & 9. & 10. \\
\hline 1. Behaviour Time 1 & 1.000 & & & & & & & & & \\
\hline \multicolumn{11}{|l|}{ 2. Behaviour Time 2} \\
\hline & $.813^{* * *}$ & & & & & & & & & \\
\hline \multicolumn{11}{|l|}{ 3. Shortage } \\
\hline behaviour & $.719^{* * *}$ & $.865^{* *}$ & & & & & & & & \\
\hline \multicolumn{11}{|l|}{ 4. NEP scale } \\
\hline & $.219^{* * *}$ & $.221^{* * *}$ & $.187^{* * *}$ & & & & & & & \\
\hline \multicolumn{11}{|l|}{ 5. Preservation scale } \\
\hline & $.371^{* * *}$ & $.460^{* *}$ & $.426^{* *}$ & $.466^{* *}$ & & & & & & \\
\hline \multicolumn{11}{|l|}{ 6. Utilization scale } \\
\hline & $-.274^{* *}$ & $-.265^{* *}$ & $-.227^{* *}$ & $-.579^{* *}$ & $-.551^{* *}$ & & & & & \\
\hline 7. Severity of the & & & & & & & & & & \\
\hline shortage scale & $.187^{* * k}$ & $.197^{* * *}$ & $.216^{* *}$ & .078 & $.173^{* *}$ & .035 & & & & \\
\hline 8. Collective costs & & & & & & & & & & \\
\hline scale & $.535^{* *}$ & $.507^{* * *}$ & $.499^{* * *}$ & $.218^{* *}$ & $.387^{* *}$ & $-.252^{* *}$ & $.359^{* *}$ & & & \\
\hline 9. Impacts of the & & & & & & & & & & \\
\hline shortage scale & $.208^{* * *}$ & $.314^{* * *}$ & $.322^{* * *}$ & .004 & $.196^{* *}$ & .003 & $.246^{* *}$ & $.369^{* *}$ & & \\
\hline 10. Attitude change & & & & & & & & & & \\
\hline scale & $.182^{* * *}$ & $.312^{* *}$ & $.372^{* * *}$ & $.151^{* *}$ & $.205^{* *}$ & -.041 & $.218^{* *}$ & $.380^{* *}$ & $.592^{* * *}$ & 1.000 \\
\hline
\end{tabular}


1. Behaviour Time 1

1.000

2. Behaviour Time 2

$.813^{* *}$

3. Shortage behaviour

$.719^{* *}$

$.865^{* *}$

4. Age

.169

.003

.034

5. Gender

$-124^{* *}$

$-204^{* *}$

$-.179^{* *}$

$125^{* *}$

6. Education level

$-.040$

$-.024$

$-.252^{* *}$

.048

7. Income level

$-.189^{* *}$

$-.203^{* *}$

$-.184^{* *}$

$-.123^{* *}$

$.280^{* *}$

$.294^{* *}$

1.000 


\subsection{Discussion}

The results show consistency across time in everyday conservation actions, which suggests stability of behaviour but no indication of long term behaviour change following the shortage. However, there was a statistically significant (albeit small) increase in conservation actions during the shortage (as recalled by participants). This is to be expected in light of the conservation campaign and the extent of media interest in the issue.

The results also show consistency in the conservation actions people are most and least likely to take, regardless of the context. Highly visible or commonsense actions such as turning off lights and drying clothes on the line rather than in a clothes drier proved most popular, whilst actions that took more effort or resulted in less comfort, such as changing electricity suppliers or taking shorter showers were least popular. These findings are reflected in other studies. The most common conservation behaviours are usually simple, low-cost actions which are highly visible (e.g. lights off) (Gardner \& Stern, 2002; Kempton et al., 1985; Lutzenhiser et al., 2002; UMR Research, 2001) or behaviours that draw on commonsense or past experience (e.g. curtains or air dry clothes) (Lutzenhiser, 2002b). Also consistent with this trend are the 'other' conservation actions volunteered by respondents that favoured low-cost, practical behavioural changes over investment or more difficult decisions.

These findings seem to support the low-cost hypothesis (Diekmann \& Preisendörfer, 2003), which posits a distinction between conservation behaviours that are relatively easy to perform (low-cost behaviours) and those that are more demanding to perform (high-cost behaviours). One problem with this trend is that although these actions are easy to perform and most obvious to people they may have a limited impact on demand (Gardner \& Stern, 2002). This may be a reflection of limited knowledge about where most energy is used in the home (Kempton et al., 1985). It could also reflect norms around what actions people should take to save energy (e.g. following exposure to more than one conservation campaign), or it may simply reflect the actions promoted in the 'Powersavers' campaign (cross ref.1.4 ). 
Respondents indicated a high level of willingness to conserve electricity under everyday circumstances and in the shortage scenario. This finding was unexpected as it was anticipated that the context of a supply shortage would have positively affected people's willingness to take action and hence more of a difference would have been observed. As mentioned above, this finding might be a result of the order and time the questions were presented to participants. But it is important to highlight that the shortage did indeed have an impact on conservation behaviours.

Respondents' motivations for conserving electricity under everyday conditions were generally consistent, although there were some changes between Time 1 and 2; principally that a higher proportion of respondents were motivated solely by financial reasons in Time 1 than Time 2 . Financial benefit was an important motivator for the majority of the sample; however, it was most often in combination with other drivers. Financial motivations for conserving energy have been found throughout the literature but similar to the present study it is often in combination with other factors (Bender et al., 2004; Gmelch \& Dillman, 1988; Lutzenhiser, 2002b; Tashchian \& Slama, 1985). In the present study other factors were most commonly environmental and health benefits which may reflect an understanding among the sample group of the link between electricity consumption and environmental quality and health.

The supply shortage itself was the most common reason given among 'other' reasons for everyday conservation behaviour in Time 1 although it did not appear in Time 2 at all. Further, to avoid waste was ranked higher in Time 1 than in Time 2. These results suggest that the salience of the shortage at the time of the first survey was colouring people's perception of their everyday electricity use. This also indicates that the shortage was not in the participants' minds during Time 2, giving more credibility to the changes in the shortage recall behaviours discussed above. Other themes identified among motivating factors were habit and up-bringing, leading by example and commonsense, all of which suggest a pragmatic or normative approach to the problem and are consistent other findings (Lutzenhiser et al., 2004). 
There was a perception among respondents that the government and big business had the greatest responsibility for taking action during a shortage, although many people also saw responsibility falling on the general population and themselves. Power companies were identified as responsible parties by a significant number of respondents, even though they did not appear in the list of options included in the survey. These motivational factors have also been seen in other similar studies (Lutzenhiser et al., 2002; Lutzenhiser et al., 2004; Tashchian \& Slama, 1985).

There were statistically significant correlations between environmental attitudes and reported conservation behaviour. There was also some evidence that the shortage context increased conservation behaviour by all participants, irrespective of their usual pro-environmental attitudes. This was suggested by the lower correlation scores for the NEP and behaviour during the shortage than under everyday circumstances. The relationships seen between sociodemographic variables and conservation behaviour indicated that males and those on higher incomes were less likely to conserve electricity, a finding which is consistent with other research (Fransson \& Gärling, 1999).

There are a number of potential difficulties using questionnaire responses; the first in the relatively low response rate for the first survey. However, the sample was large $(\mathrm{N}=551)$, and whilst it had nationwide coverage it did not attempt to be nationally representative. Therefore the low response rate does not impact on the validity of results for the purposes of this study. Secondly, as shown above, the sample was weighted towards older, female Pakeha/European New Zealanders rather than the general population which may have been a result of self-selection bias (i.e. those with an existing interest in the subject were more likely to participate). There is also a risk with self-reported surveys that responses may not reflect actual behaviour (Gifford, 2007) and that self-reported behaviour may be over-reported (Whitmarsh, 2009). However, the results show consistency across time, and the findings are highly consistent with the literature suggesting validity of response. 
There were also potential limitations with the design of the survey. A scenario question was chosen to test attitudes and behaviour in a shortage context. This approach was selected because at the time it was unknown whether or not the industry would call for voluntary conservation measures, therefore signalling a shortage. The survey in Time 1 was posted the day before Transpower (the national grid operator) announced an industry-led media campaign (Transpower New Zealand, 2008, June 10). This may have impacted on participants' ability to conceptualise a scenario and to differentiate between the different contexts in which questions were being asked. This may be one reason the mean scores for willingness to conserve are so similar despite the different contexts under which the question was asked (i.e., under everyday circumstances and under a scenario). Further, it appears that the actual shortage has coloured respondents' answers to questions about motivations for conservation. One of the themes identified among 'other' reasons given for conserving as a matter of habit was supply shortages. This theme was not present in answers to the same question in Time 2, suggesting that the issue was by that time less salient and therefore not a consistent reason for conservation out of habit.

Regardless of these limitations, the survey results give important insights into electricity conservation in New Zealand households in everyday circumstances and during a shortage. It provides insights into the most and least popular conservation actions, motivations for conserving and perceptions of responsibility, which may all inform future campaign or programme design. For example, simple low-cost actions are likely to be easy to promote but techniques may need to be found to make behavioural changes with more impact on demand, such as fuel switching, more visible or acceptable. Although more difficult actions are likely to be harder to promote (Diekmann \& Preisendörfer, 2003), the unexpected response by Californians who significantly reduced their energy consumption from air conditioners in 2001 (Lutzenhiser et al., 2002) suggests this is not impossible. People are motivated by many factors.

The results also provide New Zealand based evidence of environmental attitudes and their relationship to conservation behaviour. There has been a notable gap in the New Zealand research literature in this area. 


\section{Study 3: Residential electricity demand response}

The third objective of this study, set out in Chapter 1, was to understand how behavioural changes affected electricity demand during the shortage period. This chapter presents the results of two analyses of residential electricity savings for the period of the power shortage.

\subsection{Analysing residential electricity demand}

The results presented in this section are sourced primarily from Lermit's (2009a) unpublished analysis of consumption data which compared forecast and actual residential demand during 2008. These results are supplemented with and compared against savings data published by the electricity industry. The method section of this chapter outlines the process undertaken and described by Jonathan Lermit (personal communications, $13^{\text {th }}$ January, 2009) and describes the different approach taken by the electricity industry (C. Franklin, personal communications, $28^{\text {th }}$ April, 2009). The results are presented and discussed.

\subsection{Method}

\subsubsection{Method 1 (Lermit data)}

Residential demand reduction for the period was estimated by separating residential consumption from total electricity consumption and then making a comparison with forecast demand based on historic trends.

Half hourly supply point data is gathered by the Electricity Commission across the national electricity grid and published periodically in the Centralised Dataset. This is the only publicly available electricity consumption data and it constitutes total demand (i.e. industrial, commercial and residential). Therefore, residential demand cannot be pin-pointed exactly using publicly available information. However it can be approximated using industry norms (J. Lermit, personal communications, $13^{\text {th }}$ January, 2009). 
To separate residential and total demand, supply point data was taken from five grid exit points (i.e., Central Park,Wellington; Henderson, Hepburn, Mangere and Pakuranga, Auckland), ${ }^{9}$ which are known in the industry to be largely residential. This data was taken to be a reasonably representative sample, and national residential demand was extrapolated from this.

To forecast expected residential demand, actual consumption data was taken from the same five grid exit points for a period of three years to find a trend. Data were 'decomposed' to remove the structural effects of time of day, time of week, seasonal effects, holidays, daylight saving and annual demand growth and aggregated. Once an aggregated forecast was generated the structure outlined above was re-applied to generate a realistic demand curve. These analyses did not take into account weather or economic effects.

\subsubsection{Method 2 (industry data)}

The electricity industry published savings results on the 'Powersavers' website during the campaign and in media releases. Unfortunately the exact method of analysis is unknown and the data itself is unavailable. However, it is known that the data used in the analysis also came from the Centralised Dataset and it is assumed residential savings were extrapolated using a similar method to that described above. It is known that the data was adjusted for "load growth, weather, holidays, industrial outages" (C. Franklin, personal communications $28^{\text {th }}$ April, 2009). It is also known that Lermit's (2009a) analysis did not make adjustments for weather and, as such, differences between Lermit's and the industry's results are to be expected.

\footnotetext{
${ }^{9}$ Grid exit points are the "point of connection where electricity flows out of the national grid to local networks or direct consumers" (Electricity Commission, 2007 online definition).
} 


\subsection{Results}

The results of Lermit's (2009a) analysis are shown in Figure 6.

Figure 6: Lermit's (2009a) analysis of residential savings in 2008

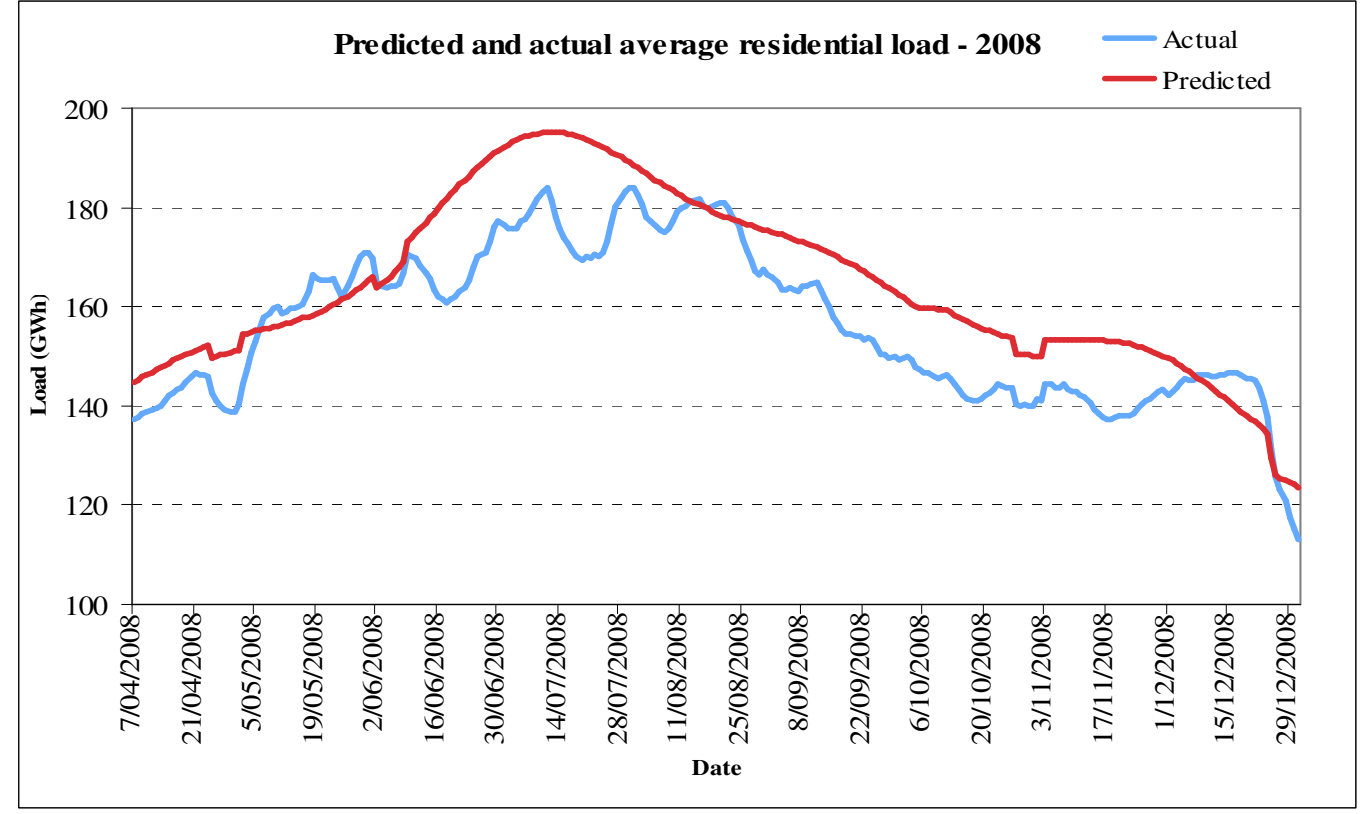

Source: Jonathan Lermit.

The graph suggests a demand response to the 'Powersavers' campaign from the residential sector. Actual demand dropped away from the forecast curve slightly before the start of the campaign (i.e. campaign launched $15^{\text {th }}$ June) and returned to forecast levels shortly after the end of the campaign (i.e. campaign ended $27^{\text {th }}$ July) strongly suggesting a behavioural response from householders to the campaign and media reports. Actual demand remained lower than forecast for the duration of the campaign. During the course of the six-week 'Powersavers' campaign, average national savings of $9.7 \%$ were estimated by Lermit, and estimated savings peaked at $12.7 \%$ on $19^{\text {th }}$ July, one week before the end of the campaign. A reduction from forecast demand can also be observed for most of the rest of the year. On average, residential demand was $4.7 \%$ lower than forecast in 2008. It is impossible to ascertain from the data what drove reduced demand throughout the year, although 2008 was a time of rising residential electricity prices and slowed economic growth, which may account for some of the demand reduction. 
In comparison to this analysis the electricity industry announced average national savings of 3.6\% (Transpower New Zealand, 2008) over the campaign period.

Because the discrepancy between results was quite large an analysis of savings from a previous shortage was undertaken to search for trends. In 2003 the electricity industry led the 'Target 10' campaign in response to a dry winter. The campaign ran from $3^{\text {rd }}$ May to $16^{\text {th }}$ June 2003 and was deemed to be successful because the target of $10 \%$ savings was reached (Communications Agencies Association of New Zealand, 2003; Meier, 2005; Winter Power Taskforce, 2003, 19 June). Therefore to determine whether the discrepancy between Jonathan Lermit's and the industry's results for 2008 were replicable or inexplicable the results for 2003 from both parties were also examined.

Lermit (2009b) undertook an analysis of savings for the campaign period using the same method described above for 2008. The results are depicted in Figure 7.

Figure 7: Lermit's (2009b) analysis of residential savings in 2003

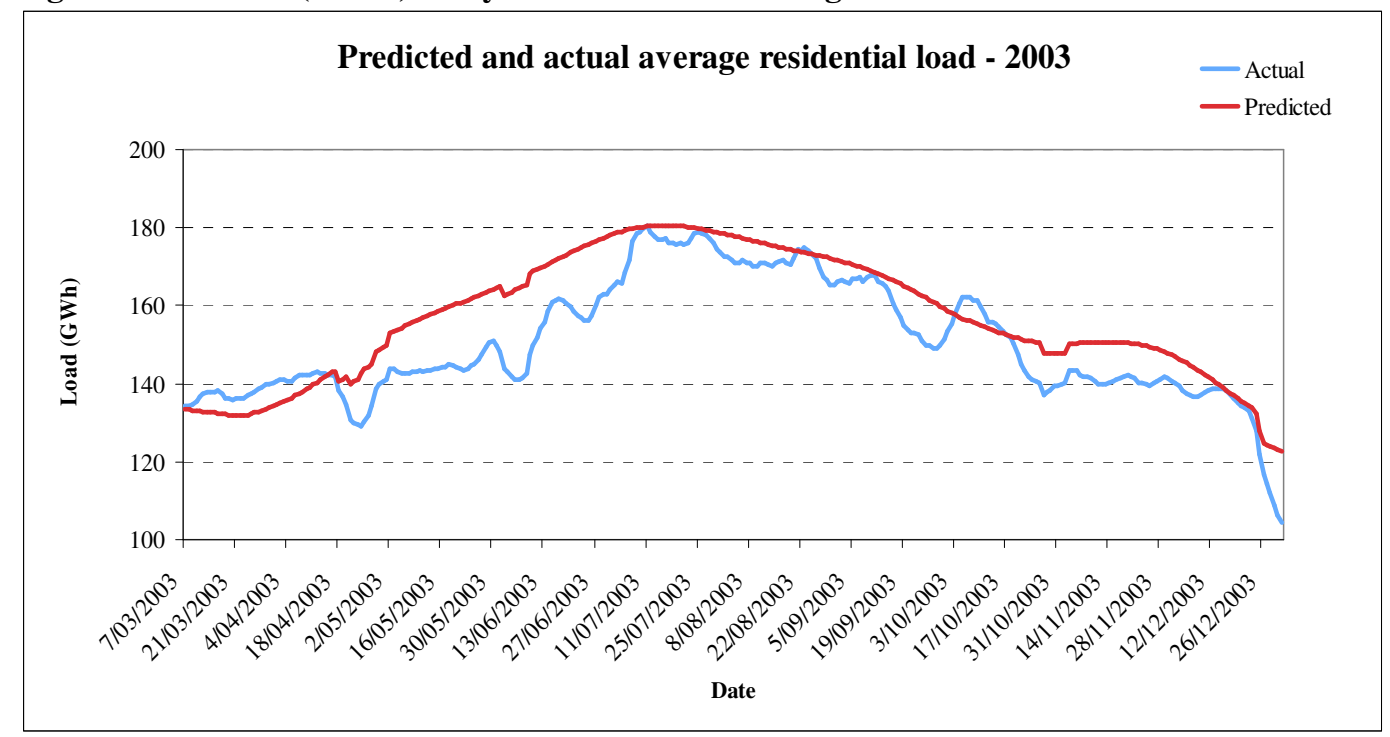

Source: Courtesy of Jonathan Lermit.

The graph shows that savings during the 2003 campaign period followed a similar trend to savings in 2008 in that actual estimated demand diverged from and returned to the forecast demand curve more or less in line with the campaign dates ( $3^{\text {rd }}$ May- $16^{\text {th }}$ June), although it did drop off a little before the campaign began. Lermit's estimate is that during the course of the 'Target 10' campaign 
average national savings of $10.6 \%$ were made with a peak of $14.2 \%$ on $6^{\text {th }}$ June 2003.

By comparison the industry supplied results which showed average savings across the same period of $6.8 \%$ with peak savings of 10.3\% (Figure 8) (Contact Energy, personal communications, $9^{\text {th }}$ September, 2008). These results have also been made publicly available (see: Communications Agencies Association of New Zealand, 2003).

Figure 8: Industry data showing residential savings during the 'Target 10' campaign in 2003

\section{Conservation Savings During Campaign}

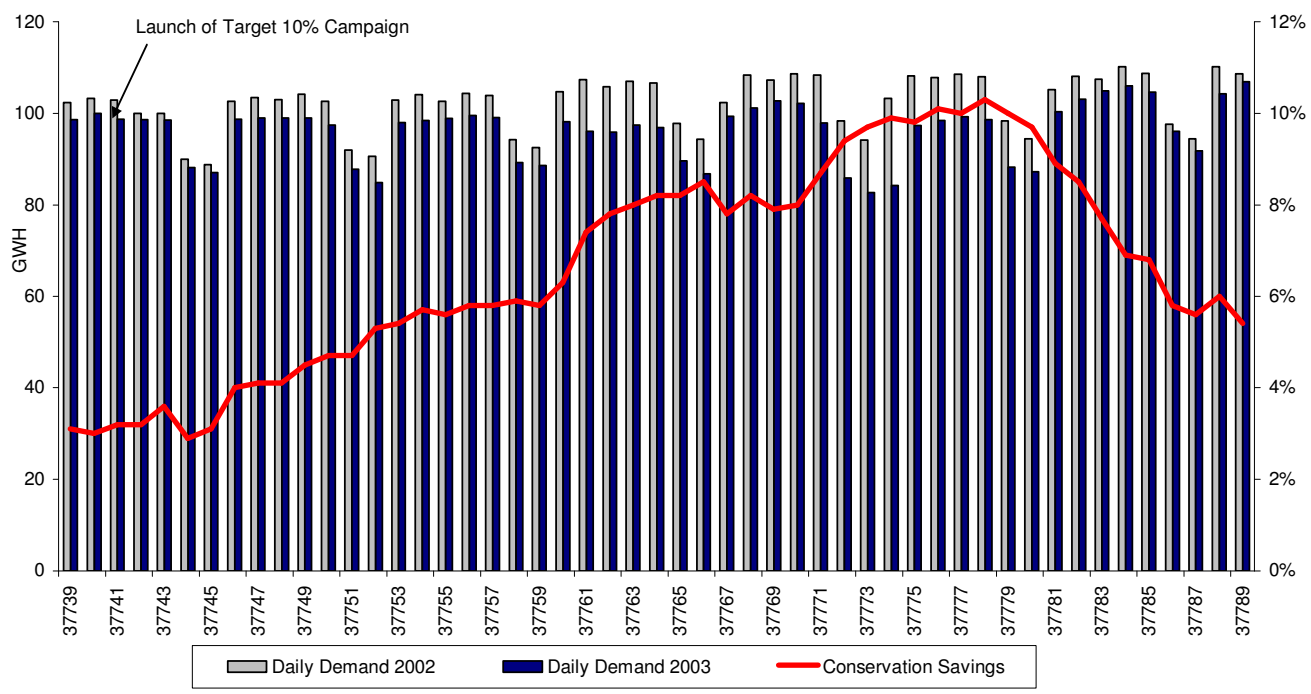

Source: Contact Energy Limited

To summarise, comparative results are included in Table 22.

Table 22: Comparison of estimated residential electricity savings results for 2008 and 2003

\begin{tabular}{llrr}
\hline Year & Source & $\begin{array}{r}\text { Average savings for } \\
\text { the period }\end{array}$ & $\begin{array}{r}\text { Peak savings for the } \\
\text { period }\end{array}$ \\
2003 & Lermit & $10.6 \%$ & $14.2 \%$ \\
& Industry & $6.8 \%$ & $10.3 \%$ \\
2008 & Lermit & $9.7 \%$ & $12.7 \%$ \\
& Industry & $3.6 \%$ & Unknown \\
\hline
\end{tabular}




\subsection{Discussion}

Some discrepancy between results was anticipated because the analyses were undertaken by two different parties using different methods. Lermit (2009a) used data from selected grid exit points known to be largely residential to identify residential savings. It is not known whether electricity industry figures included demand from the commercial and industrial sectors when accounting for savings. However, the lower demand on weekends which can be observed in electricity industry figures (Figure 8) suggests their data is not solely residential (i.e. many businesses would not operate at the weekend meaning lower overall demand). It is known that the industry analysis adjusted for industrial outages, whereas Lermit's did not (J. Lermit, personal communications, $21^{\text {st }}$ June, 2009). Further, it is known that the industry analysis adjusted for weather effects while Lermit's did not. Weather can have a significant effect on winter electricity demand because of a reliance on electrical space heating in New Zealand homes.

Although there is a discrepancy between the two sources, comparing findings during the two shortages suggests regularities. Using the average savings, which are the only measures that can be compared for both years, it is clear that the 'Powersavers' campaign resulted in fewer electricity savings from the residential sector than the 'Target 10' campaign. For the purposes of discussion average savings in the range of 3.6-9.7\% can be assumed for the 2008 shortage. The lower end of this range acknowledges the figures published by the industry as the outcome of the 'Powersavers' campaign (Transpower New Zealand, 2008). The upper end of the range has been included because the method of analysis is better understood and it is clear that non-residential data have been excluded. If the industry figures include some commercial and industrial data this may be masking savings from the residential sector (i.e. residential savings alone may be higher).

The difficulty of obtaining definitive results to understand the demand response from the shortage is a reflection of the availability of data. At present the only publicly available data is the Centralised Dataset which is aggregated data of total consumption. To access data from individual properties would have required the support of an electricity retailer, the selection of a representative 
sample and the permission of householders. That was beyond the means of this research project. However, the electricity industry in New Zealand is currently rolling out the installation of smart metering technology (Parliamentary Commissioner for the Environment, 2009) which may make accurate consumption data more readily available in the future. Therefore, although the results for 2008 included here cannot be said to be definitive, they represent the best available information. 


\section{General discussion}

This chapter draws together and discusses the results of the three empirical studies described in the preceding chapters (Chapters 3, $4 \& 5$ ).

In Study 1 (Chapter 3) a thematic analysis of media coverage and political debate related to the shortage was undertaken to investigate the socio-political context of the time. This study found that the electricity shortage was a deeply political issue, possibly made more so by the shortage preceding a general election by only five months. The key findings included that debate around the causes of and solutions to the shortage focused heavily on the supply side. Discussion of how demand-side measures such as reduced consumption or greater efficiency could contribute to load management in general was almost entirely absent. The need for electricity conservation was predominantly portrayed as a 'crisis' with deeply negative impacts on the economy, households and lifestyle. However, it was interesting to observe that for a short period during the lead-up to the 'Powersavers' campaign, reduced consumption was encouraged by parties on both sides of the political spectrum. These results suggest that electricity conservation was seen as an acceptable short-term solution to supply problems but was not on the agenda in the debate around long-term solutions to security of supply.

The second study (Chapter 4) investigated how householders changed their electricity conservation behaviour in response to the shortage and conservation campaign; it also studied consumers' environmental attitudes, willingness to conserve, motivations for conservation and preferred conservation actions. The key findings of this national study were that conservation behaviour did increase during the shortage by a small amount and participants reported a high degree of willingness to conserve. Participants preferred low-cost, low-effort conservation actions over actions which required effort or inconvenience, and they were motivated by reduced power bills in combination with concerns for the environment and personal health. The findings of this study were in line with 
behavioural literature in the area, as well as findings from studies of previous shortages.

To understand how behavioural changes affected aggregate residential demand the results of two separate analyses of electricity consumption were compared in Study 3 (Chapter 5). This comparative study found that estimated average residential savings as a result of the shortage were in the range of $3.6-9.7 \%$. It also found that with current data collection methods, pin-pointing residential electricity demand in New Zealand is problematic although the imminent introduction of smart meters into the market may alleviate this somewhat for future researchers.

\subsection{The socio-political environment and household behaviour}

The results of this research suggest that a relationship did exist between household behaviour and the socio-political context of the shortage. It seems likely that it impacted on households in a number of ways. Firstly, there is evidence to suggest that the socio-political context may have affected the design and management of the 'Powersavers' campaign, thereby weakening the conservation message and the associated level of savings. Secondly, repeated media messages portrayed the shortage as a 'crisis' with significant negative effects on the economy and individuals, and there was no media discussion of the long-term potential of demand-side solutions to alleviate future shortages. In this socio-political context social norms would have been unlikely to support high levels of electricity conservation by individuals.

A comparison of the design and leadership of, and savings from, the conservation campaigns in 2003 and 2008 suggests that the government was inhibited from encouraging greater levels of conservation in 2008. This appears to have been due to political pressure and the desire to avoid negative publicity in the lead-up to the general election. Savings during the 'Target 10' campaign in 2003 reached the target of $10 \%$ in early June (Meier, 2005) and estimated average savings ranged between $6.8 \%$ and $10.6 \%$ (see Chapter 5). In comparison estimated 
average savings from the 'Powersavers' campaign in 2008 ranged between $3.6 \%$ and $9.7 \%$.

Although the electricity industry is legally separated from government the majority of New Zealand's electricity generators and retailers are state owned enterprises (SOEs), ${ }^{10}$ which means the Minister of Energy is a shareholding minister with an important role within the industry. The campaigns in 2003 and 2008 were both led by the industry but the 'Target 10' campaign had strong ministerial support (Staley, 2006), whereas the Minister of Energy appeared to distance himself from the campaign in 2008. He chose to "endorse" the industryled campaign "when he saw the nature of the campaign and that there would be no specific target for savings" (Small, 2008). In 2008 Minister Parker was careful to avoid any suggestion that the shortage constituted a serious situation, required effort or would have negative impacts on householders. He did this by using his language carefully, requesting 'prudence' only and presenting the situation as a well-managed event (cross ref. 3.3.1.3). It could be argued that the Labour-led government in 2008 was trying to distance itself from blame for the situation and therefore did not provide strong leadership on the issue.

Furthermore, in 2003 an ambitious marketing strategy was developed to galvanise the community to 'own' the problem and work together to save electricity in a short timeframe (Communications Agencies Association of New Zealand, 2003, p. 3). Celebrities and public figures were used to promote conservation messages and there was a conscious effort to "deflect away from the 'Prevention/Supply' problems" (Communications Agencies Association of New Zealand, 2003, p. 3) and avoid negative media coverage. In comparison the campaign in 2008 did not include a savings target or use public personalities as role models and there was a very strong focus on prevention/supply issues in the media as seen in Chapter 3.

The absence of a savings targets was a facet of the campaign which was commented on in the media and for which the government received criticism

\footnotetext{
${ }^{10}$ With the exception of Contact Energy and TrustPower Ltd
} 
(Eaton, 2008). It seemed to work against the campaign's objectives by sending an ambiguous message. On the one hand a conservation campaign was launched but on the other the message about what was required was unclear:

We're not calling for people to turn off all their towel rails, but we would like them to think about whether they should leave them on overnight, $\mathrm{Mr}$ Parker said. [Otago Daily Times, $10^{\text {th }}$ June, 2008]

Further, the literature suggests that a harder target (such as 20\%) is likely to be more successful in encouraging conservation than a very small target $(2 \%)$ (Becker, 1978) and people are more likely to achieve targets set for them rather than targets they set themselves (Harkins \& Lowe, 2000). This suggests that the absence of a target in the 'Powersavers' campaign is likely to have influenced the effectiveness of the campaign. Thus, the political context of the time appears to have impacted on the design of the media campaign and by extension the behavioural response of householders.

The results of this study also suggest that certain social norms existed during the shortage which may have influenced individual behaviour by either constraining or encouraging electricity conservation. It is argued here that these social norms may influence electricity conservation in accordance with Stern's (2008) causal model of environmentally relevant behaviour and other sociological theories of energy demand discussed in Chapter 2. These theories state that although environmentally significant behaviour can be predicted the strongest influences on individual behaviour are often contextual. Behaviour may be constrained or facilitated by these higher level social influences (Stern, 2008). They also state that electricity demand is "culturally sensitive and collectively sanctioned" (Lutzenhiser, 1992, p. 54), meaning people are not entirely autonomous in their energy behaviour and are influenced by cultural and social norms. In light of these theories it is suggested that the social norms reflected in the media extracts (Chapter 3) and observed in responses to the survey (Chapter 4) could be expected to have influenced electricity conservation behaviour.

Messages about the shortage received by the public through the media were overwhelmingly focused on the negative aspects of reducing electricity 
consumption for households and the economy, and the 'problem' was predominantly portrayed as one of insufficient supply (i.e. to solve it more generation was required). The Concern with demand sub-theme (Chapter 3) demonstrated that there was a relatively small collection of media extracts which acknowledged the role of demand in managing the overall electricity system. Despite these there was no clear or explicit debate around the potential economywide benefits of reducing demand, such as avoided expenditure on infrastructure and new generation, and environmental benefits from reduced emissions or landuse impacts. These findings seem to suggest that social norms existed around the conceptualisation of the supply shortage and its implications (i.e. a problem of not enough supply rather than too much demand) which were reflected in and reinforced by the media.

Consumption is valued in contemporary society and consumer rights are paramount (Frame \& Newtown, 2007). Although energy researchers have argued that it is more acceptable to frame demand-side management as efficiency (Gardner \& Stern, 2002), the promotion of reduced consumption or conservation has proved to be less politically acceptable (Lutzenhiser et al., 2004). However, it is argued that truly sustainable development requires a reduction in consumption, not just efficiency gains (Jackson, 2009). An analysis of the evolution of international sustainable development policies since the 1992 Earth Summit suggests efforts in this area are likely to be constrained by the global political and economic setting (Fuchs \& Lorek, 2005). Likewise, it appears there was no place for a debate around reducing consumption in the socio-political context examined in Study 1 (Chapter 3). Stern's (2008) causal model suggests that these contextual factors (i.e. social and political norms) would be likely to constrain behaviour at a lower level of causality. This may explain the lower levels of electricity savings in 2008 compared to 2003 (i.e. when the socio-political context was different) and the small observed increase in conservation actions in Study 2.

In Study 2 (Chapter 4) a number of the results also suggest the existence of norms around electricity conservation during a shortage, which may have encouraged savings. The relationship between environmental attitudes and 
behaviour was weaker during the shortage than under everyday circumstances. This suggests that situational factors (i.e. the shortage context) may have altered the relationship and respondents increased their conservation behaviour during the shortage regardless of their environmental attitudes. This appears to reflect social norms about how to act during a shortage, even among those who would not normally conserve. There was also evidence of the presence of social norms in the 'other' reasons given for saving electricity provided by respondents. There was a sense that people knew what needed to be and should be done to save electricity: it was a matter of habit, up-bringing and commonsense. It is reasonable to expect that these norms would have worked in favour of electricity savings.

The results also reflect an interesting observation about how a change in context can shift the messages received by the public about electricity consumption via the media. By extension this may have shifted social norms on the issue. The media have been identified as among the most important sources of information about energy issues during a shortage (Goldman et al., 2002; Lutzenhiser, 2002b; Morrison et al., 1978). In the Californian 'energy crisis' of 2001, media reports of the shortage were found to be more influential than campaign messages (Lutzenhiser, 2002b); similarly it can be expected that the media in New Zealand would also have been an important influence on householders. The results of the current study show that within the socio-political context already discussed (i.e. where demand reduction per se was devalued), for a short time during the leadup to the campaign those generally opposed to conservation as a solution to managing electricity load were seen encouraging householders to conserve electricity. This was in the context of a 'crisis' and it appears to have been acceptable only as a short-term solution. Notwithstanding this, it showed that the media could present different messages about electricity supply if the political or social views they reflected supported it. According to Stern's (2008) causal model, if social norms around these issues were more favourable these contextual factors may encourage rather than constrain conservation behaviour at a household level. 


\subsection{Implications for behaviour change}

The results of the research provide a number of insights which could usefully inform future behaviour-change programmes under shortage conditions or everyday circumstances. Firstly, the results from Study 2 (Chapter 4) identify the most and least preferred electricity conservation actions and motivations for conservation which could be used in future programmes. Secondly, Stern's (2008) causal model suggests contextual influences need to be addressed to support pro-environmental behaviour such as electricity conservation. The possibilities presented by shifting political norms around the value of demandside management have been implied by this study, but Stern's model also suggests other variables which must be considered. This will require a strong interdisciplinary approach to managing electricity demand that takes a broad view of household energy demand and the influences on it.

The results from Study 2 (Chapter 4) are well supported by the literature in this area, suggesting the findings are valid. Therefore they can be used to inform designers of short-term (shortage) or long-term behaviour-change programmes. The results showed consistency across time (Time 1, Time 2 and the shortage recall) for the most and least popular conservation actions. Most popular were: lights off, heat rooms in use, curtains, air-dry clothes and cold water wash. In contrast, least popular actions were: shorter showers, green supply and use appliances less. Consistent with the literature, these suggest that people prefer taking actions which are low-cost and low-effort with little impact on their lifestyle (Diekmann \& Preisendörfer, 2003). These are also actions which are fairly visible (Stern et al., 1986) and commonsense.

It is likely that people in New Zealand are familiar with common conservation actions such as these because they have been exposed to conservation campaigns periodically during their lifetimes. Commonsense, habit/I was brought up that way, it's the right thing to do all featured as reasons for conservation that were not prompted by questions in the survey. These findings suggest New Zealanders already have a store of knowledge about how to reduce their energy consumption which could be drawn upon to reinforce conservation messages. 
A problem with some of the most popular actions (e.g. lights off) is that they may have little impact on demand. Stern (2000) identifies this as the difference between behaviour driven by impact and behaviour driven by intent. Consistent with the low-cost hypothesis (Diekmann \& Preisendörfer, 2003), the least popular actions require more effort or a loss of comfort. Shorter showers and using appliances less may signify a loss of comfort or lifestyle and switching electricity retailers to a 'greener' supplier requires effort and risk (Dawnay \& Shah, 2005). Future programme designers should identify which actions are most important in terms of impact to find ways to overcome barriers to their uptake whether they are behavioural or social barriers, or contextual constraints such as income or knowledge. Of course, there is a case for a balance to be struck between the easy low-cost measures people are familiar with, making them feel they are taking action, and the more difficult measures such as reducing the use of appliances, which may require addressing social norms or values around consumption. Focusing on easy actions with the highest degree of impact could be important.

The survey results also give insights into what motivates people to conserve electricity. Participants were asked about their motivations for conservation under everyday conditions in Time 1 and Time 2 . A high proportion of respondents said to save money was one of their motivating factors $(94.2 \%$ in Time 1 and $93.6 \%$ in Time 2), although a much smaller number gave it as their only reason (16.5\% in Time 1 and $11.7 \%$ in Time 2). Respondents' most common combination factors were it's good for the environment and because it's good for you and your family's health and well-being. In combination with financial concerns, environmental concerns were cited by more than half $(59.2 \%$ in Time 1 and $62.8 \%$ in Time 2) of all respondents as a motivation for conserving electricity. This supports an approach to encouraging savings that emphasise the co-benefits of reducing demand for householders rather than focusing on one strategy.

The sample in Study 2 was weighted towards older New Zealand European/Pakeha women. This appears to be a result of self-selection bias. Examining the differences between socio-demographic groups in New Zealand 
in relation to energy consumption may be a useful avenue for future research. The example of cultural differences in energy demand seen in Japan and Norway (Wilhite et al., 1996) suggests understanding cultural differences in New Zealand may offer insights into more effective demand management.

\subsubsection{Limitations}

The main limitations of this research are related to problems of measurement. The potential problems of using a self-reported questionnaire to measure behaviour have been discussed in Chapter 4. Likewise, the difficulties in obtaining electricity consumption data have been discussed in Chapter 5. A number of other limitations should be mentioned. A second issue related to consumption data is that it has not been possible within the scope of this study to measure the direct relationship between behaviour and consumption as the two data sets cannot be correlated. However, it has been possible to observe trends and comment on the findings, in light of the literature, using the best available information. Future studies would benefit from using household specific consumption and behavioural data so that direct correlations can be made.

Another issue, related to Study 1, is that the exploration of the socio-political environment was preliminary only, and limited to an interpretation from print media extracts. It is understood that the relationship between the socio-political context and energy behaviour has not previously been examined in an academic study in New Zealand. Therefore the results of the thematic analysis will provide a foundation for future research. Future studies could take a broader view of the socio-political environment and explore the relationship between politics and energy demand more directly by using sample-specific data. Further, social and political norms could be measured by other methods such as using a wider range of media, analysing government policy documents, interviews and conducting more in-depth surveys and interviews.

\subsection{Other considerations}

Although the current research has studied behaviour in a social context, it is not contended here that voluntary behaviour change is a panacea to the 
environmental problems related to energy demand. The current study has focused on the social and behavioural influences on energy behaviour as a means to reduce overall consumption because of the significant environmental impacts of energy demand. However, it is important to note that it is not solely assumed that householders can, or indeed should, be encouraged simply to reduce consumption without consideration being given to the physical and emotional health and well-being of occupants. The most obvious example of this is the serious concern about under-heating in New Zealand houses. Far from encouraging people to reduce their electricity consumption by reducing heating a more pressing issue for policy makers is ensuring houses are heated to World Health Organization minimum recommended temperatures (Howden-Chapman et al., in press). This issue adds to the case for a truly interdisciplinary understanding of energy demand.

Further, many technological and policy solutions to demand growth are already available and regularly implemented with some success. For example, minimum energy performance regulations on appliances, 'smart' technology which allows appliances to 'talk' to the national grid and incentives for insulation and efficient heating all help manage demand. Many of these technological solutions have a long life and therefore may have a significant impact on demand-reduction over time. The point made here is that to fully realise the potential of these traditional policy solutions, the role and behaviour of the individual and their place in a wider social and cultural structure over which they have little immediate control must be recognised and energy demand-reduction programmes designed accordingly. A technological solution which does not take into account social drivers of consumption such as product marketing and social norms around levels of consumption is likely to struggle to meet its objectives of reduced demand. The example of social norms around air-conditioners in the United States discussed above (Shove \& Wilhite, 1999) illustrates this point. The same concerns apply to subsidy schemes which do not take into account the affective qualities of the home (Aune, 2007) or the aesthetic qualities of products and consumer preferences (Wall \& Crosbie, 2009). By combining a social perspective on household energy consumption with more traditional policy 
avenues it is hoped effective, long-term reduction in demand and associated negative environmental effects can be achieved.

\subsection{Conclusion}

The current research was undertaken to explore whether a relationship existed between electricity conservation in households and the socio-political environment in New Zealand during the hydro-electricity shortage in 2008, so that constraints on demand-reduction initiatives might be better understood. It was hypothesised that the socio-political environment may have been a contextual factor that influenced household energy behaviour according to Stern's (2008) causal model of environmentally relevant behaviour.

The results have shown that the socio-political environment of the winter electricity shortage may indeed have constrained the behavioural response at a household level. This was suggested by the design and management of the conservation campaign and social norms which generally viewed the need for electricity conservation by householders as an 'unacceptable' notion. This is supported by results which show only a small increase in conservation actions during the shortage period and smaller estimated average electricity savings than during the pervious industry-led campaign in 2003. This finding suggests that the socio-political context of the time may have constrained potential electricity savings during the shortage period.

However, the results showed that shifts in the socio-political context may also encourage electricity conservation behaviour. For a brief period leading up to the shortage the media reflected messages which promoted energy conservation from parties generally opposed to it, and for a time electricity conservation was portrayed as more 'acceptable'. The influence of situational variables (i.e. a change of context) on behaviour was also implied by the altered relationship between environmental attitudes and behaviour during the shortage. People appeared to have increased their conservation behaviour during the shortage regardless of the strength of their pro-environmental attitudes. Accordingly, if the socio-political environment generally placed more value on reducing electricity consumption, social norms that support electricity conservation rather than 
constrain it may be observed. According to Stern's (2000) causal model this would help encourage rather than constrain variables at other levels of influence.

The research has taken a social psychology and sociological perspective on an energy demand issue, adopting a view that is broader than a focus on just the individual. It recognises the influential role of contextual factors on the energy consumption of individuals. This study makes a case for a truly interdisciplinary approach which takes into account the personal and social context within which energy consumption occurs and the multi-faceted social drivers of demand, so that electricity demand may be better managed. Energy policies which successfully achieve demand reduction whilst allowing for the well-being of householders are increasingly important in the current global environment of increasing energy demand and the potentially catastrophic environmental effects that are currently predicted if this demand is not reduced. 


\section{Appendices}

Appendix 1: References to media extracts used as data in thematic analysis

\begin{tabular}{|c|c|c|c|c|c|}
\hline & Media source & Headline & Date & Written By & $\begin{array}{l}\text { Type of } \\
\text { Extract/Section }\end{array}$ \\
\hline 1 & Bay of Plenty Times & Start saving power, plead energy bosses & $7^{\text {th }}$ June, 2008 & $\begin{array}{l}\text { APN News \& } \\
\text { Media Ltd }\end{array}$ & Not specified \\
\hline 2 & Bay of Plenty Times & Power and hypocrisy & $10^{\text {th }}$ June, 2008 & Laura Franklin & Editorial \\
\hline 3 & Bay of Plenty Times & No blackouts in Bay, says TrustPower chief & $11^{\text {th }}$ June, 2008 & Graham Skellern & Not specified \\
\hline 4 & Bay of Plenty Times & $\begin{array}{l}\text { City of lights - But who knows how long it will } \\
\text { last: So, will there be power cuts? }\end{array}$ & $19^{\text {th }}$ June, 2008 & $\begin{array}{l}\text { APN News \& } \\
\text { Media Ltd }\end{array}$ & Not specified \\
\hline 5 & Bay of Plenty Times & $\begin{array}{l}\text { Your view readers write: I'll give you a solution } \\
\text { to the power crisis }\end{array}$ & $26^{\text {th }}$ June, 2008 & R J Jordan & Not specified \\
\hline 6 & Bay of Plenty Times & Ten Mins & $26^{\text {th }}$ June, 2008 & Not specified & Not specified \\
\hline 7 & The Daily Post & $\begin{array}{l}\text { Power supply under threat Energy: Low lake } \\
\text { levels may lead to job losses in Rotorua }\end{array}$ & $30^{\text {th }}$ May, 2008 & Alison Brown & Not specified \\
\hline 8 & The Daily Post & $\begin{array}{l}\text { Crisis or not, it makes good sense to turn it off: } \\
\text { Our view }\end{array}$ & $11^{\text {th }}$ June, 2008 & Not specified & Leader \\
\hline 9 & The Daily Post & $\begin{array}{l}\text { Rotorua warned to save power Impact: Any cuts } \\
\text { would have dire consequences }\end{array}$ & $11^{\text {th }}$ June, 2008 & Cherie Taylor & Not specified \\
\hline 10 & Dominion Post & Low lakes threaten supply & $2^{\text {nd }}$ May, 2008 & James Weir & \\
\hline 11 & Dominion Post & Power firms barn of Blackouts & $3^{\text {rd }}$ May, 2008 & James Weir & National News \\
\hline 12 & Dominion Post & Price of light could switch the balance of power & $3^{\text {rd }}$ May, 2008 & James Weir & Business (Comment) \\
\hline 13 & Dominion Post & Tiwai smelter cuts power use & $3^{\text {rd }}$ May, 2008 & Marta Steeman & Business \\
\hline 14 & Dominion Post & Lakes still have the power over us & $13^{\text {th }}$ May, 2008 & James Weir & Business \\
\hline 15 & Dominion Post & Risk of blackouts 'being ignored' & $28^{\text {th }}$ May, 2008 & James Weir & Business \\
\hline 16 & Dominion Post & Restart eases fears of blackouts & $29^{\text {th }}$ May, 2008 & James Weir & Business \\
\hline 17 & Dominion Post & Lakes at 'grim' $53 \mathrm{pc}$ of average & $4^{\text {th }}$ June, 2008 & James Weir & Business \\
\hline 18 & Dominion Post & Ban on gas daft, says users group & $5^{\text {th }}$ June, 2008 & James Weir & Business \\
\hline
\end{tabular}




\begin{tabular}{|c|c|c|c|c|c|}
\hline 19 & Dominion Post & Power station failure increases chance of cuts & $6^{\text {th }}$ June, 2008 & James Weir & Business \\
\hline 20 & Dominion Post & Peak-time cuts & $9^{\text {th }}$ June, 2008 & Paul Easton & National News \\
\hline 21 & Dominion Post & Power crisis? What power crisis? & $10^{\text {th }}$ June, 2008 & Tracy Watkins & National News \\
\hline 22 & Dominion Post & Beer fridges 'bad for the nation' & $10^{\text {th }}$ June, 2008 & Matt Calman & National News \\
\hline 23 & Dominion Post & Power outlook grim despite gas burning & $10^{\text {th }}$ June, 2008 & James Weir & Business \\
\hline 24 & Dominion Post & Getting to grips with the power struggle & $12^{\text {th }}$ June, 2008 & Vernon Small & Features \\
\hline 25 & Dominion Post & Power Rangers & $13^{\text {th }}$ June, 2008 & James Weir & National News \\
\hline 26 & Dominion Post & They say & $14^{\text {th }}$ June, 2008 & $\begin{array}{l}\text { Nathan } \\
\text { Beaumont }\end{array}$ & National News \\
\hline 27 & Dominion Post & Call to keep saving power & $16^{\text {th }}$ June, 2008 & Ben Fawkes & National News \\
\hline 28 & Dominion Post & Power crisis is over, so let's tackle real issues & $19^{\text {th }}$ June, 2008 & Vernon Small & Features \\
\hline 29 & Dominion Post & Power prices high despite rain & $24^{\text {th }}$ June, 2008 & James Weir & Business \\
\hline 30 & Dominion Post & Transpower tells of big wave of new generation & $16^{\text {th }}$ July, 2008 & James Weir & Business \\
\hline 31 & Dominion Post & Power guzzlers call for review & $21^{\text {st }}$ July, 2008 & Anna Chalmers & National News \\
\hline 32 & Dominion Post & Balance of power & $15^{\text {th }}$ August, 2008 & James Weir & Business \\
\hline 33 & Dominion Post & Hydro lakes still too low & $19^{\text {th }}$ August, 2008 & Not specified & Business \\
\hline 34 & Dominion Post & Low rain, low lakes, high power prices & $26^{\text {th }}$ August, 2008 & James Weir & Business \\
\hline 35 & Dominion Post & Whirinaki elephant has to go & $30^{\text {th }}$ August, 2008 & James Weir & Business (Comment) \\
\hline 36 & Hawkes Bay Today & NZ's in the dark ages & $7^{\text {th }}$ May, 2008 & Mark August & Letter to the Editor \\
\hline 37 & Hawkes Bay Today & Crisis or not, turning it off is sensible & $10^{\text {th }}$ June, 2008 & Not specified & Editorial \\
\hline 38 & Hawkes Bay Today & TV campaign ‘reminder’ & $10^{\text {th }}$ June, 2008 & Not specified & Not specified \\
\hline 39 & Hawkes Bay Today & Mill slows down as power cost soars & $11^{\text {th }}$ June, 2008 & Roger Moroney & Not specified \\
\hline 40 & $\begin{array}{l}\text { Independent Financial } \\
\text { Review }\end{array}$ & Electricity Shortages & $12^{\text {th }}$ June, 2008 & Not specified & Weekly wrap \\
\hline 41 & $\begin{array}{l}\text { Independent Financial } \\
\text { Review }\end{array}$ & (No Headline) & $17^{\text {th }}$ June, 2008 & Not specified & Diary \\
\hline 42 & Manawatu Standard & Power plague peeves pitiful politicians & $28^{\text {th }}$ May, 2008 & Not specified & Editorial \\
\hline 43 & Manawatu Standard & Spend this money on something else & $11^{\text {th }}$ June, 2008 & Lee Matthews & Editorial \\
\hline 44 & Manawatu Standard & Too nice for a power shortage & $13^{\text {th }}$ June, 2008 & B Kay & Letter to the Editor \\
\hline 45 & Nelson Mail & Not a crisis, but ... & $10^{\text {th }}$ June, 2008 & Not specified & Editorial \\
\hline 46 & Nelson Mail & Why pull together when our leaders don't? & $13^{\text {th }}$ June, 2008 & C Winslow & Letter to the Editor \\
\hline 47 & Nelson Mail & Power shortage & $27^{\text {th }}$ June, 2008 & Boris Leegwater & Letter to the Editor \\
\hline 48 & Nelson Mail & More power play & $18^{\text {th }}$ August, 2008 & Not specified & Editorial \\
\hline
\end{tabular}




\begin{tabular}{|c|c|c|c|c|c|}
\hline 49 & Nelson Mail & Power use petition & $20^{\text {th }}$ August, 2008 & $\begin{array}{l}\text { Mike Drake, } \\
\text { WRAP }\end{array}$ & Letter to the Editor \\
\hline 50 & New Zealand Herald & Emissions plan load of hot air & $4^{\text {th }}$ May, 2008 & Not specified & Not specified \\
\hline 51 & New Zealand Herald & More power-price rises likely by winter's end & $10^{\text {th }}$ May, 2008 & Eloise Gibson & Not specified \\
\hline 52 & New Zealand Herald & The power surge & $10^{\text {th }}$ May, 2008 & Grant Bradley & Not specified \\
\hline 53 & New Zealand Herald & Power boss exits with $\$ 350 \mathrm{k}$ & $11^{\text {th }}$ May, 2008 & Stephen Cook & Not specified \\
\hline 54 & New Zealand Herald & Cabinet's fresh faces survive sour week in politics & $29^{\text {th }}$ May, 2008 & John Armstrong & Not specified \\
\hline 55 & New Zealand Herald & $\begin{array}{l}\text { Clear and oh, so dry in power heartland Picture- } \\
\text { perfect tourist weather bad news for all who rely } \\
\text { on nation's hydro lakes }\end{array}$ & $7^{\text {th }}$ June, 2008 & Grant Bradley & Not specified \\
\hline 56 & New Zealand Herald & $\begin{array}{l}\text { Low lakes and high demand put us on track for an } \\
\text { electricity crisis within a month - unless it rains }\end{array}$ & $7^{\text {th }}$ June, 2008 & $\begin{array}{l}\text { Craig Borley and } \\
\text { Wayne } \\
\text { Thompson }\end{array}$ & Not specified \\
\hline 57 & New Zealand Herald & Rain, snow but not for lakes & $7^{\text {th }}$ June, 2008 & Not specified & Not specified \\
\hline 58 & New Zealand Herald & $\begin{array}{l}\text { Get ready to save power_ but there's no crisis } \\
\text { Government's sending mixed messages and } \\
\text { praying for rain, says National }\end{array}$ & $10^{\text {th }}$ June, 2008 & Paula Oliver & Not specified \\
\hline 59 & New Zealand Herald & Political games over energy & $11^{\text {th }}$ June, 2008 & Not specified & Editorial \\
\hline 60 & New Zealand Herald & Rain forecast for thirsty lakes & $12^{\text {th }}$ June, 2008 & Jarrod Booker & Not specified \\
\hline 61 & New Zealand Herald & More power to the people & $15^{\text {th }}$ June, 2008 & Not specified & Not specified \\
\hline 62 & New Zealand Herald & Power bill best source of conservation advice & $21^{\text {st }}$ June, 2008 & Not specified & Not specified \\
\hline 63 & New Zealand Herald & Businesses reluctant to turn off after-hours lights & $23^{\text {rd }}$ June, 2008 & $\begin{array}{l}\text { Alanah May } \\
\text { Eriksen and } \\
\text { James Ihaka }\end{array}$ & Not specified \\
\hline 64 & New Zealand Herald & Lake Hawea close to minimum level & $28^{\text {th }}$ June, 2008 & Grant Bradley & Not specified \\
\hline 65 & New Zealand Herald & $\begin{array}{l}\text { Rising lake levels ease fears of power cuts } \\
\text { Consumers still urged to continue to save } \\
\text { electricity till waters rise above 'min zone' }\end{array}$ & $9^{\text {th }}$ July, 2008 & Jarrod Booker & Not specified \\
\hline 66 & New Zealand Herald & $\begin{array}{l}\text { The price of keeping lights on Whirinaki prime } \\
\text { example of market-tampering behaviour }\end{array}$ & $17^{\text {th }}$ July, 2008 & Brian Fallow & Economics \\
\hline 67 & New Zealand Herald & $\begin{array}{l}\text { Power shortages cost economy } \$ 3 \text { b Domestic } \\
\text { users save } 3.6 \text { per cent over six-week campaign }\end{array}$ & $28^{\text {th }}$ July, 2008 & Grant Bradley & Not specified \\
\hline 68 & New Zealand Herald & Power 'crisis' all just politics & $31^{\text {st }}$ July, 2008 & Not specified & Editorial \\
\hline
\end{tabular}




\begin{tabular}{|c|c|c|c|c|c|}
\hline 69 & New Zealand Herald & Party plays on fears with energy policy & $15^{\text {th }}$ August, 2008 & Not specified & Not specified \\
\hline 70 & New Zealand Herald & Low lakes leave power supply in south precarious & $26^{\text {th }}$ August, 2008 & Grant Bradley & Not specified \\
\hline 71 & Northern Advocate & Another view: Hazy talk leaves voters in dark & $13^{\text {th }}$ June, 2008 & Not specified & Not specified \\
\hline 72 & Otago Daily Times & Hydro storage levels hit 26-year low & $27^{\text {th }}$ May, 2008 & Not specified & News \\
\hline 73 & Otago Daily Times & Contact confident of power station's safety & $29^{\text {th }}$ May, 2008 & Not specified & News \\
\hline 74 & Otago Daily Times & $\begin{array}{l}\text { Renewed call for national power savings } \\
\text { campaign }\end{array}$ & $4^{\text {th }}$ June, 2008 & $\begin{array}{l}\mathrm{NZ} \text { press } \\
\text { association }\end{array}$ & News \\
\hline 75 & Otago Daily Times & $\mathrm{NZ}$ on wrong track with energy strategy & $5^{\text {th }}$ June, 2008 & Grahame Sydney & Opinion \\
\hline 76 & Otago Daily Times & Electricity savings on agenda & $9^{\text {th }}$ June, 2008 & $\begin{array}{l}\text { David Loughrey } \\
\text { with NZ press } \\
\text { association }\end{array}$ & Not specified \\
\hline 77 & Otago Daily Times & Wind, hydro complimentary & $9^{\text {th }}$ June, 2008 & Graeme Purchas & Opinion \\
\hline 78 & Otago Daily Times & Parker plays down power problems & $10^{\text {th }}$ June, 2008 & Not specified & News \\
\hline 79 & Otago Daily Times & Alarm bells not ringing over falling lake level & $14^{\text {th }}$ June, 2008 & $\begin{array}{l}\text { Hamish } \\
\text { McNeilly }\end{array}$ & News \\
\hline 80 & Otago Daily Times & Rolling power cuts very 'unlikely': commission & $21^{\text {st }}$ June, 2008 & David Bruce & News \\
\hline 81 & Otago Daily Times & Lake Hawea group warns about water levels & $27^{\text {th }}$ June, 2008 & Not specified & Not specified \\
\hline 82 & Otago Daily Times & Power prices plunge & $24^{\text {th }}$ July, 2008 & Not specified & News \\
\hline 83 & Otago Daily Times & Fuel security is right on our doorstep & $11^{\text {th }}$ August, 2008 & Geoff Kearsley & Opinion \\
\hline 84 & Otago Daily Times & Fears over South Island hydro levels & $26^{\text {th }}$ August, 2008 & Not specified & News \\
\hline 85 & The Press & Blackout fears & $2^{\text {nd }}$ May, 2008 & Dan Eaton & National News \\
\hline 86 & The Press & Costs force smelter into huge power cuts & $3^{\text {rd }}$ May, 2008 & Marta Steeman & National News \\
\hline 87 & The Press & $\begin{array}{l}\text { Proper planning and conservation only answer to } \\
\text { our electricity woes }\end{array}$ & $3^{\text {rd }}$ May, 2008 & Not specified & Editorial \\
\hline 88 & The Press & Government, electricity companies criticised & $6^{\text {th }}$ May, 2008 & Marta Steeman & Business \\
\hline 89 & The Press & Electricity supply & $10^{\text {th }}$ May, 2008 & Paul Gorman & National News \\
\hline 90 & The Press & Rain eases risk of power cuts & $13^{\text {th }}$ May, 2008 & James Weir & Business \\
\hline 91 & The Press & Higher power prices forecast & $27^{\text {th }}$ May, 2008 & Paul Gorman & National News \\
\hline 92 & The Press & Hydro lakes keep falling & $4^{\text {th }}$ June, 2008 & James Weir & Business \\
\hline 93 & The Press & Power plight worse as station fixed & $6^{\text {th }}$ June, 2008 & James Weir & Business \\
\hline 94 & The Press & Push to slash hydro storage & $9^{\text {th }}$ June, 2008 & Paul Gorman & National News \\
\hline 95 & The Press & 'No crisis' but save power now & $10^{\text {th }}$ June, 2008 & Colin Espiner & National News \\
\hline 96 & The Press & Lowering lakes an environmental risk & $10^{\text {th }}$ June, 2008 & Paul Gorman & National News \\
\hline
\end{tabular}




\begin{tabular}{|c|c|c|c|c|c|}
\hline 97 & The Press & National slates power strategy & $11^{\text {th }}$ June, 2008 & Colin Espiner & National News \\
\hline 98 & The Press & Dangerous denial & $11^{\text {th }}$ June, 2008 & Not specified & Editorial \\
\hline 99 & The Press & Councils, firms prune power use & $12^{\text {th }}$ June, 2008 & Giles Brown & National News \\
\hline 100 & The Press & In a few words & $12^{\text {th }}$ June, 2008 & P. Foster & Letter to the Editor \\
\hline 101 & The Press & In a few words & $13^{\text {th }}$ June, 2008 & B. Kay & Letter to the Editor \\
\hline 102 & The Press & Running out of energy & $16^{\text {th }}$ June, 2008 & Colin Espiner & Opinion \\
\hline 103 & The Press & Power supply & $17^{\text {th }}$ June, 2008 & Paul Gorman & National News \\
\hline 104 & The Press & Electricity use & $18^{\text {th }}$ June, 2008 & Dan Eaton & National News \\
\hline 105 & The Press & Electricity generation & $6^{\text {th }}$ August, 2008 & Paul Gorman & National News \\
\hline 106 & The Press & Energy divide & $15^{\text {th }}$ August, 2008 & Not specified & Editorial \\
\hline 107 & The Press & Spring power crisis looms & $19^{\text {th }}$ August, 2008 & Paul Gorman & National News \\
\hline 108 & Scoop & New policy approach needed in electricity trading & $2^{\text {nd }}$ May, 2008 & Business NZ & Press Release \\
\hline 109 & Scoop & Thermal generation going like the clappers & $21^{\text {st }}$ May, 2008 & National Party & Press Release \\
\hline 110 & Scoop & Questions and Answers in the House & $28^{\text {th }}$ May, 2008 & $\begin{array}{l}\text { Parliamentary } \\
\text { wire }\end{array}$ & Parliamentary Debate \\
\hline 111 & Scoop & Make the power conservation call now, Minister & $30^{\text {th }}$ May, 2008 & National Party & Press Release \\
\hline 112 & Scoop & Questions and Answers in the House & $1^{\text {st }}$ June, 2008 & $\begin{array}{l}\text { Parliamentary } \\
\text { wire }\end{array}$ & Parliamentary Debate \\
\hline 113 & Scoop & Parker gambling on lights staying on & $3^{\text {rd }}$ June, 2008 & National Party & Press Release \\
\hline 114 & Scoop & Seriousness of lake storage levels & $4^{\text {th }}$ June, 2008 & $\begin{array}{l}\text { Major Electricity } \\
\text { Users Group }\end{array}$ & Press Release \\
\hline 115 & Scoop & Will Minister confirm power plant breakdown? & $5^{\text {th }}$ June, 2008 & National Party & Press Release \\
\hline 116 & Scoop & Reliance on giant wind 'foolishness' & $6^{\text {th }}$ June, 2008 & Save Central & Press Release \\
\hline 117 & Scoop & What to expect in electricity crisis campaign & $6^{\text {th }}$ June, 2008 & National Party & Press Release \\
\hline 118 & Scoop & Grahame Sydney "thinks to new depths" & $6^{\text {th }}$ June, 2008 & TrustPower & Press Release \\
\hline 119 & Scoop & Electricity leadership for Wellington & $9^{\text {th }}$ June, 2008 & National Party & Press Release \\
\hline 120 & Scoop & Power users may face extra bill of $\$ 165$ million & $25^{\text {th }}$ June, 2008 & National Party & Press Release \\
\hline 121 & Scoop & Lake Hawea level cause for real worry & $30^{\text {th }}$ June, 2008 & National Party & Press Release \\
\hline 122 & Scoop & Communism in electricity doesn't work & $30^{\text {th }}$ June, 2008 & $\begin{array}{l}\text { Sense of Life } \\
\text { Objectivists }\end{array}$ & Press Release \\
\hline 123 & Scoop & Parker muddies waters on likely power hikes & $1^{\text {st }}$ July, 2008 & National Party & Press Release \\
\hline 124 & Scoop & $\begin{array}{l}\text { Australia leads the way again on renewable } \\
\text { energy }\end{array}$ & $8^{\text {th }}$ July, 2008 & SEANZ & Press Release \\
\hline
\end{tabular}




\begin{tabular}{|c|c|c|c|c|c|}
\hline 125 & Scoop & Good management key to weathering dry winter & $15^{\text {th }}$ July, 2008 & NZ Government & Press Release \\
\hline 126 & Scoop & Power crisis? What power crisis? & $17^{\text {th }}$ July, 2008 & $\begin{array}{l}\text { Manufacturers } \\
\text { and Exporters } \\
\text { association }\end{array}$ & Press Release \\
\hline 127 & Scoop & Questions and Answers in the House & $22^{\text {nd }}$ July 2008 & $\begin{array}{l}\text { Parliamentary } \\
\text { wire }\end{array}$ & Parliamentary Debate \\
\hline 128 & Scoop & Project Hayes and global warming & $23^{\text {rd }}$ July, 2008 & Roch Sullivan & Press Release \\
\hline 129 & Scoop & Questions and Answers in the House & $7^{\text {th }}$ August, 2008 & $\begin{array}{l}\text { Parliamentary } \\
\text { wire }\end{array}$ & Parliamentary Debate \\
\hline 130 & Scoop & John Key: Going For Growth Speech & $14^{\text {th }}$ August, 2008 & National Party & Press Release \\
\hline 131 & Scoop & Nats propose higher emissions, higher prices & $14^{\text {th }}$ August, 2008 & NZ Government & Press Release \\
\hline 132 & Southland Times & Tiwai cuts to save power & $3^{\text {rd }}$ May, 2008 & Evan Harding & National News \\
\hline 133 & Southland Times & Smelter output cut as costs rise & $14^{\text {th }}$ May, 2008 & Evan Harding & National News \\
\hline 134 & Southland Times & Power problem & $7^{\text {th }}$ June, 2008 & N. Stronach & Letter to the Editor \\
\hline 135 & Southland Times & Rain over hydro lakes expected today & $13^{\text {th }}$ June, 2008 & Evan Harding & National News \\
\hline 136 & Sunday Star Times & Shining examples of great waste & $1^{\text {st }}$ June, 2008 & Esther Harward & National News \\
\hline 137 & Sunday Star Times & Asbestos find an 'excuse' to mothball plant & $1^{\text {st }}$ June, 2008 & Tim Hunter & Business \\
\hline 138 & Sunday Star Times & Electricity savings campaign 'too late' & $8^{\text {th }}$ June, 2008 & Lois Watson & National News \\
\hline 139 & Sunday Star Times & 'Big Dry' generators crank up greenhouse gases & $8^{\text {th }}$ June, 2008 & Garry Sheeran & Business \\
\hline 140 & Sunday Star Times & $\begin{array}{l}\text { So far it has cost us } \$ 230 \mathrm{~m} \text {. The security of our } \\
\text { power is in its hands. }\end{array}$ & $22^{\text {nd }}$ June, 2008 & Garry Sheeran & Business \\
\hline 141 & Waikato Times & The great turn-off & $14^{\text {th }}$ June, 2008 & Kate Monahan & Features \\
\hline 142 & Waikato Times & Remembering the power crisis that wasn't & $14^{\text {th }}$ June, 2008 & Not specified & Features \\
\hline 143 & Waikato Times & Time to prove we are savers & $17^{\text {th }}$ June, 2008 & Not specified & Editorial \\
\hline 144 & Waikato Times & Business lead the way saving power & $18^{\text {th }}$ June, 2008 & Rebecca Harper & National News \\
\hline
\end{tabular}


Appendix 2: Social Attitudes Surveys

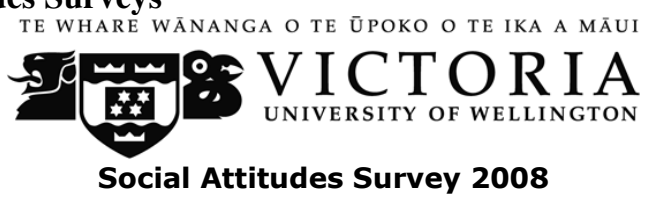

PART 1. General questions about you

The following phrases describe people's behaviours. Please rate how accurately each statement describes you.

\begin{tabular}{|c|c|c|c|c|c|c|}
\hline $\begin{array}{c}1 \\
\text { Strongly } \\
\text { disagree }\end{array}$ & $\begin{array}{c}2 \\
\text { Disagree }\end{array}$ & $\begin{array}{c}3 \\
\text { Somewhat } \\
\text { disagree }\end{array}$ & $\begin{array}{c}4 \\
\text { Unsure/ } \\
\text { neutral }\end{array}$ & $\begin{array}{c}\mathbf{5} \\
\begin{array}{c}\text { Somewhat } \\
\text { agree }\end{array} \\
\end{array}$ & & $\begin{array}{c}7 \\
\text { Strongly } \\
\text { agree }\end{array}$ \\
\hline \multicolumn{6}{|c|}{ Extraverted, enthusiastic. } & 1234567 \\
\hline \multicolumn{6}{|c|}{ Critical, quarrelsome. } & 1234567 \\
\hline \multicolumn{6}{|c|}{ Dependable, self-disciplined. } & 1234567 \\
\hline \multicolumn{6}{|c|}{ Anxious, easily upset. } & 1234567 \\
\hline \multicolumn{6}{|c|}{ Open to new experiences, complex. } & 1234567 \\
\hline \multicolumn{6}{|c|}{ Reserved, quiet. } & 1234567 \\
\hline \multicolumn{6}{|c|}{ Sympathetic, warm. } & 1234567 \\
\hline \multicolumn{6}{|c|}{ Disorganised, careless. } & 1234567 \\
\hline \multicolumn{6}{|c|}{ Calm, emotionally stable. } & 1234567 \\
\hline \multicolumn{6}{|c|}{ Conventional, uncreative. } & 1234567 \\
\hline \multicolumn{6}{|c|}{ When I hear other people talking privately, I avoid listening. } & 1234567 \\
\hline \multicolumn{6}{|c|}{ There have been occasions when I have taken advantage of someone. } & 1234567 \\
\hline \multicolumn{6}{|c|}{ I never cover up my mistakes. } & 1234567 \\
\hline \multicolumn{6}{|c|}{ I sometimes try to get even rather than forgive and forget. } & 1234567 \\
\hline \multicolumn{6}{|c|}{ I always obey laws, even if I'm unlikely to get caught. } & 1234567 \\
\hline \multicolumn{6}{|c|}{ I have said something bad about a friend behind his or her back. } & 1234567 \\
\hline \multicolumn{6}{|c|}{ I never swear. } & 1234567 \\
\hline \multicolumn{6}{|c|}{ I have received too much change from a salesperson without telling him or her. } & 1234567 \\
\hline \multicolumn{6}{|c|}{ I have never dropped litter on the street. } & 1234567 \\
\hline \multicolumn{6}{|c|}{ I sometimes tell lies if I have to. } & 1234567 \\
\hline
\end{tabular}

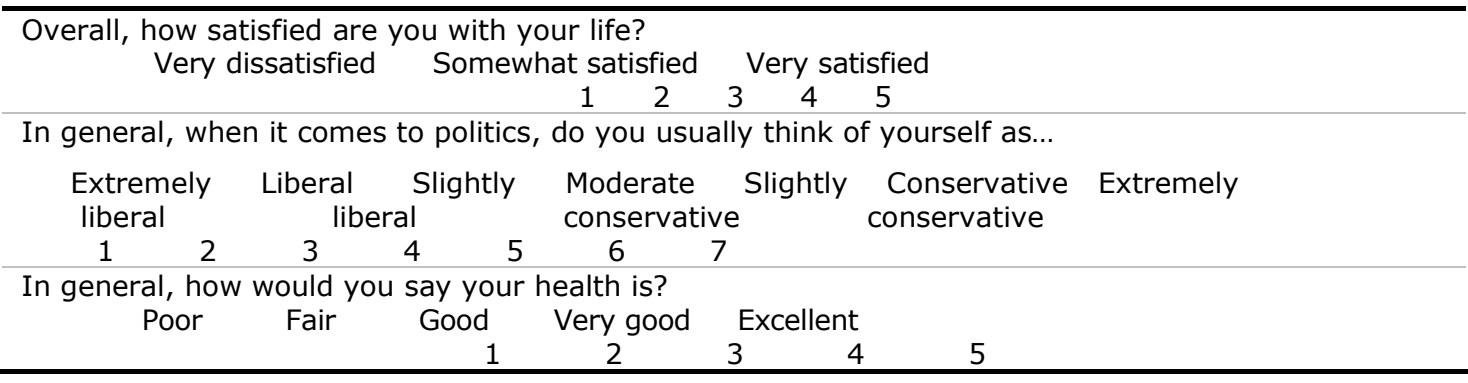


Do you think New Zealand may face an electricity shortage this winter? $\square$ Yes $\square$ No

Do you own a car? $\square$ Yes $\square$ No

How many cars are there in your home?

How many people live in your home?

How many bedrooms are there in your home?

Please select the figure below that best describes your relationship with the natural environment. How interconnected are you with nature?

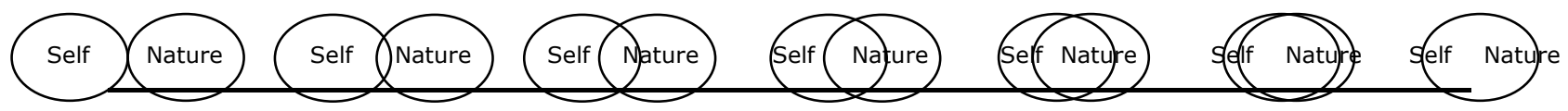

Listed below are statements about the relationship between humans and the environment. Please indicate the extent to which you agree or disagree with each of the following statements.

\begin{tabular}{|c|c|c|c|c|}
\hline $\begin{array}{c}1 \\
\text { Strongly } \\
\text { disagree }\end{array}$ & $\begin{array}{c}2 \\
\text { Disagree }\end{array}$ & $\begin{array}{c}3 \\
\text { Unsure }\end{array}$ & $\begin{array}{c}\mathbf{5} \\
\text { Agree }\end{array}$ & Strongly agree \\
\hline
\end{tabular}

We are approaching the limit of the number of people the earth can support.

Humans have the right to modify the natural environment to suit their needs.

When humans interfere with nature it often produces disastrous consequences.

Humans are severely abusing the environment.

The earth has plenty of natural resources if we just learn how to develop them.

Plants and animals have as much right as humans to exist.

The balance of nature is strong enough to cope with the impacts of modern industrial nations.

Despite our special abilities humans are still subject to the laws of nature.

The so-called "ecological crisis" facing humankind has been greatly exaggerated.

The earth is like a spaceship with very limited room and resources.

The balance of nature is very delicate and easily upset.

If things continue on their present course, we will soon experience a major ecological catastrophe.

\section{PART 3. Questions about global warming and climate change}

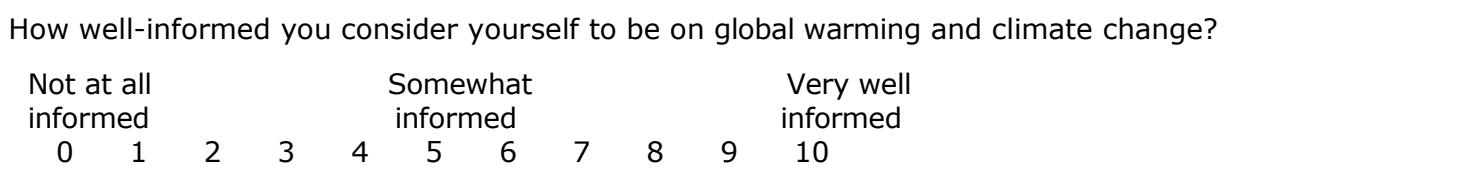

How clearly do you think scientists understand global warming and climate change? 


\begin{tabular}{cccccc} 
Very unclear & Very clear & & \\
understanding & understanding & & \\
& 1 & 2 & 3 & 4 \\
\hline
\end{tabular}

What is the risk of global warming and climate change exerting a significant impact on...

No risk $123 \quad 3 \quad 4$ Extreme risk

Public health in your town or city? $\quad \begin{array}{lllll}1 & 2 & 3 & 4\end{array}$

Economic development in your town or city? $\quad \begin{array}{llllll}1 & 2 & 3 & 4\end{array}$

The environment in your town or city? $\quad \begin{array}{lllll}1 & 2 & 3 & 4\end{array}$

Please indicate the extent to which you agree or disagree with the following statements.

\begin{tabular}{|c|c|c|c|}
\hline $\mathbf{1}$ & $\mathbf{2}$ & $\mathbf{3}$ & $\mathbf{4}$ \\
Strongly disagree & Disagree & Agree & Strongly agree \\
\hline
\end{tabular}

Global warming and climate change will have a noticeably negative impact on my health in the next 25 years.

Global warming and climate change will have a noticeably negative impact on my economic and financial situation in the next 25 years.

Global warming and climate change will have a noticeably negative impact on the environment in which my family and I live.

I believe my actions have an influence on global warming and climate change.

My actions to reduce the effects of global warming and climate change in my community will encourage others to reduce the effects of global warming through their own actions.

Human beings are responsible for global warming and climate change.

Please indicate the trustworthiness of information on global warming and climate change provided by the following media and groups.

\begin{tabular}{|llllllllllll|}
\hline $\begin{array}{l}\text { Not trustworthy } \\
\text { at all }\end{array}$ & \multicolumn{1}{c|}{ Very } \\
& 0 & 1 & 2 & 3 & 4 & 5 & 6 & 7 & 8 & 9 & 10 \\
\hline
\end{tabular}

\begin{tabular}{llllllllllll}
\hline Newspapers & 0 & 1 & 2 & 3 & 4 & 5 & 6 & 7 & 8 & 9 & 10 \\
Television news & 0 & 1 & 2 & 3 & 4 & 5 & 6 & 7 & 8 & 9 & 10 \\
Radio & 0 & 1 & 2 & 3 & 4 & 5 & 6 & 7 & 8 & 9 & 10 \\
Internet & 0 & 1 & 2 & 3 & 4 & 5 & 6 & 7 & 8 & 9 & 10 \\
University academics & 0 & 1 & 2 & 3 & 4 & 5 & 6 & 7 & 8 & 9 & 10 \\
Scientists & 0 & 1 & 2 & 3 & 4 & 5 & 6 & 7 & 8 & 9 & 10 \\
Government agencies & 0 & 1 & 2 & 3 & 4 & 5 & 6 & 7 & 8 & 9 & 10 \\
Nonprofit organisations & 0 & 1 & 2 & 3 & 4 & 5 & 6 & 7 & 8 & 9 & 10 \\
Environmental interest groups & 0 & 1 & 2 & 3 & 4 & 5 & 6 & 7 & 8 & 9 & 10 \\
Other interest groups & 0 & 1 & 2 & 3 & 4 & 5 & 6 & 7 & 8 & 9 & 10
\end{tabular}

PART 4. Questions about the use of electricity

In general, how willing are you to conserve electricity at home?

\begin{tabular}{|c|c|c|c|}
\hline $\begin{array}{l}\text { Not at all } \\
\text { willing }\end{array}$ & & $\begin{array}{l}\text { Somewhat } \\
\text { willing }\end{array}$ & $\begin{array}{l}\text { Very } \\
\text { willing }\end{array}$ \\
\hline $\begin{array}{ll}0 & 1\end{array}$ & 2 & 4 & 6 \\
\hline
\end{tabular}


Please think about the general use of electricity in your home. Can you please indicate which of the following things you do regularly, out of habit, to save electricity?

\begin{tabular}{|c|c|c|c|c|}
\hline $\begin{array}{c}1 \\
\text { Never } \\
\end{array}$ & $\begin{array}{c}\mathbf{2} \\
\text { Rarely }\end{array}$ & $\begin{array}{c}3 \\
\text { Sometimes } \\
\end{array}$ & $\begin{array}{c}4 \\
\text { Often } \\
\end{array}$ & $\begin{array}{c}5 \\
\text { Very often } \\
\end{array}$ \\
\hline \multicolumn{4}{|c|}{ Turn the lights off in rooms that are not being used. } & 12345 \\
\hline \multicolumn{4}{|c|}{$\begin{array}{l}\text { Unplug appliances or switch them off at the wall when they're not in use (i.e., avoid } \\
\text { leaving appliances on stand-by) }\end{array}$} & 12345 \\
\hline \multicolumn{4}{|c|}{ Use energy-efficient appliances or electrical equipment. } & 12345 \\
\hline \multicolumn{4}{|c|}{ Pull the curtains before dark to keep the heat in. } & 12345 \\
\hline \multicolumn{4}{|c|}{ Only heat rooms which are in use. } & 12345 \\
\hline \multicolumn{4}{|c|}{ Air-dry clothes instead of putting them in a clothes drier. } & 12345 \\
\hline \multicolumn{4}{|c|}{ Pro-actively choose 'green' electricity products and services. } & 12345 \\
\hline \multicolumn{4}{|c|}{ Restrict the length of showers to save electricity. } & 12345 \\
\hline \multicolumn{4}{|c|}{ Turn off equipment (television, computers, etc) when not in use. } & 12345 \\
\hline \multicolumn{4}{|c|}{ Air-dry towels instead of putting them on heated towel rails. } & 12345 \\
\hline \multicolumn{4}{|c|}{ Use cold water instead of hot or warm water when washing clothes. } & 12345 \\
\hline \multicolumn{4}{|c|}{ Keep your hot water cylinder thermostat at $60^{\circ} \mathrm{C}$. } & 12345 \\
\hline \multicolumn{4}{|c|}{ Use thermostats and timers on electrical equipment (e.g., heated towel rails, heaters). } & 12345 \\
\hline \multicolumn{4}{|c|}{ Use electrical devices less often. } & 12345 \\
\hline \multicolumn{4}{|c|}{ Use blankets or warm clothes instead of turning the heating on. } & 12345 \\
\hline \multicolumn{4}{|l|}{ Other: } & 12345 \\
\hline \multicolumn{4}{|l|}{ Other: } & 12345 \\
\hline
\end{tabular}

For which of the following reasons do you do these things to save electricity? (tick as many as apply to you)

$\square$ To save money $\quad \square$ Because it's good for you and your family's health and well-being

$\square$ It's what your friends are doing $\square$ It's good for the environment

$\square$ Don't know/No particular reason $\square$ Another reason (please specify):

\section{PART 5. Questions about electricity shortage}

SCENARIO: Suppose New Zealand faces an electricity shortage this winter.

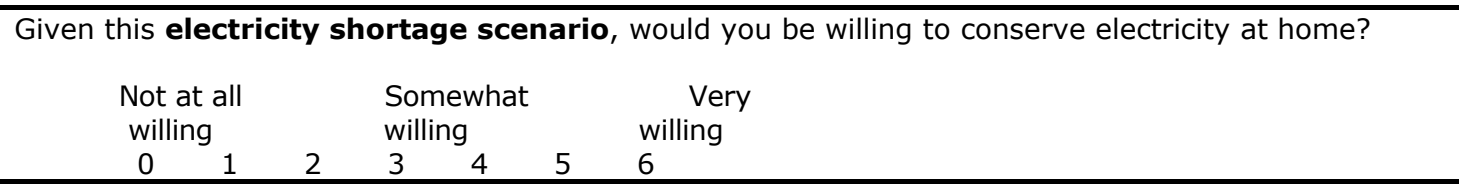

Given this electricity shortage scenario, please indicate whether you agree or disagree with the following questions:

\begin{tabular}{|c|c|c|c|c|}
\hline $\begin{array}{c}1 \\
\text { Strongly } \\
\text { disagree }\end{array}$ & $\begin{array}{c}2 \\
\text { Disagree }\end{array}$ & $\begin{array}{c}3 \\
\text { Unsure }\end{array}$ & $\begin{array}{c}4 \\
\text { Agree }\end{array}$ & $\begin{array}{c}5 \\
\text { Strongly agree }\end{array}$ \\
\hline
\end{tabular}

The electricity shortage would have an important impact on me and other members of my household.

The electricity shortage would have an important impact on the people living in my community. 
The electricity shortage would have an important impact on people all over New Zealand.

The electricity shortage would have an important impact on our economy.

I would be willing to exercise restraint because I would feel personally concerned about the electricity shortage.

I would be willing to exercise restraint because there may be consequences for others.

I would not need to be asked by the government to save electricity because of the shortage, I would have done so anyway.

I would not need to be asked by the electricity company to save electricity because of the shortage, I would have done so anyway.

There should be incentives for me to reduce my electricity consumption.

During the shortage, I would seek information on how to use electricity wisely and how to conserve.

I am already using as little electricity as possible because I am concerned about the environment.

I am already using as little electricity as possible because I am concerned about my electricity bills.

Given this electricity shortage scenario, who do you believe would be responsible for doing something about it?

\begin{tabular}{|cccccccc|}
\hline Not at all & Somewhat & \multicolumn{4}{c|}{ Very } \\
responsible & $\begin{array}{r}\text { responsible } \\
\text { responsible }\end{array}$ \\
& 0 & 1 & 2 & 3 & 4 & 5 & 6 \\
\hline
\end{tabular}

\begin{tabular}{l|l}
\hline The Government & 12345 \\
Regional/local councils & 12345 \\
Farmers & 12345 \\
All industry and business in general & 12345 \\
All New Zealanders/Everyone & 12345 \\
Myself & 12345 \\
Small to medium enterprises & 12345 \\
Large scale industrial or commercial users & 12345 \\
Other (specify): & 12345 \\
Other (specify): & 12345 \\
\hline
\end{tabular}

PART 6. Background questions (Please remember that your responses are confidential)

1. How old are you? years.
2. What is your gender?

$\square$ Female $\square$ Male
3. Are you member of any environmental organisation (e.g., Greenpeace)?

$\square$ Yes $\square$ No

4. Which of these best describe your highest educational qualification?

$\square$ Secondary School Incomplete

$\square$ NCEA, School Certificate, or other secondary school qualification

$\square$ Polytechnic qualification or Trade Certificate

$\square$ Undergraduate Degree $\quad \square$ Postgraduate Degree $\quad \square$ Masters $\quad \square$ Doctorate

5. Which country were you born in?

6. Which ethnic group(s) do you belong to? (Tick as many as apply. If you identify with multiple groups, then please circle the group that you feel you most strongly belong to)

$\square$ Indian $\square$ Māori

$\square$ Asian

$\square$ Other (please specify):

7. In which of the following areas do you live?
$\square$ Northland
$\square$ Gisborne
$\square$ Auckland
$\square$ Hawke's Bay
$\square$ Wellington-Wairarapa
$\square$ West Coast
Canterbury
$\square$ Waikato
$\square$ Taranaki
$\square$ Tasman
$\square$ Nelson

Otago

$\square$ Bay of Plenty $\square$ Manawatu-Wanganui $\square$ Marlborough

8. Which of the following best describes where you grew up? I grew up in a... 


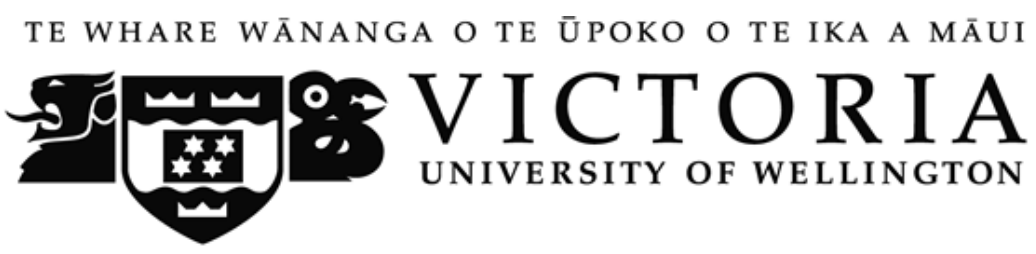

Social Attitudes Survey 2008 (b)

PART 1. General questions about you

Please read carefully the basic human values and their descriptions listed below, and answer the following question: AS A GUIDING PRINCIPLE IN YOUR LIFE, this value is...

\begin{tabular}{|c|c|c|c|c|c|c|}
\hline $\begin{array}{c}\text { Completely } \\
\text { unimportant }\end{array}$ & $\begin{array}{c}\text { Not } \\
\text { important }\end{array}$ & $\begin{array}{c}\text { Not very } \\
\text { important }\end{array}$ & $\begin{array}{c}\text { More or } \\
\text { less } \\
\text { important }\end{array}$ & $\begin{array}{c}5 \\
\text { Important }\end{array}$ & $\begin{array}{c}6 \\
\text { Very } \\
\text { important }\end{array}$ & $\begin{array}{c}\text { of the } \\
\text { utmost } \\
\text { importance }\end{array}$ \\
\hline
\end{tabular}

AFFECTIVITY. To have a deep and enduring affectionate relationship; to have somebody to share successes and failures.

1234567

BEAUTY. To be able to appreciate the best in art, music and literature; to go to museums or exhibitions where you can see beautiful things.

1234567

BELONGING. To have good neighbourly relationships; to form part of a group (e.g., social, religious, sporting, etc.)

EMOTION. To enjoy challenges or unknown situations; to look for adventure.

1234567

HEALTH. To look after your health at all times, not just when sick; not to be sick.

1234567

1234567

KNOWLEDGE. To look for up to date news on not very well-known matters; to try to discover new things about the world.

1234567

MATURITY. To feel that your purpose in life has been fulfilled; to develop all your capacities.

OBEDIENCE. To fulfil your daily duties and obligations; to respect your parents, superiors or elders.

PERSONAL STABILITY. To have the certainty that tomorrow you will have all that you have today; to have an organised and planned life.

PLEASURE. To live for the moment; to satisfy all your desires.

1234567

1234567

1234567

1234567

POWER. To have the power to influence others and to control decisions; to be the boss of a team.

PRESTIGE. To know that a lot of people know and admire you; when you are older to receive homage or a tribute for your contributions.

1234567

1234567

PROTECTING THE ENVIRONMENT. To preserve nature.

1234567

RESPECTING THE EARTH. To seek harmony with other species.

1234567

RELIGIOSITY. To hold religious faith and belief; to complete the will of God.

1234567

SEXUALITY. To have sexual relationships; to obtain sexual pleasure.

1234567

SOCIAL SUPPORT. To obtain help when you need it; to feel that you are not alone in the world.

SUCCESS. To reach your goals; to be efficient in everything you do.

1234567

1234567

SURVIVAL. To have water, food and shelter every day in your life; to live in a place with enough food.

TRADITION. To follow the social norms of your country; to respect the traditions of your society.

UNITY WITH NATURE. To fit into nature.

1234567

1234567

1234567 
PART 1.1. Listed below are a number of statements that may or may not apply to you. Please indicate the extent to which you agree or disagree with each statement.

\begin{tabular}{|c|c|c|c|c|c|c|}
\hline $\begin{array}{c}1 \\
\text { Strongly } \\
\text { disagree }\end{array}$ & $\begin{array}{c}2 \\
\text { Disagree }\end{array}$ & $\begin{array}{c}3 \\
\begin{array}{c}\text { Somewhat } \\
\text { disagree }\end{array}\end{array}$ & $\begin{array}{c}4 \\
\text { Unsure/ } \\
\text { neutral } \\
\end{array}$ & $\begin{array}{c}5 \\
\begin{array}{c}\text { Somewhat } \\
\text { agree }\end{array} \\
\end{array}$ & $\begin{array}{c}6 \\
\text { Agree }\end{array}$ & $\begin{array}{c}7 \\
\text { Strongly } \\
\text { agree }\end{array}$ \\
\hline \multicolumn{6}{|c|}{ When I hear other people talking privately, I avoid listening. } & 1234567 \\
\hline \multicolumn{6}{|c|}{ I feel envy every day. } & 1234567 \\
\hline \multicolumn{6}{|c|}{ There have been occasions when I have taken advantage of someone. } & 1234567 \\
\hline \multicolumn{6}{|c|}{ The truth is that I generally feel inferior to others. } & 1234567 \\
\hline \multicolumn{6}{|c|}{ I never cover up my mistakes. } & 1234567 \\
\hline \multicolumn{6}{|c|}{ Feelings of envy constantly torment me. } & 1234567 \\
\hline \multicolumn{6}{|c|}{ I sometimes try to get even rather than forgive and forget. } & 1234567 \\
\hline \multicolumn{6}{|c|}{ It is so frustrating to see some people succeed so easily. } & 1234567 \\
\hline \multicolumn{6}{|c|}{ I always obey laws, even if I'm unlikely to get caught. } & 1234567 \\
\hline \multicolumn{6}{|c|}{ No matter what I do, envy always plagues me. } & 1234567 \\
\hline \multicolumn{6}{|c|}{ I have said something bad about a friend behind his or her back. } & 1234567 \\
\hline \multicolumn{6}{|c|}{ I am troubled by feelings of inadequacy. } & 1234567 \\
\hline \multicolumn{6}{|c|}{ I never swear. } & 1234567 \\
\hline \multicolumn{6}{|c|}{ I have received too much change from a salesperson without telling him or her. } & 1234567 \\
\hline \multicolumn{6}{|c|}{ It somehow doesn't seem fair that some people seem to have all the talent. } & 1234567 \\
\hline \multicolumn{6}{|c|}{ I have never dropped litter on the street. } & 1234567 \\
\hline \multicolumn{6}{|c|}{ I sometimes tell lies if I have to. } & 1234567 \\
\hline \multicolumn{6}{|c|}{ Frankly, the success of my neighbours makes me resent them. } & 1234567 \\
\hline
\end{tabular}

\section{PART 1.2.}

Here are a number of personality traits that may or may not apply to you. Please indicate the extent to which you agree or disagree with each statement. You should rate the extent to which each pair of traits applies to you, even if one characteristic applies more strongly than the other.

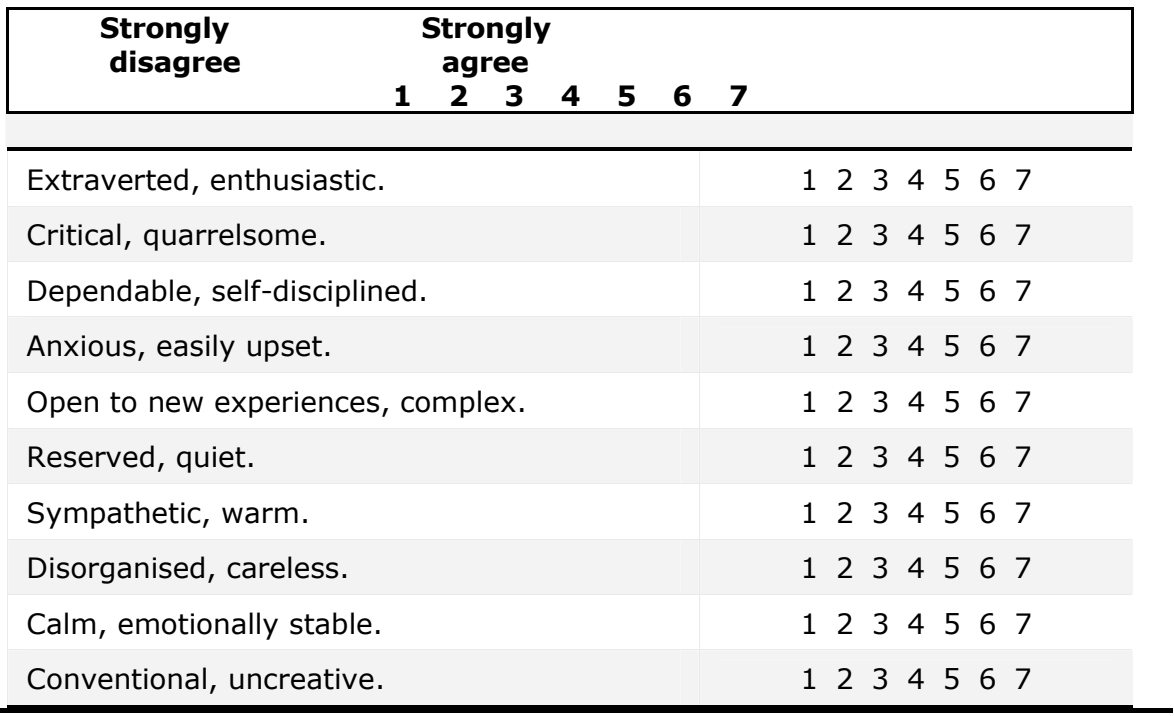


Please indicate how strongly you supported/opposed the following political parties in the general election (November 2008).

\begin{tabular}{|c|c|c|c|c|c|c|c|}
\hline \multirow[t]{2}{*}{$\begin{array}{l}\text { Strongly } \\
\text { opposed }\end{array}$} & \multicolumn{4}{|c|}{$\begin{array}{l}\text { Strongly } \\
\text { supported }\end{array}$} & \multirow[b]{2}{*}{6} & \multirow[b]{2}{*}{7} & \\
\hline & 1 & 23 & 4 & 5 & & & \\
\hline The Green Party & & & & & & & $\begin{array}{lllllll}1 & 2 & 3 & 4 & 5 & 6 & 7\end{array}$ \\
\hline The Labour Party & & & & & & & 1234567 \\
\hline The Māori Party & & & & & & & 1234567 \\
\hline The National Party & & & & & & & 1234567 \\
\hline The NZ First Party & & & & & & & 1234567 \\
\hline Other (specify): & & & & & & & 1234567 \\
\hline Other (specify): & & . & & & & & $\begin{array}{lllllll}1 & 2 & 3 & 4 & 5 & 6 & 7\end{array}$ \\
\hline
\end{tabular}

\section{PART 2. Questions about the use of electricity}

Please think about the general use of electricity in your home. Can you please indicate which of the following things you do regularly, out of habit, to save electricity?

\begin{tabular}{|c|c|c|c|c|}
\hline $\begin{array}{c}1 \\
\text { Never } \\
\end{array}$ & $\begin{array}{c}2 \\
\text { Rarely }\end{array}$ & $\begin{array}{c}3 \\
\text { Sometimes }\end{array}$ & $\begin{array}{c}4 \\
\text { Often } \\
\end{array}$ & $\begin{array}{c}5 \\
\text { Very often }\end{array}$ \\
\hline \multicolumn{4}{|c|}{ Turn the lights off in rooms that are not being used. } & 12345 \\
\hline \multicolumn{4}{|c|}{$\begin{array}{l}\text { Unplug appliances or switch them off at the wall when they're not in use (i.e., avoid } \\
\text { leaving appliances on stand-by) }\end{array}$} & 12345 \\
\hline \multicolumn{4}{|c|}{ Use energy-efficient appliances or electrical equipment. } & 12345 \\
\hline \multicolumn{4}{|c|}{ Pull the curtains before dark to keep the heat in. } & 12345 \\
\hline \multicolumn{4}{|c|}{ Only heat rooms which are in use. } & 12345 \\
\hline \multicolumn{4}{|c|}{ Air-dry clothes instead of putting them in a clothes drier. } & 12345 \\
\hline \multicolumn{4}{|c|}{ Pro-actively choose 'green' electricity products and services. } & 12345 \\
\hline \multicolumn{4}{|c|}{ Restrict the length of showers to save electricity. } & 12345 \\
\hline \multicolumn{4}{|c|}{ Turn off equipment (television, computers, etc) when not in use. } & 12345 \\
\hline \multicolumn{4}{|c|}{ Air-dry towels instead of putting them on heated towel rails. } & 12345 \\
\hline \multicolumn{4}{|c|}{ Use cold water instead of hot or warm water when washing clothes. } & 12345 \\
\hline \multicolumn{4}{|c|}{ Use electrical devices less often. } & 12345 \\
\hline \multicolumn{4}{|c|}{ Use blankets or warm clothes instead of turning the heating on. } & 12345 \\
\hline
\end{tabular}

For which of the following reasons do you do these things to save electricity? (tick as many as apply to you)

$\square$ To save money

$\square$ It's what your friends are doing

$\square$ It's good for the environment

$\square$ Because it's good for you and your family's health and well-being

$\square$ Don't know/No particular reason

$\square$ Another reason (please specify): 
PART 3. General questions about environmental issues

Listed below are statements about the relationship between humans and the environment. Please indicate the extent to which you agree or disagree with each of the following statements.

\begin{tabular}{|c|c|c|c|c|c|c|}
\hline $\begin{array}{c}1 \\
\text { Strongly } \\
\text { disagree }\end{array}$ & Disagree & $\begin{array}{c}\mathbf{2} \\
\text { Somewhat } \\
\text { disagree }\end{array}$ & $\begin{array}{c}\mathbf{4} \\
\text { Unsure/ } \\
\text { neutral }\end{array}$ & $\begin{array}{c}\mathbf{5} \\
\text { Somewhat } \\
\text { agree }\end{array}$ & $\begin{array}{c}\mathbf{6} \\
\text { Agree }\end{array}$ & $\begin{array}{c}\mathbf{7} \\
\text { Strongly } \\
\text { agree }\end{array}$ \\
\hline
\end{tabular}

I really like going on trips into the countryside, for example to forests or fields.

1234567

I do not believe humans were created or evolved to dominate the rest of nature.

1234567

Protecting the environment is more important than protecting people's jobs.

1234567

Whenever possible, I try to save natural resources.

1234567

We need to keep rivers and lakes clean in order to protect the environment, and not as places for people to enjoy water sports.

1234567

I think spending time in nature is boring.

1234567

I do not believe that the environment has been severely abused by humans.

1234567

I'd much prefer a garden that is well groomed and ordered to a wild and natural one.

1234567

Modern science will solve our environmental problems.

1234567

One of the most important reasons to keep lakes and rivers clean is so that people have a place to enjoy water sports.

Protecting people's jobs is more important than protecting the environment.

1234567

Humans are severely abusing the environment.

1234567

Governments should control the rate at which raw materials are used to ensure that they last as long as possible.

1234567

Modern science will not be able to solve our environmental problems.

1234567

I would like to join and actively participate in an environmental group.

A couple should have as many children as they wish, as long as they can adequately provide for them.

1234567

It makes me sad to see forests cleared for agriculture.

1234567

I would not get involved in an environmental organisation.

1234567

Human beings were created or evolved to dominate the rest of nature.

1234567

I am not the kind of person who makes efforts to conserve natural resources.

I am opposed to governments controlling and regulating the way raw materials are used in order to try and make them last longer.

Families should be encouraged to limit themselves to two children or less.

I'd prefer a garden that is wild and natural to a well groomed and ordered one.

\section{PART 4. Questions about global warming and climate change}

How well-informed do you consider yourself to be on global warming and climate change?

$\begin{array}{ccccccccccc}\begin{array}{c}\text { Not at all } \\ \text { informed } \\ 0\end{array} & 1 & 2 & 3 & 4 & 5 & 6 & \begin{array}{c}\text { Somewhat } \\ \text { informed }\end{array} & & \text { Very well } \\ \text { informed } & 8 & 9 & 10\end{array}$

How clearly do you think scientists understand global warming and climate change?

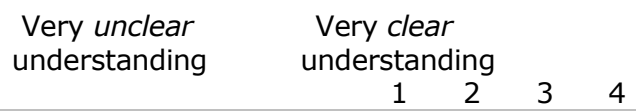


What is the risk of global warming and climate change exerting a significant impact on...

No risk $1 \quad 2 \quad 3 \quad 4$ Extreme risk

Public health in your town or city?

Economic development in your town or city?

$\begin{array}{llll}1 & 2 & 3 & 4\end{array}$

The environment in your town or city?

$\begin{array}{llll}1 & 2 & 3 & 4\end{array}$

$\begin{array}{llll}1 & 2 & 3 & 4\end{array}$

Please indicate the extent to which you agree or disagree with the following statements.

\begin{tabular}{|c|c|c|c|}
\hline 1 & 2 & 3 & 4 \\
Strongly disagree & Disagree & Agree & Strongly agree \\
\hline
\end{tabular}

Global warming and climate change will have a noticeably negative impact on my health in the next 25 years.

1234

Global warming and climate change will have a noticeably negative impact on my economic and financial situation in the next 25 years.

1234

Global warming and climate change will have a noticeably negative impact on the environment in which my family and I live.

1234

I believe my actions have an influence on global warming and climate change.

My actions to reduce the effects of global warming and climate change in my community will encourage others to reduce the effects of global warming through their own actions.

Human beings are responsible for global warming and climate change.

1234

1234

Please indicate the trustworthiness of information on global warming and climate change provided by the following media and groups.

\begin{tabular}{|llllllllllll|}
\hline $\begin{array}{l}\text { Not trustworthy } \\
\text { at all }\end{array}$ & \multicolumn{11}{c|}{ Very } \\
& 0 & 1 & 2 & 3 & 4 & 5 & 6 & 7 & 8 & 9 & 10 \\
\hline
\end{tabular}

\begin{tabular}{llllllllllll}
\hline Newspapers & 0 & 1 & 2 & 3 & 4 & 5 & 6 & 7 & 8 & 9 & 10 \\
Television news & 0 & 1 & 2 & 3 & 4 & 5 & 6 & 7 & 8 & 9 & 10 \\
Radio & 0 & 1 & 2 & 3 & 4 & 5 & 6 & 7 & 8 & 9 & 10 \\
Internet & 0 & 1 & 2 & 3 & 4 & 5 & 6 & 7 & 8 & 9 & 10 \\
University academics & 0 & 1 & 2 & 3 & 4 & 5 & 6 & 7 & 8 & 9 & 10 \\
Scientists & 0 & 1 & 2 & 3 & 4 & 5 & 6 & 7 & 8 & 9 & 10 \\
Government agencies & 0 & 1 & 2 & 3 & 4 & 5 & 6 & 7 & 8 & 9 & 10 \\
Nonprofit organisations & 0 & 1 & 2 & 3 & 4 & 5 & 6 & 7 & 8 & 9 & 10 \\
Environmental interest groups & 0 & 1 & 2 & 3 & 4 & 5 & 6 & 7 & 8 & 9 & 10 \\
Other interest groups & 0 & 1 & 2 & 3 & 4 & 5 & 6 & 7 & 8 & 9 & 10 \\
\hline
\end{tabular}


IMPORTANT:

As you may remember, New Zealand faced an electricity shortage this winter (Jun - Jul 2008). The following questions are about this electricity shortage.

Please think about the general use of electricity in your home. Can you please indicate which of the following things you did to save electricity during the shortage?

\begin{tabular}{|c|c|c|c|c|}
\hline $\begin{array}{c}1 \\
\text { Never } \\
\end{array}$ & $\begin{array}{c}\mathbf{2} \\
\text { Rarely } \\
\end{array}$ & $\begin{array}{c}3 \\
\text { Sometimes } \\
\end{array}$ & $\begin{array}{c}4 \\
\\
\text { Often }\end{array}$ & $\begin{array}{c}5 \\
\text { Very often } \\
\end{array}$ \\
\hline \multicolumn{4}{|c|}{ Turned the lights off in rooms that were not being used. } & 12345 \\
\hline \multicolumn{4}{|c|}{$\begin{array}{l}\text { Unplugged appliances or switched them off at the wall when they were not in use (i.e., } \\
\text { avoided leaving appliances on stand-by) }\end{array}$} & 12345 \\
\hline \multicolumn{4}{|c|}{ Used energy-efficient appliances or electrical equipment. } & 12345 \\
\hline \multicolumn{4}{|c|}{ Pulled the curtains before dark to keep the heat in. } & 12345 \\
\hline \multicolumn{4}{|c|}{ Only heated rooms which were in use. } & 12345 \\
\hline \multicolumn{4}{|c|}{ Air-dried clothes instead of putting them in a clothes drier. } & 12345 \\
\hline \multicolumn{4}{|c|}{ Pro-actively chose 'green' electricity products and services. } & 12345 \\
\hline \multicolumn{4}{|c|}{ Restricted the length of showers to save electricity. } & 12345 \\
\hline \multicolumn{4}{|c|}{ Turned off equipment (television, computers, etc) when not in use. } & 12345 \\
\hline \multicolumn{4}{|c|}{ Air-dried towels instead of putting them on heated towel rails. } & 12345 \\
\hline \multicolumn{4}{|c|}{ Used cold water instead of hot or warm water when washing clothes. } & 12345 \\
\hline \multicolumn{4}{|c|}{ Used electrical devices less often. } & 12345 \\
\hline \multicolumn{4}{|c|}{ Used blankets or warm clothes instead of turning the heating on. } & 12345 \\
\hline
\end{tabular}

Given the electricity shortage, please indicate whether you agree or disagree with the following questions:

\begin{tabular}{|c|c|c|c|c|}
\hline $\begin{array}{c}1 \\
\text { Strongly } \\
\text { disagree }\end{array}$ & $\begin{array}{c}2 \\
\text { Disagree }\end{array}$ & $\begin{array}{c}3 \\
\text { Unsure }\end{array}$ & $\begin{array}{c}4 \\
\text { Agree }\end{array}$ & $\begin{array}{l}5 \\
\text { ngly agree }\end{array}$ \\
\hline \multicolumn{4}{|c|}{ I now use less electricity then before the shortage. } & 12345 \\
\hline \multicolumn{4}{|c|}{$\begin{array}{l}\text { The electricity shortage had an important impact on me and other members of my } \\
\text { household. }\end{array}$} & 12345 \\
\hline \multicolumn{4}{|c|}{ I was willing to conserve electricity at home during the electricity shortage. } & 12345 \\
\hline \multicolumn{4}{|c|}{ The shortage did not change my use of electricity. } & 12345 \\
\hline \multicolumn{4}{|c|}{ The electricity shortage had an important impact on our economy. } & 12345 \\
\hline \multicolumn{4}{|c|}{ My attitude to using electricity at home changed since the electricity shortage. } & 12345 \\
\hline \multicolumn{4}{|c|}{ I now use more electricity then before the shortage. } & 12345 \\
\hline
\end{tabular}

PART 6. Background questions (Please remember that your responses are confidential)
1. How old are you? years.
2. What is your gender? $\square$ Female
$\square$ Male 


\section{Appendix 3: Dunlap et al's. (2000) new ecological paradigm scale}

1. We are approaching the limit of the number of people the earth can support

2. Humans have the right to modify the natural environment to suit their needs

3. When humans interfere with nature it often produces disastrous consequences

4. Human ingenuity will insure that we do not make the earth unliveable

5. Humans are severely abusing the environment

6. The earth has plenty of natural resources if we just learn how to develop them

7. Plants and animals have as much right as humans to exist

8. The balance of nature is strong enough to cope with the impacts of modern industrial nations

9. Despite our special abilities humans are still subject to the laws of nature

10. The so-called "ecological crisis" facing humankind has been greatly exaggerated

11. The earth is like a spaceship with very limited room and resources

12. Humans were meant to rule over the rest of nature

13. The balance of nature is very delicate and easily upset

14. Humans will eventually learn enough about how nature works to be able to control it

15. If things continue on their present course, we will soon experience a major ecological catastrophe

Source: Dunlap, et al. (2000) Measuring endorsement of the new ecological paradigm: A revised NEP scale. Journal of Social Issues, 56, 425-442. 


\section{Appendix 4: Milfont and Duckitt's (2007) preservation and utilization scales}

1. I really like going on trips into the countryside, for example to forests or fields

2. I do not believe humans were created or evolved to dominate the rest of nature

3. Protecting the environment is more important than protecting people's jobs

4. Whenever possible, I try to save natural resources

5. We need to keep rivers and lakes clean in order to protect the environment, and not as places for people to enjoy water sports

6. I think spending time in nature is boring

7. I do not believe that the environment has been severely abused by humans

8. I'd much prefer a garden that is well groomed and ordered to a wild and natural one

9. Modern science will solve our environmental problems

10. One of the most important reasons to keep lakes and rivers clean is so that people have a place to enjoy water sports

11. Protecting people's jobs is more important than protecting the environment

12. Humans are severely abusing the environment

13. Governments should control the rate at which raw materials are used to ensure that they last as long as possible

14. Modern science will not be able to solve our environmental problems

15. I would like to join and actively participate in an environmental group

16. A couple should have as many children as they wish, as long as they can adequately provide for them.

17. It makes me sad to see forests cleared for agriculture

18. I would not get involved in an environmental organisation

19. Human beings were created or evolved to dominate the rest of nature

20. I am not the kind of person who makes efforts to conserve natural resources

21. I am opposed to governments controlling and regulating the way raw materials are used in order to try and make them last longer

22. Families should be encouraged to limit themselves to two children or less

23. I'd prefer a garden that is wild and natural to a well groomed and ordered one

24. It does not make me sad to see natural environments destroyed

Source: Milfont, T. L., \& Duckitt, J. (2007). A brief version of the environmental attitudes inventory. Unpublished manuscript. 
Appendix 5: 'Other' reasons given for conserving electricity in Time 1 and Time 2

\section{Time 1 responses}

1. As strongly requested by husband

2. Avoid shortages

3. Aware of waste

4. Because I've always done things this way since I was very young and have passed this knowledge on to my own children

5. Because the Govt and the Power Companies waste(!) more than I ever will

6. Because we are running out of options

7. Brought up that way!

8. Commonsense

9. Commonsense

10. Contributing to larger change

11. Cost

12. Do not have electricity in my home

13. Don't have appliances such as heated towel rail

14. Don't like waste

15. Don't use lights until necessary

16. Don't waste a precious resource which we take for granted

17. Easy to do

18. Educate the young ones

19. Good discipline saves waste

20. Good habit to only use what need

21. Habit

22. Habit from childhood

23. Habit/upbringing

24. Help in a power crisis

25. I don't like wastage

26. I have my own power solar and wind

27. I've wet back hot water and refuse to save power because of a tight-fisted money grabbing - labour government

28. Issue of safety, reducing risk of fires/floods etc, whilst not at home

29. It feels good to be trying to help

30. It's just what I do!

31. It's sensible

32. Just being practical

33. Lake levels

34. Less fire hazard

35. Less fire hazard

36. Living in a motor home

37. Makes sense

38. My partner tells me

39. Not to cause waste

40. Parents did it

41. Power shortage

42. Power shortages

43. Prefer light wood fire for heating

44. Prevent power crisis happening

45. Raised to save in everything where possible

46. Reduce consumption

47. Reduce national consumption

48. Safety

49. Save power 
50. Save power for country

51. Save the lake levels

52. Saving electricity

53. Shortage of power

54. Teaching our children to look after their environment

55. To avoid blackouts

56. To help avoid electricity cuts

57. To help to reduce the shortage of electricity

58. To keep warm

59. To not waste

60. To save energy

61. To save lake levels

62. To save power

63. To try and ensure power supply is available to the elderly

64. Too many power cuts

65 . Try not to waste resources

66. Turn things off when not in use

67. Was brought up that way

68. Wasteful

69. We are possibly facing an electricity crisis this winter

70. We have solar power!

71. Wood/coal cheaper

\section{Time 2 responses}

1. Appliances will last longer

2. Because I like my stuff last longer

3. Because it's the right thing to do

4. Conserves the natural resources

5. Don't have electricity at all

6. Easy to do

7. Ethical

8. Feel good trying not to waste anything

9. Gives longer life out of appliances

10. Have solar energy production

11. Help with costs and environment

12. I hate waste

13. Influenced by upbringing

14. It makes sense

15. It's what my parents do

16. Keep noise down, extend life of computers, etc

17. Like the smell of clothes etc., dried outdoors

18. Limit demand / avoid shortages in total consumption

19. Obviously thing to do!

20. Sustainability

21. The habits of a lifetime

22. The sun's shining \& it makes sense!

23. To avoid waste of electricity

24. To suit myself - only partially to save electricity

25. To teach our children good habits

26. We grew up during and following the war, and old habits die hard

27. We shouldn't rely on something that someone else has control over 
Appendix 6: 'Other' conservation actions provided by respondents - Time 1

1. Pour extra heated water in jug into thermos flash for later drinks

2. Use energy efficient light bulbs

3. Cook multiple meals in oven, slow cooker or pot and freeze extra portions for later use

4. Use wood stove for cooking and heating

5. Hot water heated by gas

6. Gas oven and stove

7. Wetback for heating rooms/water

8. No heated towel rails

9. Install solar panels

10. Install double blaze and insulation on whole house

11. Install heat pumps

12. Rarely use dishwasher

13. Fill kettle (jug) with just enough water for use

14. energy-efficient light bulbs

15. No hot water available

16. No cloth dryer (do not buy into it!)

17. Heating only by woodstove with wetback

18. Wetback fire system

19. Use human instead of electrical power

20. Do the best we can on the budget we have, green is not cheap!

21. Turn hot water cylinder off between 0600 and 2100

22. HRV system installed to keep the house dry

23. Hot water bottles instead of electrical blankets

24. Log burner with wet back (winter water heating)

25. Heat pump instead of heaters

26. Save all the washing up to do in one go

27. Use wood/coal for heating/water heating

28. Use dry firewood for space and water heating

29. Bath children together instead of showers

30. Read the last power bill

31. Don't use electric blanket

32. Use gas heater

33. Use dehumidifier instead of heater

34. Actively reduce number of items in-use at one time

35. Cook using fewer appliances/creating less dishes to wash

36. Do not use electricity for heating

37. Don't own a heater

38. Change heating from 'under floor' to 'heat pump'

39. Cook meals on the stove top rather than oven bake. If using the oven do several things while its heated

40. Keep doors and windows closed when cold

41. Have family discussions on power saving

42. Have cold showers outside in summer, bathe in thermal pool in winter

43. Wash up in sink rather than using dishwasher

44. Turning hot water cylinder off in summer

45. Wash up by hand not dishwasher

46. Use fresh food to avoid need to purchase a freezer

47. Got home insulated

48. Don't use electric blankets 


\section{References}

Abrahamse, W., Steg, L., Vlek, C., \& Rothengatter, T. (2005). A review of intervention studies aimed at household energy conservation. Journal of Environmental Psychology, 25, 273-291.

Abrahamse, W., Steg, L., Vlek, C., \& Rothengatter, T. (2007). The effect of tailored information, goal setting, and tailored feedback on household energy use, energy-related behaviors, and behavioral antecedents. Journal of Environmental Psychology, 27, 265-276.

Archer, D., Pettigrew, T., Constanzo, M., Iritani, B., Walker, I., \& White, L. (1987). Energy conservation and public policy: The mediation of individual behavior. In W. Kempton \& M. Neiman (Eds.), Energy efficiency: perspectives on individual behavior. Washington DC: American Council for an Energy-Efficient Economy.

Aronson, E. (1990). Applying social psychology to desegregation and energy conservation. Personality and Social Psychology Bulletin, 16, 118-132.

Aune, M. (2007). Energy comes home. Energy Policy, 35, 5457-5465.

Becker, L. J. (1978). Joint effect of feedback and goal-setting on performance: A field study of residential energy conservation. Journal of Applied Psychology, 63, 428-433.

Belk, R., Painter, J., \& Semenik, R. (1981). Preferred solutions to the energy crisis as a function of causal attributions. Journal of Consumer Research, 8, 306-312.

Bender, S., Kandel, A., \& Goldstone, S. (2004). Behavioral economics: The link between human dimensions and market transformation. Paper presented at the 2004 ACEEE summer study on energy efficiency in buildings, Pacific Grove, California.

Bender, S., Moezzi, M., Hill Gossard, M., \& Lutzenhiser, L. (2002). Using mass media to influence energy consumption behaviour: California's 2001 "Flex Your Power" campaign as a case study. Paper presented at the 2002 ACEEE Summer Study on Energy Efficiency in Buildings, Pacific Grove, California.

Black, J. S., Stern, P. C., \& Elworth, J. T. (1985). Personal and contextual influences on household energy adaptations. Journal of Applied Psychology, 70, 3-21.

Brandon, G., \& Lewis, A. (1999). Reducing household energy consumption: A qualitative and quantitative field study. Journal of Environmental Psychology, 19, 75-85.

Braun, V., \& Clarke, V. (2006). Using thematic analysis in psychology. Qualitative Research in Psychology, 3, 77-101.

Cialdini, R. B., Kallgren, C. A., \& Reno, R. R. (1991). A focus theory of normative conduct: A theoretical refinement and reevaluation of the role of norms in human behavior. Advances in Experimental Social Psychology, 24, 202-232.

Communications Agencies Association of New Zealand. (2003). 2003 Effie awards case study: winter power task force, Target 10 [case study]. Retrieved. from http://www.caanz.co.nz/pdf/effie_2003_87.pdf.

Constanzo, M., Archer, D., Aronson, E., \& Pettigrew, T. (1986). Energy conservation behavior: The difficult path from information to action. American Psychologist, 41, 521-528. 
Creswell, J. W., \& Plano Clark, V. L. (2007). Designing and conducting mixed methods research. Thousand Oaks, California: SAGE Publications.

Crossley, D. J. (1983). Identifying barriers to the success of consumer energy conservation policies. Energy, 8, 533-546.

Dawnay, S., \& Shah, H. (2005). Behavioural economics: seven principles for policy makers (briefing paper). Retrieved. from http://www.neweconomics.org/gen/z_sys_PublicationDetail.aspx?PID=2 13.

Dennis, M., Soderstron, E. J., Koncinski, W. S., \& Cavanaugh, B. (1990). Effective dissemination of energy-related information: applying social psychology and evaluation research. American Psychologist, 45, 11091117.

DiCamillo, M., \& Field, M. (2001). The Field Poll [Release \# 1992]. Retrieved. from http://www.field.com/fieldpollonline/subscribers/Release1992.pdf.

Diekmann, A., \& Preisendörfer, P. (2003). Green and greenback: The behavioral effects of environmental attitudes in low-cost and high-cost situations. Rationality and Society, 15, 441-472.

Dunlap, R., \& Van Liere, K. (1978). The "new ecological paradigm": A proposed measuring instrument and preliminary results. Journal of Environmental Education, 9, 10-19.

Dunlap, R., Van Liere, K., Mertig, A. G., \& Jones, R. E. (2000). Measuring endorsement of the new ecological paradigm: A revised NEP scale. Journal of Social Issues, 56, 425-442.

Eaton, D. (2008, 18 June). Electricity Use. The Press.

Electricity Commission. (2007). Definition: Grid Exit Point (GXP). Retrieved 17 December, 2008, from http://www.electricitycommission.govt.nz/glossary/gxp/?searchterm=flo ws

Ellis, S. J., \& Kitzinger, C. (2002). Denying equality: An analysis of arguements against lowering the age of consent for sex between men. Journal of Community and Applied Social Psychology, 12, 167-180.

Faiers, A., Cook, M., \& Neame, C. (2007). Towards a contemporary approach for understanding consumer behaviour in the context of domestic energy use. Energy Policy, 35(8), 4381-4390.

Fishbein, M., \& Ajzen, I. (1975). Belief, attitude, intention and behavior: An introduction to theory and research. Reading, Massachusetts: AddisonWesley.

Frame, B., \& Newtown, B. (2007). Promoting sustainability through social marketing: examples from New Zealand. International Journal of Consumer Studies, 31, 571-581.

Fransson, N., \& Gärling, T. (1999). Environmental concern: Conceptual definitions, measurement methods, and research findings. Journal of Environmental Psychology, 19, 369-382.

Fuchs, D. A., \& Lorek, S. (2005). Sustainable consumption governance: A history of promises and failures. Journal of Consumer Policy, 28, 261 288.

Gardner, G. T., \& Stern, P. C. (2002). Behavioral solutions in context: Ecological and societal systems. In Environmental problems and human behaviour (2nd ed., pp. 253-276). Boston: Pearson Custom Publishing. 
Gifford, R. (2007). Environmental psychology: principles and practice (4th ed.). Canada: Optimal Books.

Gmelch, P. L., \& Dillman, J. J. (1988). Household energy-conservation motivators: A factor analytic approach. Housing and Society, 15, 238245.

Goldman, C. A., Barbose, G. L., \& Eto, J. H. (2002). California customer load reductions during the electricity crisis: Did they help to keep the lights on? Journal of Industry, Competition and Trade, 2, 113-142.

Gorman, P. (2008, 18 February). Calls to cut power use. The Press.

Haas, R., Auer, H., \& Biermayr, P. (1998). The impact of consumer behavior on residential energy demand for space heating. Energy and Buildings, 27, 195-205.

Hansen, J., Sato, M., Kharecha, P., Beerling, D., Masson-Delmotte, V., Pagani, M., et al. (2008). Target atmospheric $\mathrm{CO}_{2}$ : Where should humanity aim? The Open Atmospheric Science Journal, 2, 217-231.

Harkins, S. G., \& Lowe, M. D. (2000). The effects of self-set goals on task performance. Journal of Applied Social Psychology, 30, 1-40.

Heberlein, T. A. (1975). Conservation Information: The energy crisis and electricity consumption in an apartment complex. Energy Systems and Policy, 1, 105-117.

Hemphill, J. F. (2003). Interpreting the magnitudes of correlation coefficients. American Psychologist, 58, 78-80.

Heslop, L. A., Moran, L., \& Cousineau, A. (1981). "Consciousness" in energy conservation behavior: An exploratory study. Journal of Consumer Research, 8, 299-305.

Hirst, E., \& Brown, M. (1990). Closing the efficiency gap: barriers to the efficient use of energy. Resources, Conservation and Recycling, 3, 267281.

Howden-Chapman, P., Viggers, H., Chapman, R., O’Dea, D., Free, S., \& O'Sullivan, K. (in press). Warm homes: Drivers of the demand for heating in the residential sector in New Zealand. Energy Policy.

Hunt, D., \& Isles, J. (2009). Review of winter 2008 and the period leading into winter (research report). Retrieved. from http://www.electricitycommission.govt.nz/consultation/winter08.

IEA. (2006). World Energy Outlook. Paris: OECD/IEA.

IEA. (2008). Key World Energy Statistics Paris: IEA.

IEA. (2006). World Energy Outlook. Paris: OECD/IEA.

IPCC. (2000). Special report: Emissions scenarios. Retrieved. from http://www.ipcc.ch/pdf/special-reports/spm/sres-en.pdf.

IPCC. (2007a). Summary for Policy Makers. In S. Solomon, D. Qin, M. Manning, Z. Chen, M. Marquis, K. B. Averyt, M. Tignor \& H. L. Miller (Eds.), Climate Change 2007: The physical science basis. Contribution of Working Group I to the Fourth Assessment Report of the Intergovernmental Panel on Climate Change. Cambridge, UK; New York, NY, USA: Cambridge University Press.

IPCC. (2007b). Climate Change 2007: Synthesis Report: Summary for Policy Makers. Retrieved. from http://www.ipcc.ch/pdf/assessmentreport/ar4/syr/ar4_syr_spm.pdf.

IPCC. (2007c). Summary for Policymakers. In M. L. Parry, O. F. Canziani, J. P. Palutikof, P. J. van der Linden \& C. E. Hanson (Eds.), Climate change 
2007: Impacts, adaptation and vulnerability. Contribution of Working Group II to the Fourth Assessment Report of the Intergovernmental Panel on Climate Change. Cambridge, UK: Cambridge University Press.

Jackson, T. (2005). Motivating sustainable consumption: A review of evidence on consumer behaviour and behavioural change (A report to the sustainable development research network). Guildford, UK: Centre for Environmental Strategy, University of Surrey.

Jackson, T. (2009). Prosperity without growth? That transition to a sustainable economy: Sustainable Development Commission.

Joerges, B., \& Müller, H. (1983). Energy conservation programs for consumers: A comparative analysis of policy conflicts and program results in eight western countries. Journal of Economic Psychology, 4, 1-35.

Kaiser, F. G., Wölfing, S., \& Fuhrer, U. (1999). Environmental attitude and ecological behaviour. Journal of Environmental Psychology, 19, 1-19.

Keirstead, J. (2006). Evaluating the applicability of integrated domestic energy consumption frameworks in the UK. Energy Policy, 34, 3065-3077.

Kempton, W., Darley, J. M., \& Stern, P. C. (1992). Psychological research for the new energy problems: Strategies and opportunities. American Psychologist, 47, 1213-1223.

Kempton, W., Harris, C., Keith, J., \& Weihl, J. (1985). Do consumers know "what works" in energy conservation? Marriage and Family Review, 9, 115-133.

Kurz, T., Donaghue, N., \& Walker, I. (2005). Utilizing a social-ecological framework to promote water and energy conservation: A field experiment. Journal of Applied Social Psychology, 35, 1281-1300.

Lermit, J. (2009a). [New Zealand residential demand 2008] Unpublished raw data.

Lermit, J. (2009b). [New Zealand residential demand 2003] Unpublished raw data.

Lundmark, C. (2007). The new ecological paradigm revisited: anchoring the NEP scale in environmental ethics. Environmental Education Research, 13, 329-347.

Lutzenhiser, L. (1992). A cultural model of household energy consumption. Energy, 17, 47-60.

Lutzenhiser, L. (1993). Social and behavioral aspects of energy use. 18, 247-289.

Lutzenhiser, L. (2002a). Marketing household energy conservation: The message and the reality. In T. Dietz \& P. Stern (Eds.), New tools for environmental protection: Education, information and voluntary measures. Washington, D.C.: National Academy Press.

Lutzenhiser, L. (2002b). An exploratory analysis of residential electricity conservation survey and billing data (Research report for Southern California Edison). Retrieved. from http://www.energy.ca.gov/reports/2002-05-20_400-02-006F.PDF.

Lutzenhiser, L., Hill Gossard, M., \& Bender, S. (2002). Crisis in paradise: Understanding the household conservation response to California's 2001 energy crisis. Paper presented at the 2002 ACEEE Summer Study on Energy Efficiency in Buildings, Pacific Grove, California. Retrieved 5th May, 2008, from http://www.eceee.org/conference_proceedings/ACEEE_buildings/2002/P anel_8/p8_13/. 
Lutzenhiser, L., Kunkle, R., Woods, J., Lutzenhiser, S., \& Bender, S. (2004). Lasting impressions: Conservation and the 2001 California energy crisis. Paper presented at the 2004 ACEEE Summer Study on Energy Efficiency in Buildings, Pacific Grove, California.

McKenzie-Mohr, D. (1994). Social marketing for sustainability: The case for residential energy conservation. Futures, 26, 224.

Mediaedge:cia. (2008). [Powersavers media schedule] Unpublished raw data.

Meier, A. (2005). Saving electricity in a hurry: Dealing with temporary shortfalls in electricity supplies. Paris: OECD/IEA.

Meridian Energy. (2008, 15 April). Draft report not relevant to real-world hydro prop [press release]. Retrieved. from http://scoop.co.nz/stories/BU0804/S00276.htm.

Milfont, T. L., \& Duckitt, J. (2004). The structure of environmental attitudes: First- and second-order confirmatory factor analysis. Journal of Environmental Psychology, 24, 289-303.

Milfont, T. L., \& Duckitt, J. (2008). The environmental attitudes inventory: A valid and reliable measure to assess the structure of environmental attitudes.Unpublished manuscript.

Milfont, T. L., \& Gouveia, V. V. (2006). Time perspective and values: An exploratory study of their relations to environmental attitudes. Journal of Environmental Psychology, 26, 72-82.

Milfont, T. L., Sibley, C. G., \& Duckitt, J. (in press). Testing the moderating role of the components of norm activation on the relationship between values and environmental behaviour. Journal of Cross-Cultural Psychology.

Ministry for the Environment. (2007). A framework for a New Zealand emissions trading scheme: Ministry for the Environment/New Zealand Treasury.

Ministry for the Environment/Research New Zealand. (2008). Household Sustainability Benchmark Questionnaire (Research New Zealand report 3671).

Ministry of Economic Development. (2006). New Zealand's energy outlook to 2030. Retrieved. from http://www.med.govt.nz/upload/38641/eo-2006final.pdf.

Ministry of Economic Development. (2008a). New Zealand energy data file: June 2008. Retrieved. from http://www.med.govt.nz/upload/59482/00_EDF-June2008.pdf.

Ministry of Economic Development. (2008b). New Zealand energy greenhouse gas emissions 1990 - 2007. Retrieved. from http://www.med.govt.nz/upload/63349/GHG\%20Report.pdf.

Ministry of Economic Development. (2008c). Government policy statement on electricity governance Retrieved. from http://www.med.govt.nz/upload/58232/gps.pdf.

Ministry of Economic Development. (2009). New Zealand Energy Indicators. Retrieved. from http://www.med.govt.nz/templates/MultipageDocumentTOC 40798.a spx.

Ministry of Economic Development. (n.d.). Electricity: quarterly updates. Retrieved. from http://www.med.govt.nz/templates/ContentTopicSummary 21417.asp $\mathrm{x}$. 
Morrison, B., Gladhart, P., Zuiches, J., Keith, J., Keefe, D., \& Long, B. (1978). Energy and families: The crisis and the response. Journal of Home Economics (Winter), 18-21.

New Zealand Government. (2008,16 December). Thermal ban repeal [press release] Retrieved. from http://scoop.co.nz/stories/PA0812/S00193.htm.

New Zealand Press Association. (2008, 26 September). DOC opposes Meridian dam plan. New Zealand Herald.

Nolan, J. M., Schultz, P. W., Cialdini, R. B., Goldstein, N. J., \& Griskevicius, V. (2008). Normative social influence is underdetected. Personality and Social Psychology Bulletin, 34, 913-923.

Nunally, J. C. (1978). Psychometric theory (2 ed.). New York: McGraw-Hill.

Owens, S., \& Driffill, L. (2008). How to change attitudes and behaviours in the context of energy. Energy Policy, 36, 4412-4418.

Pallant, J. (2007). SPSS survival manual: A step by step guide to data analysis using SPSS for Windows (3rd ed.). Maidenhead, England: Open University Press.

Parliamentary Commissioner for the Environment. (2009). Smart electricity meters: How household and the environment can benefit. Wellington: Parliamentary Commissioner for the Environment.

Patton, M. Q. (1990). Qualitative evaluation and research methods (2nd ed.). Newbury Park, California: Sage Publications.

Prentice, D. A. (2007). Norms, prescriptive and descriptive [Electronic Version]. Encyclopedia of Social Psychology. Retrieved 12 June, 2009 from $<$ http://www.sage-ereference.com/socialpsychology/Article_n376.html>.

Richardson, K., Steffen, W., Schnellhuber, H. J., Alcamo, J., Barker, T., Kammen, D. M., et al. (2009). Synthesis report: Climate change: Global risks, challenges and decisions. Paper presented at Copenhagen 2009. from http://climatecongress.ku.dk/pdf/synthesisreport.

Ritchie, J. R. B., Gordon, H. G. M., \& Claxton, J. D. (1981). Complexities of household energy consumption and conservation. Journal of Consumer Research, 8, 233-242.

Rosenberg, D. M., Bodaly, R. A., \& Usher, P. J. (1995). Environmental and social impacts of large scale hydroelectric development: Who is listening? Global Environmental Change, 5, 127-148.

Schultz, W. P., Nolan, J. M., Cialdini, R. B., Goldstein, N. J., \& Griskevicius, V. (2007). The constructive, destructive and reconstructive power of social norms. Psychological Science, 18, 429-434.

Schwartz, S. H. (1977). Normative influences on altruism. Advances in Experimental Social Psychology, 10, 222 - 275.

Scoop Independent News. (n.d.). About Scoop: Introducing Scoop.co.nz. Retrieved May 15, 2009, from http://www.scoop.co.nz/about/about.html

Shove, E., \& Wilhite, H. (1999). Energy Policy: What it forgot and what it might yet recognise. Paper presented at the The European Council for an Energy Efficiency Economy Summer Study, Côte d'Azur, France.

Sims, R. E. H., Schock, R. N., Adegbululgbe, A., Fenhann, J., Konstantinaviciute, W., Moomaw, W., et al. (2007). Energy Supply. In B. Metz, O. R. Davidson, P. R. Bosch, R. Dave \& L. A. Meyer (Eds.), Climate Change 2007: Mitigation. Contribution of Working Group III to the Fourth Assessment Report of the Intergovernmental Panel on Climate Change. Cambridge: Cambridge University Press. 
Small, V. (2008, 19 June). Power crisis is over, so let's tackle real issues. Dominion Post.

Staley, H. (2006). Saving electricity in a hurry: New Zealand's experience [Powerpoint slides]. from http://www.ret.gov.au/Documents/mce/_documents/Heather_Staley_Pres entation20060626115748.pdf.

Statistics New Zealand. (2006). 2006 Census of population and dwellings: Regional summary tables by regional council [data file]. Retrieved. from http://www.stats.govt.nz/census/2006-census-data/regional-summarytables.htm.

Statistics New Zealand. (2009a). New Zealand in Profile: An overview of New Zealand's people, economy and environment Retrieved. from http://www.stats.govt.nz/NR/rdonlyres/C6D10FA4-78F4-4379-9D1589E3B896C2B6/0/newzealandinprofile2009.pdf.

Statistics New Zealand. (2009b). QuickStats About New Zealand. Retrieved 19th February, 2009, from www.stats.govt.nz/census/census-outputs/quickstats

Stern, P. C. (1986). Blind spots in policy analysis: What economics doesn't say about energy use. Journal of Policy Analysis and Management, 5, 200227.

Stern, P. C. (1992). What psychology knows about energy conservation. American Psychologist, 47, 1224-1232.

Stern, P. C. (2000). Toward a coherent theory of environmentally significant behavior. Journal of Social Issues, 56, 407-424.

Stern, P. C. (2008). Environmentally significant behavior in the home. In A. Lewis (Ed.), The Cambridge handbook of psychology and economic behaviour. Cambridge: Cambridge University Press.

Stern, P. C., Aronson, E., Darley, J. M., Hill, D. H., Hirst, E., Kempton, W., et al. (1986). The effectiveness of incentives for residential energy conservation Evaluation Review, 10, 147-176.

Stern, P. C., Dietz, T., Abel, T., Guagnano, G. A., \& Kalof, L. (1999). A valuebelief-norm theory of support for social movements: The case of environmentalism. Human Ecology Review, 6, 81-97.

Stern, P. C., \& Oskamp, S. (1991). Managing scarce environmental resources. In D. Stokols \& I. Altman (Eds.), Handbook of environmental psychology (Reprint. ed., Vol. 2, pp. 1043-1088). Malabar, Florida: Krieger Publishing Company.

Tashchian, R. O., \& Slama, M. E. (1985). Survey data on attitudes and behaviors relevant to energy: Implications for policy. Marriage and Family Review, 9, 29-51.

Taylor Baines \& Associates. (2008, March). Mokihinui Hydro Electric Power Proposal: Social Impact Assessment. Final draft (Report): Prepared by Taylor Baines \& Associates for Anderson Lloyd Lawyers on Behalf of Meridian Energy.

Throne-Holst, H., Strandbakken, P., \& Stø, E. (2008). Identification of households' barriers to energy saving solutions. Management of Environmental Quality, 19, 54-66.

Transpower New Zealand. (2008). 'Powersavers' advertising campaign draws to a close [Press release]. Retrieved. from http://scoop.co.nz/stories/BU0807/S00379.htm. 
Transpower New Zealand. (2008, June 10). Update on Winter Power [Press release]. Retrieved. from http://scoop.co.nz/stories/BU0806/S00185.htm.

Ueno, T., Sano, F., Saeki, O., \& Tsuji, K. (2006). Effectiveness of an energyconsumption information system on energy savings in residential houses based on monitored data. Applied Energy, 83, 166-183.

UMR Research. (2001). UMR Research presentation to EECA [powerpoint presentation]. from made available by UMR Research New Zealand.

Van Vugt, M., \& Samuelson, C. D. (1999). The impact of personal metering in the management of a natural resource crisis: A social dilema analysis. Personality and Social Psychology Bulletin, 25(6), 735-750.

Wall, R., \& Crosbie, T. (2009). Potential for reducing electricity demand for lighting in households: An exploratory socio-technical study. Energy Policy, 37, 1021-1031.

Weir, J. (2008, 10 June). Power outlook grim despite gas burning. The Dominion Post.

Weiss, J. A., \& Tschirhart, M. (1994). Public information campaigns as policy instruments. Journal of Policy Analysis and Management, 13, 82-119.

Whitmarsh, L. (2009). Behavioural responses to climate change: Asymmetry of intentions and impacts. Journal of Environmental Psychology, 29, 13-23.

Wilhite, H., Nakagami, H., Masuda, T., Yamaga, Y., \& Haneda, H. (1996). A cross-cultural analysis of household energy use behaviour in Japan and Norway. Energy Policy, 24, 795.

Wilhite, H., Shove, E., Lutzenhiser, L., \& Kempton, W. (2000). The legacy of twenty years of energy demand management: We know more about individual behavior but next to nothing about demand. In E. Jochem, J. Sathaye \& D. Bouille (Eds.), Society, behaviour and climate change mitigation (pp. 109-126). Dordrecht, the Netherlands: Kluwer Academic Publishers.

Wilson, C., \& Dowlatabadi, H. (2007). Models of decision making and residential energy use. Annual Review of Environment and Resources, 32, 169-203.

Winter Power Taskforce. (2003, 19 June). Target 10 averts winter power shortages [Press release]. Retrieved. from http://scoop.co.nz/stories/BU0306/S00205.htm.

Y\&R Marketing New Zealand. (2008). Winterpower - campaign post-analysis [powerpoint slides]. from made available by Contact Energy Ltd.

Yamamoto, Y., Suzuki, A., Fuwa, Y., \& Sato, T. (2008). Decision-making in electrical appliance use in the home. Energy Policy, 36, 1679-1686. 